\title{
Web Appendix: A Simple and Successful Shrinkage Method for Weighting Estimators of Treatment Effects
}

\author{
Winfried Pohlmeier ${ }^{a}$, Ruben Seiberlich ${ }^{a}$, Selver Derya Uysal ${ }^{b, 1}$ \\ ${ }^{a}$ University of Konstanz, Department of Economics, Konstanz, Germany \\ ${ }^{b} I H S$, Department of Economics and Finance, Vienna, Austria
}

\begin{abstract}
${ }^{1}$ Corresponding author. Department of Economics and Finance, IHS, Vienna, Stumpergasse 56, A-1060, Vienna, Austria. Phone +43 159991 156, email:uysal@ihs.ac.at. The authors gratefully acknowledge financial support from the German Research Foundation (DFG) through research unit FOR 1882 "Psychoeconomics" and from the Oesterreichische Nationalbank (Anniversary Fund, project number: 14986). This paper benefited from helpful ideas and discussions with NamHuyan Kim, Bertrand Koebel, Fabian Krüger and Bernd Fitzenberger. Furthermore, we thank the participants at the DFH Workshop "Applied Econometrics" 2012, Königsfeld, Germany, the participants at the Workshop of the German Statistical Association (DStatG) 2012, Vienna, Austria as well as the session participants at the European Meeting of the Econometric Society 2012, Málaga, Spain, for their helpful comments. We also like to thank two anonymous referees whose comments and suggestions clearly improved the paper.
\end{abstract}


Table A.1: Percentage improvement in MSE for the ATE if the shrunken propensity scores are used instead of the conventional propensity scores, fixed valued $\lambda$

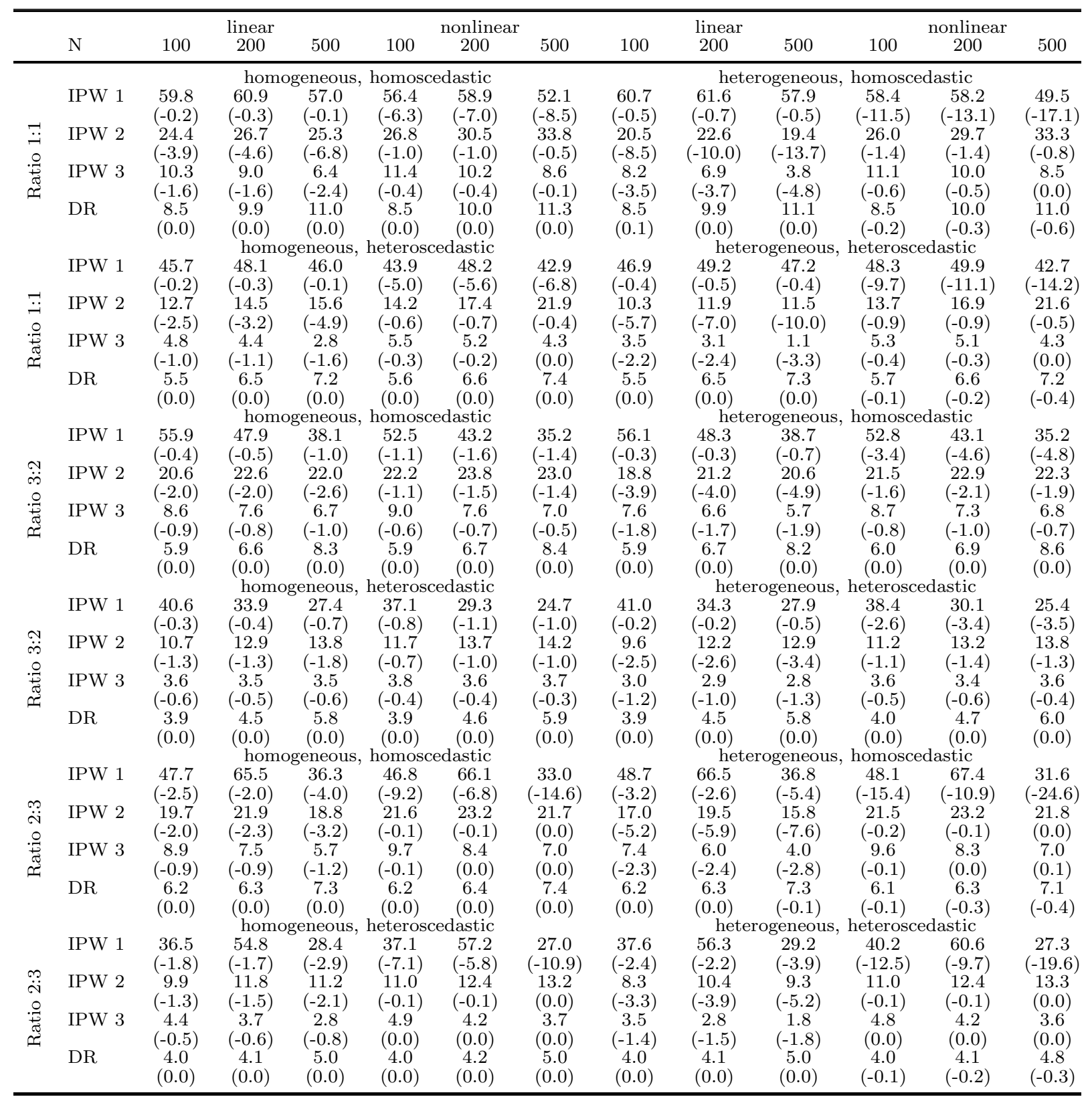

Note: The percentage improvements in MSE of ATE estimates due to the shrunken propensity score for each estimation method and for each possible DGP are reported along with the percentage change which is due to the bias introduced by shrinkage, i.e., $\left(\frac{\operatorname{bias}^{2}(\operatorname{ATE}(\hat{p}))-\operatorname{bias}^{2}\left(\operatorname{ATE}\left(\hat{p}^{s}\right)\right)}{\operatorname{bias}^{2}(\operatorname{ATE}(\hat{p}))+\operatorname{Var}(\operatorname{ATE}(\hat{p}))}\right)$. (in parenthesis). The tuning parameter $\lambda$ is chosen according to the fixed tuning parameter method. 
Table A.2: Percentage improvement in MSE for the ATE if the shrunken propensity scores are used instead of the conventional propensity scores, $\operatorname{MSE}\left(\hat{p}_{i}^{s}\right)$-minimizing $\lambda$

\begin{tabular}{|c|c|c|c|c|c|c|c|c|c|c|c|c|c|}
\hline & $N$ & 100 & $\begin{array}{c}\text { linear } \\
200\end{array}$ & 500 & 100 & $\begin{array}{c}\text { nonline } \\
200\end{array}$ & 500 & 100 & $\begin{array}{l}\text { linear } \\
200\end{array}$ & 500 & 100 & $\begin{array}{c}\text { 1onlinear } \\
200\end{array}$ & 500 \\
\hline \multirow{9}{*}{ 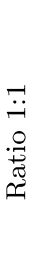 } & & & hom & geneous & homose & dastic & & \multicolumn{6}{|c|}{ heterogeneous, homoscedastic } \\
\hline & IPW 1 & 60.9 & 66.3 & 66.3 & 57.5 & 63.3 & 58.4 & 61.6 & 67.3 & 66.3 & 58.1 & 64.6 & 56.9 \\
\hline & & $(-0.2)$ & $(-0.3)$ & $(-0.2)$ & $(-6.2)$ & $(-6.2)$ & $(-7.3)$ & $(-0.4)$ & $(-0.6)$ & $(-0.5)$ & $(-11.8)$ & $(-11.0)$ & $(-13.9)$ \\
\hline & IPW 2 & 24.6 & 26.5 & 31.3 & 27.7 & 29.0 & 34.3 & 20.5 & 22.5 & 28.0 & 27.0 & 28.3 & 33.8 \\
\hline & & $(-4.3)$ & $(-3.9)$ & $(-5.3)$ & $(-0.9)$ & $(-1.3)$ & $(-0.9)$ & $(-9.2)$ & $(-8.9)$ & $(-10.7)$ & $(-1.3)$ & $(-1.7)$ & $(-1.3)$ \\
\hline & IPW 3 & 9.9 & 9.3 & 7.3 & 11.4 & 10.0 & 8.7 & 7.6 & 7.3 & 5.3 & 11.2 & 9.8 & 8.6 \\
\hline & & $(-1.8)$ & $(-1.4)$ & $(-1.7)$ & $(-0.4)$ & $(-0.5)$ & $(-0.3)$ & $(-4.0)$ & $(-3.2)$ & $(-3.6)$ & $(-0.5)$ & $(-0.6)$ & $(-0.3)$ \\
\hline & DR & 8.5 & 9.6 & 11.2 & 8.6 & 9.8 & 11.7 & 8.4 & 9.6 & 11.1 & 8.6 & 9.9 & 11.7 \\
\hline & & $(0.0)$ & $(0.0)$ & $(0.0)$ & $(0.0)$ & $(0.0)$ & $(0.0)$ & $(0.0)$ & $(0.0)$ & $(0.0)$ & $(-0.2)$ & $(-0.2)$ & $(-0.4)$ \\
\hline \multirow{9}{*}{ 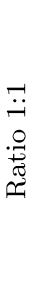 } & \multicolumn{7}{|c|}{ homogeneous, heteroscedastic } & \multicolumn{6}{|c|}{ heterogeneous, heteroscedastic } \\
\hline & IPW 1 & $\begin{array}{c}46.4 \\
(-0.2)\end{array}$ & $\begin{array}{c}54.1 \\
(-0.3)\end{array}$ & $\begin{array}{c}56.5 \\
(-0.1)\end{array}$ & $\begin{array}{c}44.8 \\
(-4.8)\end{array}$ & $\begin{array}{c}52.6 \\
(-5.1)\end{array}$ & $\begin{array}{c}49.7 \\
(-6.1)\end{array}$ & $\begin{array}{c}47.5 \\
(-0.3)\end{array}$ & $\begin{array}{c}55.5 \\
(-0.5)\end{array}$ & $\begin{array}{c}56.8 \\
(-0.4)\end{array}$ & $\begin{array}{c}47.9 \\
(-9.7)\end{array}$ & $\begin{array}{c}56.1 \\
(-9.5)\end{array}$ & $\begin{array}{c}50.2 \\
(-12.2)\end{array}$ \\
\hline & IPW 2 & 11.9 & 15.8 & 21.4 & 13.7 & 17.2 & 23.2 & 9.5 & 13.4 & 19.7 & 13.3 & 16.8 & 22.8 \\
\hline & & $(-2.7)$ & $(-2.6)$ & $(-3.9)$ & $(-0.6)$ & $(-0.9)$ & $(-0.7)$ & $(-5.9)$ & $(-5.9)$ & $(-7.9)$ & $(-0.9)$ & $(-1.2)$ & $(-0.9)$ \\
\hline & IPW 3 & 4.1 & 4.5 & 3.9 & 5.0 & 4.9 & 5.0 & 2.7 & 3.3 & 2.5 & 4.9 & 4.8 & 4.9 \\
\hline & & $(-1.1)$ & $(-0.8)$ & $(-1.2)$ & $(-0.3)$ & $(-0.3)$ & $(-0.2)$ & $(-2.4)$ & $(-2.0)$ & $(-2.5)$ & $(-0.3)$ & $(-0.4)$ & $(-0.2)$ \\
\hline & DR & 4.8 & 6.6 & 7.7 & 4.9 & 6.7 & 8.3 & 4.9 & 6.6 & 7.7 & 5.0 & 6.8 & 8.4 \\
\hline & & $(0.0)$ & $(0.0)$ & $(0.0)$ & $(0.0)$ & $(0.0)$ & $(0.0)$ & $(0.0)$ & $(0.0)$ & $(0.0)$ & $(-0.1)$ & $(-0.1)$ & $(-0.3)$ \\
\hline & & & hom & geneous & homoss & dastic & & & het & rogeneo & homosc & lastic & \\
\hline \multirow{9}{*}{ 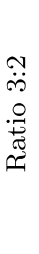 } & IPW 1 & 51.9 & 86.8 & 42.0 & 47.7 & 71.8 & 41.0 & 52.4 & 86.7 & 42.9 & 48.8 & 70.6 & 42.8 \\
\hline & & $(-0.5)$ & $(-0.2)$ & $(-0.7)$ & $(-1.4)$ & $(-0.7)$ & $(-1.8)$ & $(-0.4)$ & $(-0.1)$ & $(-0.5)$ & $(-4.3)$ & $(-2.4)$ & $(-5.0)$ \\
\hline & IPW 2 & 21.0 & 21.3 & 22.2 & 22.0 & 22.6 & 24.3 & 19.1 & 19.3 & 20.6 & 21.1 & 21.8 & 23.5 \\
\hline & & $(-2.4)$ & $(-2.5)$ & $(-2.0)$ & $(-1.2)$ & $(-1.4)$ & $(-2.0)$ & $(-4.7)$ & $(-4.8)$ & $(-4.1)$ & $(-1.8)$ & $(-2.0)$ & $(-2.6)$ \\
\hline & IPW 3 & 9.5 & 8.1 & 6.9 & 9.9 & 8.6 & 6.7 & 8.3 & 7.0 & 6.0 & 9.6 & 8.3 & 6.4 \\
\hline & & $(-1.2)$ & $(-1.0)$ & $(-0.6)$ & $(-0.6)$ & $(-0.6)$ & $(-0.8)$ & $(-2.3)$ & $(-2.1)$ & $(-1.4)$ & $(-0.9)$ & $(-0.9)$ & $(-1.0)$ \\
\hline & DR & 6.1 & 6.7 & 8.3 & 6.2 & 6.7 & 8.5 & 6.1 & 6.6 & 8.3 & 6.3 & 6.9 & 8.8 \\
\hline & & $(0.0)$ & $(0.0)$ & $(-0.1)$ & $(0.0)$ & $(0.0)$ & $(0.0)$ & $(0.0)$ & $(0.0)$ & $(0.0)$ & $(0.0)$ & $(0.0)$ & $(0.0)$ \\
\hline & \multicolumn{7}{|c|}{ homogeneous, heteroscedastic } & \multicolumn{6}{|c|}{ heterogeneous, heteroscedastic } \\
\hline \multirow{9}{*}{ 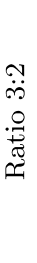 } & IPW 1 & 36.1 & 79.4 & 30.5 & 32.0 & 59.6 & 29.5 & 36.6 & 79.3 & 31.3 & 34.2 & 59.1 & 31.9 \\
\hline & & $(-0.4)$ & $(-0.2)$ & $(-0.5)$ & $(-1.0)$ & $(-0.6)$ & $(-1.3)$ & $(-0.3)$ & $(-0.1)$ & $(-0.3)$ & $(-3.1)$ & $(-2.1)$ & $(-3.8)$ \\
\hline & IPW 2 & 10.1 & 11.8 & 13.9 & 10.7 & 12.9 & 15.7 & 9.0 & 10.5 & 12.8 & 10.1 & 12.4 & 15.1 \\
\hline & & $(-1.5)$ & $(-1.7)$ & $(-1.4)$ & $(-0.8)$ & $(-0.9)$ & $(-1.4)$ & $(-3.0)$ & $(-3.3)$ & $(-2.9)$ & $(-1.2)$ & $(-1.3)$ & $(-1.8)$ \\
\hline & IPW 3 & 3.8 & 3.9 & 3.7 & 4.1 & 4.2 & 3.6 & 3.1 & 3.1 & 3.1 & 3.8 & 4.0 & 3.4 \\
\hline & & $(-0.7)$ & $(-0.7)$ & $(-0.4)$ & $(-0.4)$ & $(-0.4)$ & $(-0.5)$ & $(-1.4)$ & $(-1.4)$ & $(-1.0)$ & $(-0.6)$ & $(-0.6)$ & $(-0.7)$ \\
\hline & DR & 3.8 & 4.5 & 5.9 & 3.9 & 4.6 & 6.0 & 3.8 & 4.5 & 5.9 & 4.0 & 4.7 & 6.2 \\
\hline & & $(0.0)$ & $(0.0)$ & $(0.0)$ & $(0.0)$ & $(0.0)$ & $(0.0)$ & $(0.0)$ & $(0.0)$ & $(0.0)$ & $(0.0)$ & $(0.0)$ & $(0.0)$ \\
\hline & & & hom & geneous & homoss & dastic & & & het & rogeneo & homosc & lastic & \\
\hline \multirow{8}{*}{ 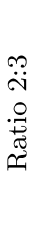 } & IPW 1 & 72.5 & 56.0 & 38.6 & 74.2 & 56.0 & 33.9 & 73.5 & 57.1 & 38.8 & 75.6 & 56.9 & 34.5 \\
\hline & & $(-1.3)$ & $(-2.6)$ & $(-4.7)$ & $(-4.9)$ & $(-9.2)$ & $(-16.0)$ & $(-1.7)$ & $(-3.4)$ & $(-6.2)$ & $(-7.9)$ & $(-15.0)$ & $(-25.2)$ \\
\hline & IPW 2 & 21.3 & 21.7 & 24.5 & 23.6 & 24.0 & 24.8 & 18.3 & 18.7 & 22.9 & 23.5 & 23.9 & 25.0 \\
\hline & & $(-2.7)$ & $(-2.6)$ & $(-2.0)$ & $(-0.1)$ & $(-0.1)$ & $(-0.1)$ & $(-6.4)$ & $(-6.5)$ & $(-5.7)$ & $(-0.1)$ & $(-0.1)$ & $(-0.1)$ \\
\hline & IPW 3 & 9.2 & 8.0 & 6.5 & 10.5 & 9.1 & 7.1 & 7.3 & 6.3 & 5.1 & 10.5 & 9.0 & 7.1 \\
\hline & & $(-1.3)$ & $(-1.1)$ & $(-0.7)$ & $(0.0)$ & $(0.0)$ & $(-0.1)$ & $(-3.1)$ & $(-2.7)$ & $(-2.0)$ & $(0.0)$ & $(0.0)$ & $(-0.1)$ \\
\hline & DR & 6.4 & 7.1 & 7.6 & 6.4 & 7.1 & 7.8 & 6.3 & 7.1 & 7.5 & 6.3 & 7.0 & 7.8 \\
\hline & & $(0.0)$ & $(0.0)$ & $(0.0)$ & $(0.0)$ & $(0.0)$ & $(0.0)$ & $(0.0)$ & $(-0.1)$ & $(-0.1)$ & $(-0.2)$ & $(-0.2)$ & $(-0.2)$ \\
\hline & & & hom & eneous, & heteros & dastic & & & het & ogeneo & heterosc & dastic & \\
\hline & IPW 1 & 61.1 & 44.9 & 29.9 & 64.9 & 46.6 & 27.1 & 62.7 & 46.3 & 30.3 & 68.7 & 49.7 & 29.1 \\
\hline & & $(-1.1)$ & $(-2.0)$ & $(-3.6)$ & $(-4.2)$ & $(-7.3)$ & $(-12.6)$ & $(-1.4)$ & $(-2.6)$ & $(-4.8)$ & $(-7.1)$ & $(-12.7)$ & $(-21.2)$ \\
\hline$\ddot{\sim}$ & IPW 2 & 9.7 & 11.8 & 15.6 & 11.1 & 13.2 & 15.5 & 8.1 & 10.1 & 15.1 & 11.1 & 13.2 & 15.7 \\
\hline 0 & & $(-1.6)$ & $(-1.6)$ & $(-1.4)$ & $(-0.1)$ & $(-0.1)$ & $(-0.1)$ & $(-4.0)$ & $(-4.1)$ & $(-4.0)$ & $(-0.1)$ & $(-0.1)$ & $(-0.1)$ \\
\hline 栗 & IPW 3 & 3.8 & 3.7 & 3.2 & 4.6 & 4.3 & 3.6 & 2.7 & 2.6 & 2.4 & 4.6 & 4.3 & 3.6 \\
\hline ฯ & & $(-0.7)$ & $(-0.7)$ & $(-0.5)$ & $(0.0)$ & $(0.0)$ & $(-0.1)$ & $(-1.8)$ & $(-1.7)$ & $(-1.3)$ & $(0.0)$ & $(0.0)$ & $(-0.1)$ \\
\hline & DR & 3.5 & 4.6 & 4.9 & 3.6 & 4.6 & 5.1 & 3.5 & 4.6 & 4.8 & 3.6 & 4.6 & 5.2 \\
\hline & & $(0.0)$ & $(0.0)$ & $(0.0)$ & $(0.0)$ & $(0.0)$ & $(0.0)$ & $(0.0)$ & $(0.0)$ & $(0.0)$ & $(-0.1)$ & $(-0.2)$ & $(-0.1)$ \\
\hline
\end{tabular}
ble DGP are reported along with the percentage change which is due to the bias introduced by shrinkage, i.e., $\left(\frac{\operatorname{bias}^{2}(\operatorname{ATE}(\hat{p}))-\operatorname{bias}^{2}\left(\operatorname{ATE}\left(\hat{p}^{s}\right)\right)}{\operatorname{bias}^{2}(\operatorname{ATE}(\hat{p}))+\operatorname{Var}(\operatorname{ATE}(\hat{p}))}\right)$. (in parenthesis). The tuning parameter $\lambda$ is chosen according to the MSE minimizing tuning parameter method. 
Table A.3: Percentage improvement in MSE for the ATE if the shrunken propensity scores are used instead of the conventional propensity scores, cross validated $\lambda$

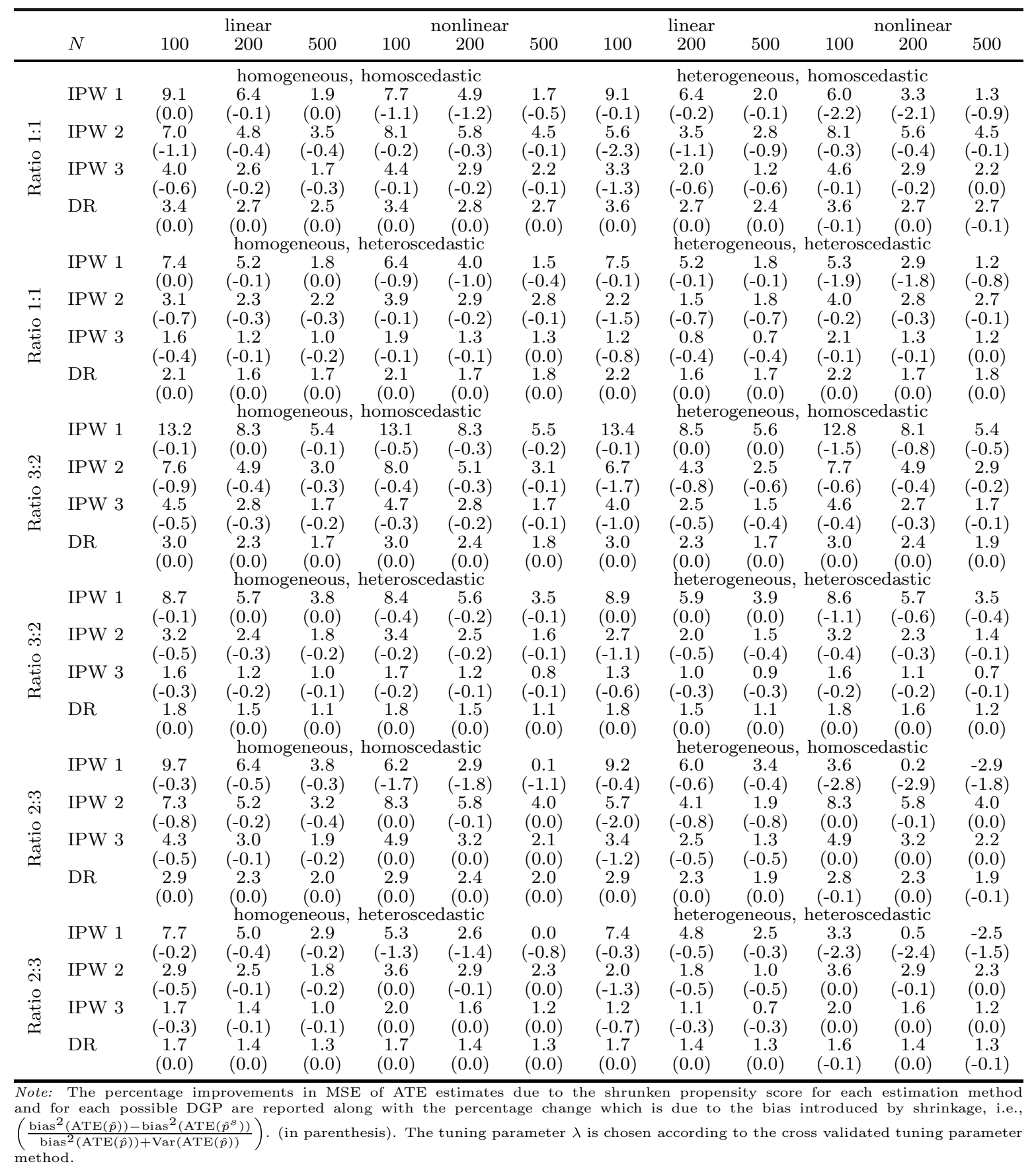


Table A.4: Percentage improvement in MSE for the ATE if the shrunken propensity scores are used with trimming rule 2 instead of the conventional propensity scores, fixed valued $\lambda$

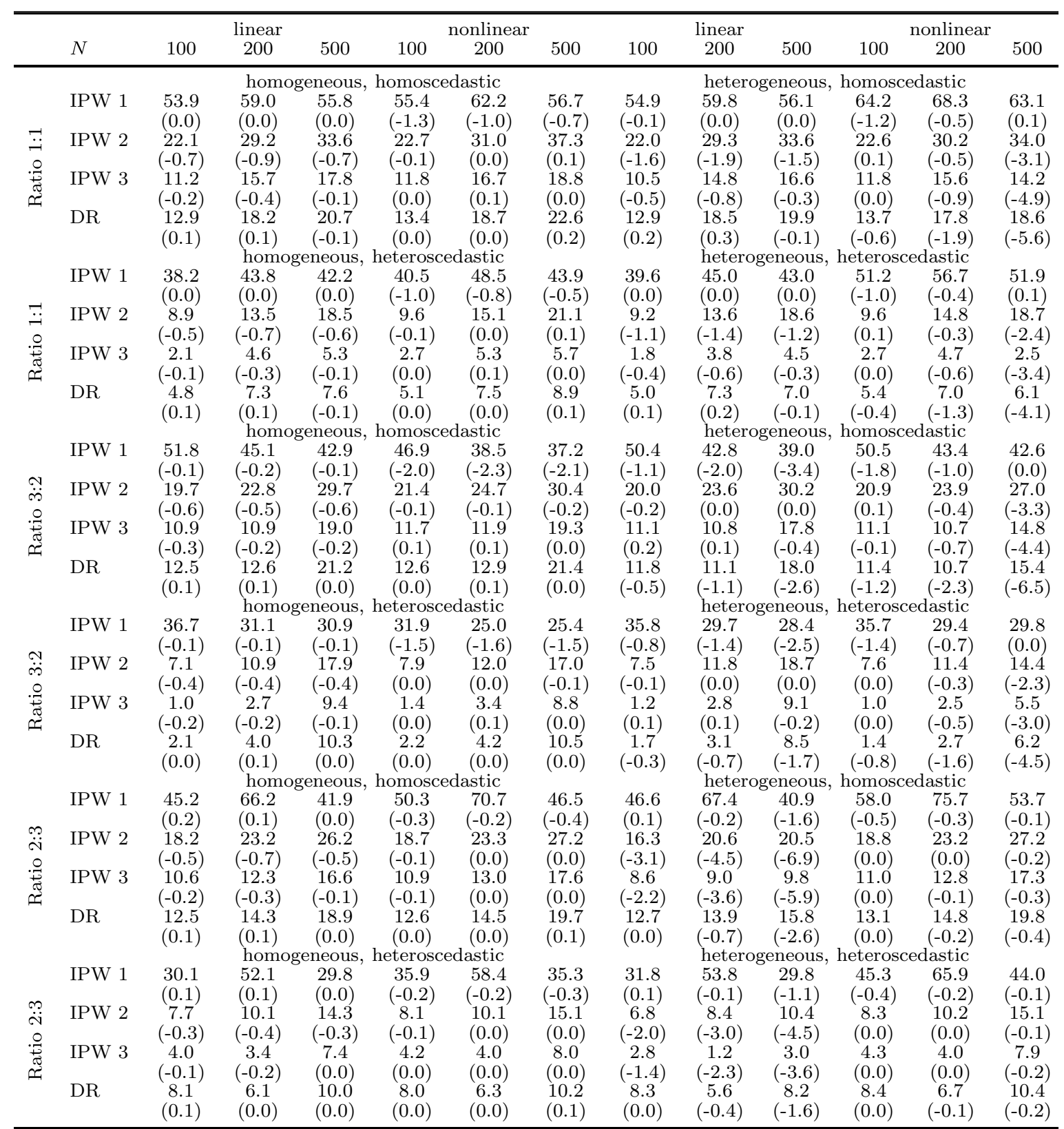

Note: The percentage improvements in MSE of ATE estimates due to the shrunken propensity score combined with trimming rule 2 wespect to the conventional propensity score for each estimation method and for each possible DGP are reported along with the percentage change which is due to the bias introduced by shrinkage, i.e., $\left(\frac{\operatorname{bias}^{2}(\operatorname{ATE}(\hat{p}))-\operatorname{bias}^{2}\left(\operatorname{ATE}\left(\hat{p}^{s}\right)\right)}{\operatorname{bias}^{2}(\operatorname{ATE}(\hat{p}))+\operatorname{Var}(\operatorname{ATE}(\hat{p}))}\right)$. (in parenthesis). The tuning parameter $\lambda$ is chosen according to the fixed tuning parameter method. 
Table A.5: Percentage improvement in MSE for the ATE if the shrunken propensity scores are used with trimming rule 2 instead of the conventional propensity scores with trimming rule 1 , fixed valued $\lambda$

\begin{tabular}{|c|c|c|c|c|c|c|c|c|c|c|c|c|c|}
\hline & $N$ & 100 & $\begin{array}{l}\text { linear } \\
200\end{array}$ & 500 & 100 & $\begin{array}{c}\text { nonlinear } \\
200\end{array}$ & 500 & 100 & $\begin{array}{l}\text { linear } \\
200\end{array}$ & 500 & 100 & $\begin{array}{c}\text { nonlinear } \\
200\end{array}$ & 500 \\
\hline 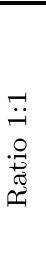 & $\begin{array}{l}\text { IPW } 3 \\
\text { DR }\end{array}$ & $\begin{array}{c}26.7 \\
(0.0) \\
15.0 \\
(-1.0) \\
13.9 \\
(-0.5) \\
10.2 \\
(0.0)\end{array}$ & $\begin{array}{c}\text { homo } \\
19.3 \\
(-0.1) \\
11.4 \\
(-1.3) \\
10.3 \\
(-0.6) \\
7.0 \\
(0.0)\end{array}$ & $\begin{array}{c}\text { geneous, } \\
17.0 \\
(0.1) \\
10.5 \\
(-1.7) \\
8.8 \\
(-0.8) \\
7.2 \\
(0.1)\end{array}$ & $\begin{array}{c}\text { homosc } \\
29.4 \\
(-2.2) \\
15.4 \\
(-0.2) \\
14.1 \\
(-0.1) \\
9.9 \\
(0.0)\end{array}$ & $\begin{array}{c}\text { dastic } \\
19.4 \\
(-2.4) \\
12.3 \\
(-0.1) \\
10.9 \\
(0.0) \\
7.1 \\
(0.0)\end{array}$ & $\begin{array}{c}13.7 \\
(-1.4) \\
11.6 \\
(0.2) \\
9.6 \\
(0.2) \\
7.7 \\
(0.1)\end{array}$ & $\begin{array}{c}34.0 \\
(-0.1) \\
15.1 \\
(-2.3) \\
14.5 \\
(-1.1) \\
11.1 \\
(0.0)\end{array}$ & $\begin{array}{c}\text { heterc } \\
24.3 \\
(-0.1) \\
10.8 \\
(-2.8) \\
10.2 \\
(-1.4) \\
7.5 \\
(0.0)\end{array}$ & $\begin{array}{c}\text { geneous, } \\
19.4 \\
(0.1) \\
9.6 \\
(-3.1) \\
8.6 \\
(-1.5) \\
7.7 \\
(0.1)\end{array}$ & $\begin{array}{c}\text { homosc } \\
34.2 \\
(-3.0) \\
16.7 \\
(1.1) \\
15.2 \\
(1.1) \\
10.3 \\
(0.9)\end{array}$ & $\begin{array}{c}\text { edastic } \\
24.7 \\
(-0.8) \\
14.2 \\
(1.4) \\
12.4 \\
(1.2) \\
7.8 \\
(0.3)\end{array}$ & $\begin{array}{c}17.6 \\
(2.1) \\
11.3 \\
(-0.3) \\
8.6 \\
(-1.0) \\
5.3 \\
(-2.7)\end{array}$ \\
\hline 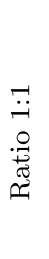 & $\begin{array}{l}\text { IPW } 3 \\
\text { DR }\end{array}$ & $\begin{array}{c}21.8 \\
(0.0) \\
11.9 \\
(-0.6) \\
12.1 \\
(-0.3) \\
11.6 \\
(0.0)\end{array}$ & $\begin{array}{c}\text { homo } \\
13.5 \\
(0.0) \\
6.3 \\
(-0.8) \\
6.4 \\
(-0.4) \\
6.0 \\
(0.0)\end{array}$ & $\begin{array}{c}\text { eneous, } \\
10.6 \\
(0.1) \\
5.4 \\
(-1.1) \\
4.7 \\
(-0.5) \\
4.8 \\
(0.0)\end{array}$ & $\begin{array}{c}\text { heterosc } \\
23.8 \\
(-1.4) \\
12.1 \\
(-0.1) \\
12.2 \\
(-0.1) \\
11.4 \\
(0.0)\end{array}$ & $\begin{array}{c}\text { edastic } \\
14.1 \\
(-1.5) \\
7.2 \\
(-0.1) \\
6.9 \\
(0.0) \\
6.1 \\
(0.0)\end{array}$ & $\begin{array}{c}8.6 \\
(-0.8) \\
6.1 \\
(0.1) \\
5.2 \\
(0.1) \\
5.1 \\
(0.1)\end{array}$ & $\begin{array}{c}27.0 \\
(-0.1) \\
12.1 \\
(-1.4) \\
12.6 \\
(-0.7) \\
12.3 \\
(0.0)\end{array}$ & $\begin{array}{c}\text { hetero } \\
16.7 \\
(-0.1) \\
5.4 \\
(-1.7) \\
5.8 \\
(-0.8) \\
5.9 \\
(0.0)\end{array}$ & $\begin{array}{c}\text { seneous, } \\
12.0 \\
(0.1) \\
4.4 \\
(-2.0) \\
4.1 \\
(-1.0) \\
4.5 \\
(0.0)\end{array}$ & $\begin{array}{c}\text { heterosc } \\
27.8 \\
(-2.0) \\
12.9 \\
(0.7) \\
12.8 \\
(0.7) \\
11.6 \\
(0.6)\end{array}$ & $\begin{array}{c}\text { cedastic } \\
18.6 \\
(-0.5) \\
8.7 \\
(0.9) \\
8.2 \\
(0.8) \\
6.7 \\
(0.2)\end{array}$ & $\begin{array}{c}12.0 \\
(1.5) \\
6.3 \\
(-0.2) \\
4.9 \\
(-0.7) \\
4.0 \\
(-1.7)\end{array}$ \\
\hline 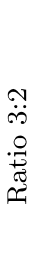 & IPW 3 & $\begin{array}{c}23.7 \\
(-0.2) \\
15.0 \\
(-0.7) \\
14.3 \\
(-0.4) \\
10.3 \\
(0.0)\end{array}$ & $\begin{array}{c}\text { homo } \\
15.9 \\
(-0.3) \\
10.0 \\
(-0.6) \\
8.9 \\
(-0.3) \\
6.0 \\
(0.0)\end{array}$ & $\begin{array}{c}\text { peneous, } \\
15.0 \\
(-0.2) \\
10.6 \\
(-0.8) \\
9.5 \\
(-0.3) \\
8.0 \\
(0.0)\end{array}$ & $\begin{array}{c}\text { homosc } \\
24.2 \\
(-2.8) \\
14.8 \\
(-0.2) \\
14.1 \\
(-0.1) \\
10.1 \\
(0.0)\end{array}$ & $\begin{array}{c}\text { dastic } \\
14.9 \\
(-3.2) \\
10.7 \\
(-0.3) \\
9.3 \\
(-0.1) \\
6.0 \\
(0.0)\end{array}$ & $\begin{array}{c}12.3 \\
(-2.9) \\
12.2 \\
(-0.2) \\
10.4 \\
(-0.1) \\
8.2 \\
(0.0)\end{array}$ & $\begin{array}{c}28.1 \\
(-1.5) \\
16.7 \\
(-0.3) \\
15.8 \\
(0.0) \\
10.5 \\
(-0.4)\end{array}$ & $\begin{array}{c}\text { heter } \\
17.5 \\
(-2.6) \\
11.3 \\
(0.1) \\
9.8 \\
(0.2) \\
5.0 \\
(-1.0)\end{array}$ & $\begin{array}{c}\text { geneous } \\
11.9 \\
(-4.8) \\
10.9 \\
(0.0) \\
8.8 \\
(-0.5) \\
4.7 \\
(-2.8)\end{array}$ & $\begin{array}{c}\text { homosc } \\
28.6 \\
(-1.9) \\
16.2 \\
(1.2) \\
15.1 \\
(1.0) \\
10.1 \\
(0.4)\end{array}$ & $\begin{array}{c}\text { edastic } \\
20.1 \\
(-0.7) \\
12.4 \\
(0.6) \\
10.5 \\
(0.3) \\
5.5 \\
(-0.9)\end{array}$ & $\begin{array}{c}18.1 \\
(1.3) \\
11.2 \\
(-2.3) \\
8.4 \\
(-3.1) \\
3.9 \\
(-5.2)\end{array}$ \\
\hline 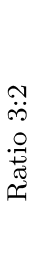 & $\begin{array}{l}\text { IPW } 1 \\
\text { IPW } 2\end{array}$ & $\begin{array}{c}19.0 \\
(-0.1) \\
11.0 \\
(-0.4) \\
11.2 \\
(-0.2) \\
10.2 \\
(0.0)\end{array}$ & $\begin{array}{c}\text { homos } \\
10.1 \\
(-0.2) \\
5.0 \\
(-0.4) \\
4.8 \\
(-0.2) \\
4.2 \\
(0.0)\end{array}$ & $\begin{array}{c}\text { eneous, } \\
8.0 \\
(-0.1) \\
3.7 \\
(-0.5) \\
3.1 \\
(-0.2) \\
2.4 \\
(0.0)\end{array}$ & $\begin{array}{c}\text { heterosc } \\
19.3 \\
(-1.8) \\
10.7 \\
(-0.1) \\
11.0 \\
(-0.1) \\
10.1 \\
(0.0)\end{array}$ & $\begin{array}{c}\text { edastic } \\
9.5 \\
(-1.9) \\
5.5 \\
(-0.1) \\
5.1 \\
(-0.1) \\
4.3 \\
(0.0)\end{array}$ & $\begin{array}{c}5.9 \\
(-1.8) \\
4.2 \\
(-0.1) \\
3.3 \\
(0.0) \\
2.5 \\
(0.0)\end{array}$ & $\begin{array}{c}22.1 \\
(-1.0) \\
12.0 \\
(-0.2) \\
12.1 \\
(0.0) \\
10.3 \\
(-0.2)\end{array}$ & $\begin{array}{c}\text { heterc } \\
11.2 \\
(-1.6) \\
5.8 \\
(0.0) \\
5.4 \\
(0.1) \\
3.5 \\
(-0.5)\end{array}$ & $\begin{array}{c}\text { oneous, } \\
6.2 \\
(-3.1) \\
4.0 \\
(0.0) \\
2.8 \\
(-0.3) \\
0.3 \\
(-1.7)\end{array}$ & $\begin{array}{c}\text { heterosc } \\
22.5 \\
(-1.2) \\
11.7 \\
(0.7) \\
11.7 \\
(0.7) \\
10.3 \\
(0.3)\end{array}$ & $\begin{array}{c}\text { cedastic } \\
12.9 \\
(-0.3) \\
6.7 \\
(0.4) \\
5.9 \\
(0.2) \\
4.1 \\
(-0.6)\end{array}$ & $\begin{array}{c}10.0 \\
(0.9) \\
3.8 \\
(-1.5) \\
2.3 \\
(-2.0) \\
0.0 \\
(-3.4)\end{array}$ \\
\hline 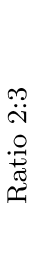 & $\begin{array}{l}\text { IPW } 3 \\
\text { DR }\end{array}$ & $\begin{array}{c}23.9 \\
(0.2) \\
13.4 \\
(-0.6) \\
12.7 \\
(-0.3) \\
9.4 \\
(0.0)\end{array}$ & $\begin{array}{c}\text { homo } \\
16.3 \\
(0.0) \\
9.1 \\
(-0.8) \\
8.5 \\
(-0.4) \\
6.0 \\
(0.0)\end{array}$ & $\begin{array}{c}\text { peneous, } \\
16.7 \\
(0.0) \\
11.1 \\
(-0.7) \\
10.3 \\
(-0.3) \\
8.8 \\
(0.1)\end{array}$ & $\begin{array}{c}\text { homosc } \\
28.1 \\
(-0.5) \\
13.1 \\
(-0.1) \\
12.5 \\
(-0.1) \\
9.1 \\
(0.0)\end{array}$ & $\begin{array}{c}\text { dastic } \\
18.5 \\
(-0.9) \\
9.6 \\
(0.0) \\
8.9 \\
(0.0) \\
5.9 \\
(0.0)\end{array}$ & $\begin{array}{c}15.8 \\
(-0.7) \\
11.2 \\
(0.0) \\
10.3 \\
(0.0) \\
8.6 \\
(0.1)\end{array}$ & $\begin{array}{c}30.3 \\
(-0.1) \\
11.7 \\
(-3.2) \\
11.8 \\
(-2.2) \\
10.1 \\
(-0.2)\end{array}$ & $\begin{array}{c}\text { heter } \\
20.7 \\
(-0.6) \\
5.1 \\
(-5.1) \\
5.6 \\
(-3.7) \\
5.7 \\
(-0.8)\end{array}$ & $\begin{array}{c}\text { geneous } \\
16.9 \\
(-2.1) \\
3.4 \\
(-8.2) \\
4.3 \\
(-6.2) \\
6.5 \\
(-2.5)\end{array}$ & $\begin{array}{c}\text { homosc } \\
33.1 \\
(-1.8) \\
13.5 \\
(0.4) \\
12.9 \\
(0.5) \\
9.4 \\
(0.6)\end{array}$ & $\begin{array}{c}\text { edastic } \\
22.2 \\
(-1.4) \\
10.5 \\
(0.8) \\
9.7 \\
(0.7) \\
6.4 \\
(0.6)\end{array}$ & $\begin{array}{c}17.5 \\
(-0.2) \\
12.1 \\
(1.0) \\
11.0 \\
(0.9) \\
9.0 \\
(0.7)\end{array}$ \\
\hline 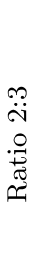 & IPW 3 & $\begin{array}{c}19.1 \\
(0.1) \\
11.2 \\
(-0.4) \\
11.5 \\
(-0.2) \\
11.8 \\
(0.0)\end{array}$ & $\begin{array}{c}\text { homos } \\
10.1 \\
(0.0) \\
4.6 \\
(-0.5) \\
5.0 \\
(-0.3) \\
5.1 \\
(0.0)\end{array}$ & $\begin{array}{c}\text { eneous, } \\
11.2 \\
(0.0) \\
6.3 \\
(-0.4) \\
6.1 \\
(-0.2) \\
5.9 \\
(0.0)\end{array}$ & $\begin{array}{c}\text { heterosc } \\
22.3 \\
(-0.3) \\
11.0 \\
(-0.1) \\
11.4 \\
(0.0) \\
11.6 \\
(0.0)\end{array}$ & $\begin{array}{c}\text { edastic } \\
12.1 \\
(-0.6) \\
5.3 \\
(0.0) \\
5.5 \\
(0.0) \\
5.1 \\
(0.0)\end{array}$ & $\begin{array}{c}11.1 \\
(-0.5) \\
6.3 \\
(0.0) \\
6.0 \\
(0.0) \\
5.7 \\
(0.1)\end{array}$ & $\begin{array}{c}23.6 \\
(-0.1) \\
10.3 \\
(-1.8) \\
11.1 \\
(-1.2) \\
12.3 \\
(-0.1)\end{array}$ & $\begin{array}{c}\text { heterc } \\
13.1 \\
(-0.4) \\
2.2 \\
(-3.0) \\
3.1 \\
(-2.2) \\
4.7 \\
(-0.5)\end{array}$ & $\begin{array}{c}\text { seneous, } \\
11.6 \\
(-1.3) \\
1.6 \\
(-4.8) \\
2.4 \\
(-3.6) \\
4.5 \\
(-1.4)\end{array}$ & $\begin{array}{c}\text { heterosc } \\
26.6 \\
(-1.2) \\
11.3 \\
(0.3) \\
11.6 \\
(0.3) \\
11.7 \\
(0.4)\end{array}$ & $\begin{array}{c}\text { cedastic } \\
15.5 \\
(-1.0) \\
5.9 \\
(0.5) \\
6.1 \\
(0.4) \\
5.5 \\
(0.4)\end{array}$ & $\begin{array}{c}13.1 \\
(-0.2) \\
6.9 \\
(0.6) \\
6.5 \\
(0.6) \\
6.1 \\
(0.5)\end{array}$ \\
\hline
\end{tabular}


Table A.6: Percentage improvement in MSE for the ATE if the shrunken propensity scores are used with trimming rule 2 instead of the conventional propensity scores with trimming rule 2 , fixed valued $\lambda$

\begin{tabular}{|c|c|c|c|c|c|c|c|c|c|c|c|c|c|}
\hline & $N$ & 100 & $\begin{array}{l}\text { linear } \\
200\end{array}$ & 500 & 100 & $\begin{array}{c}\text { nonlinear } \\
200\end{array}$ & 500 & 100 & $\begin{array}{l}\text { linear } \\
200\end{array}$ & 500 & 100 & $\begin{array}{c}\text { nonlinear } \\
200\end{array}$ & 500 \\
\hline 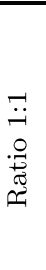 & $\begin{array}{l}\text { IPW } 3 \\
\text { DR }\end{array}$ & $\begin{array}{c}24.0 \\
(-0.1) \\
12.0 \\
(-1.1) \\
7.5 \\
(-0.5) \\
3.0 \\
(0.0)\end{array}$ & $\begin{array}{c}\text { homo } \\
18.0 \\
(0.0) \\
6.6 \\
(-1.5) \\
4.0 \\
(-0.7) \\
1.4 \\
(0.0)\end{array}$ & $\begin{array}{c}\text { eneous, } \\
10.2 \\
(0.1) \\
2.7 \\
(-2.0) \\
1.2 \\
(-1.0) \\
0.1 \\
(0.0)\end{array}$ & $\begin{array}{c}\text { homosce } \\
24.7 \\
(-2.8) \\
12.5 \\
(-0.3) \\
7.8 \\
(-0.2) \\
2.8 \\
(0.0)\end{array}$ & $\begin{array}{c}\text { dastic } \\
18.5 \\
(-2.4) \\
7.4 \\
(-0.1) \\
4.3 \\
(0.0) \\
1.1 \\
(0.0)\end{array}$ & $\begin{array}{c}9.9 \\
(-1.3) \\
4.1 \\
(0.2) \\
1.9 \\
(0.2) \\
-0.1 \\
(0.0)\end{array}$ & $\begin{array}{c}25.4 \\
(-0.2) \\
11.2 \\
(-2.5) \\
7.0 \\
(-1.3) \\
3.2 \\
(0.0)\end{array}$ & $\begin{array}{c}\text { heterc } \\
19.0 \\
(-0.1) \\
5.0 \\
(-3.2) \\
3.1 \\
(-1.6) \\
1.4 \\
(0.0)\end{array}$ & $\begin{array}{c}\text { eneous, } \\
11.0 \\
(0.1) \\
1.4 \\
(-3.7) \\
0.7 \\
(-1.8) \\
0.3 \\
(0.0)\end{array}$ & $\begin{array}{c}\text { homosce } \\
30.1 \\
(-1.9) \\
13.7 \\
(1.4) \\
8.8 \\
(1.2) \\
3.1 \\
(0.7)\end{array}$ & $\begin{array}{c}\text { edastic } \\
26.1 \\
(1.7) \\
10.0 \\
(2.8) \\
6.4 \\
(2.3) \\
2.0 \\
(1.2)\end{array}$ & $\begin{array}{c}19.6 \\
(6.9) \\
8.9 \\
(5.4) \\
5.9 \\
(4.4) \\
2.1 \\
(2.3)\end{array}$ \\
\hline 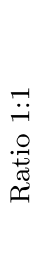 & $\begin{array}{l}\text { IPW } 2 \\
\text { IPW } 3 \\
\text { DR }\end{array}$ & $\begin{array}{c}19.2 \\
(-0.1) \\
8.5 \\
(-0.7) \\
7.2 \\
(-0.3) \\
6.1 \\
(0.0)\end{array}$ & $\begin{array}{c}\text { homo } \\
13.6 \\
(0.0) \\
4.0 \\
(-0.9) \\
3.6 \\
(-0.4) \\
3.7 \\
(0.0)\end{array}$ & $\begin{array}{c}\text { coous, } \\
6.9 \\
(0.1) \\
1.9 \\
(-1.2) \\
1.7 \\
(-0.6) \\
2.1 \\
(0.0)\end{array}$ & $\begin{array}{c}\text { heterosc } \\
19.9 \\
(-1.7) \\
8.8 \\
(-0.2) \\
7.4 \\
(-0.1) \\
5.9 \\
(0.0)\end{array}$ & $\begin{array}{c}\text { edastic } \\
14.6 \\
(-1.4) \\
5.2 \\
(-0.1) \\
4.2 \\
(0.0) \\
3.6 \\
(0.0)\end{array}$ & $\begin{array}{c}7.0 \\
(-0.7) \\
3.2 \\
(0.2) \\
2.4 \\
(0.1) \\
2.2 \\
(0.0)\end{array}$ & $\begin{array}{c}20.2 \\
(-0.1) \\
8.0 \\
(-1.5) \\
6.9 \\
(-0.8) \\
6.2 \\
(0.0)\end{array}$ & $\begin{array}{c}\text { hetero } \\
14.4 \\
(0.0) \\
3.0 \\
(-1.9) \\
3.0 \\
(-0.9) \\
3.8 \\
(0.0)\end{array}$ & $\begin{array}{c}\text { eneous, } \\
7.3 \\
(0.1) \\
1.1 \\
(-2.3) \\
1.3 \\
(-1.1) \\
2.1 \\
(0.0)\end{array}$ & $\begin{array}{c}\text { heterosc } \\
24.2 \\
(-1.2) \\
9.6 \\
(0.9) \\
8.0 \\
(0.7) \\
5.9 \\
(0.4)\end{array}$ & $\begin{array}{c}\text { edastic } \\
20.5 \\
(1.2) \\
6.8 \\
(1.7) \\
5.5 \\
(1.4) \\
4.1 \\
(0.7)\end{array}$ & $\begin{array}{c}13.9 \\
(4.9) \\
6.1 \\
(3.3) \\
4.8 \\
(2.7) \\
3.5 \\
(1.4)\end{array}$ \\
\hline 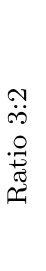 & IPW 3 & $\begin{array}{c}19.3 \\
(-0.2) \\
10.2 \\
(-0.7) \\
7.2 \\
(-0.4) \\
2.6 \\
(0.0)\end{array}$ & $\begin{array}{c}\text { homo } \\
13.9 \\
(-0.3) \\
7.2 \\
(-0.7) \\
4.8 \\
(-0.3) \\
1.8 \\
(0.0)\end{array}$ & $\begin{array}{c}\text { eneous, } \\
8.0 \\
(-0.2) \\
4.0 \\
(-0.8) \\
2.6 \\
(-0.4) \\
0.8 \\
(0.0)\end{array}$ & $\begin{array}{c}\text { homosce } \\
18.0 \\
(-3.1) \\
10.0 \\
(-0.3) \\
7.0 \\
(-0.2) \\
2.6 \\
(0.0)\end{array}$ & $\begin{array}{c}\text { dastic } \\
12.4 \\
(-3.4) \\
7.6 \\
(-0.3) \\
4.9 \\
(-0.2) \\
1.8 \\
(0.0)\end{array}$ & $\begin{array}{c}6.3 \\
(-3.2) \\
4.6 \\
(-0.2) \\
2.9 \\
(-0.1) \\
0.7 \\
(0.0)\end{array}$ & $\begin{array}{c}18.7 \\
(-1.0) \\
11.8 \\
(0.4) \\
8.3 \\
(0.5) \\
2.8 \\
(0.2)\end{array}$ & $\begin{array}{c}\text { heterc } \\
13.0 \\
(-1.5) \\
9.8 \\
(1.6) \\
6.7 \\
(1.4) \\
2.3 \\
(0.3)\end{array}$ & $\begin{array}{c}\text { eneous, } \\
6.5 \\
(-1.6) \\
8.5 \\
(3.5) \\
5.8 \\
(2.9) \\
1.6 \\
(0.8)\end{array}$ & $\begin{array}{c}\text { homosce } \\
23.6 \\
(-1.1) \\
11.6 \\
(1.7) \\
8.3 \\
(1.5) \\
3.1 \\
(0.7)\end{array}$ & $\begin{array}{c}\text { edastic } \\
20.1 \\
(1.7) \\
10.5 \\
(2.9) \\
7.3 \\
(2.4) \\
2.9 \\
(1.2)\end{array}$ & $\begin{array}{c}18.2 \\
(7.2) \\
8.9 \\
(4.5) \\
6.3 \\
(3.6) \\
2.1 \\
(1.4)\end{array}$ \\
\hline 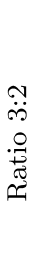 & $\begin{array}{l}\text { IPW } 3 \\
\text { DR }\end{array}$ & $\begin{array}{c}15.0 \\
(-0.1) \\
6.1 \\
(-0.4) \\
5.1 \\
(-0.2) \\
4.2 \\
(0.0)\end{array}$ & $\begin{array}{c}\text { homos } \\
10.1 \\
(-0.2) \\
4.6 \\
(-0.4) \\
3.9 \\
(-0.2) \\
3.5 \\
(0.0)\end{array}$ & $\begin{array}{c}\text { eneous, } \\
5.9 \\
(-0.1) \\
1.4 \\
(-0.5) \\
1.1 \\
(-0.2) \\
0.9 \\
(0.0)\end{array}$ & $\begin{array}{c}\text { heterosc } \\
14.2 \\
(-1.9) \\
5.9 \\
(-0.2) \\
4.9 \\
(-0.1) \\
4.1 \\
(0.0)\end{array}$ & $\begin{array}{c}\text { dastic } \\
9.2 \\
(-2.0) \\
5.0 \\
(-0.2) \\
4.1 \\
(-0.1) \\
3.5 \\
(0.0)\end{array}$ & $\begin{array}{c}5.0 \\
(-1.9) \\
1.8 \\
(-0.1) \\
1.2 \\
(-0.1) \\
0.8 \\
(0.0)\end{array}$ & $\begin{array}{c}14.7 \\
(-0.7) \\
7.0 \\
(0.2) \\
5.7 \\
(0.3) \\
4.2 \\
(0.1)\end{array}$ & $\begin{array}{c}\text { hetero } \\
9.4 \\
(-0.9) \\
6.2 \\
(0.8) \\
5.0 \\
(0.8) \\
3.6 \\
(0.1)\end{array}$ & $\begin{array}{c}\text { eneous, } \\
5.2 \\
(-1.0) \\
4.2 \\
(2.2) \\
3.0 \\
(1.7) \\
1.4 \\
(0.5)\end{array}$ & $\begin{array}{c}\text { heterosc } \\
18.1 \\
(-0.7) \\
6.9 \\
(1.0) \\
5.7 \\
(0.9) \\
4.5 \\
(0.5)\end{array}$ & $\begin{array}{c}\text { edastic } \\
14.2 \\
(1.3) \\
6.8 \\
(1.8) \\
5.5 \\
(1.5) \\
4.2 \\
(0.8)\end{array}$ & $\begin{array}{c}13.0 \\
(4.7) \\
4.5 \\
(2.7) \\
3.4 \\
(2.2) \\
1.5 \\
(0.9)\end{array}$ \\
\hline 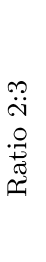 & $\begin{array}{l}\text { IPW } 2 \\
\text { IPW } 3 \\
\text { DR }\end{array}$ & $\begin{array}{c}21.0 \\
(0.0) \\
10.1 \\
(-0.6) \\
6.7 \\
(-0.3) \\
2.4 \\
(0.0)\end{array}$ & $\begin{array}{c}\text { homo } \\
14.6 \\
(0.0) \\
6.4 \\
(-0.9) \\
4.3 \\
(-0.5) \\
1.7 \\
(0.0)\end{array}$ & $\begin{array}{c}\text { eneous, } \\
11.1 \\
(0.0) \\
5.1 \\
(-0.9) \\
4.1 \\
(-0.5) \\
2.9 \\
(0.0)\end{array}$ & $\begin{array}{c}\text { homosce } \\
23.0 \\
(-1.2) \\
10.0 \\
(-0.1) \\
6.6 \\
(-0.1) \\
2.2 \\
(0.0)\end{array}$ & $\begin{array}{c}\text { dastic } \\
16.0 \\
(-0.9) \\
6.9 \\
(0.0) \\
4.6 \\
(0.0) \\
1.6 \\
(0.0)\end{array}$ & $\begin{array}{c}11.7 \\
(-0.7) \\
6.1 \\
(0.0) \\
4.7 \\
(0.0) \\
3.0 \\
(0.0)\end{array}$ & $\begin{array}{c}22.6 \\
(0.4) \\
7.7 \\
(-3.2) \\
5.2 \\
(-1.9) \\
2.7 \\
(0.2)\end{array}$ & $\begin{array}{c}\text { heterc } \\
16.3 \\
(1.1) \\
3.2 \\
(-4.2) \\
2.3 \\
(-2.4) \\
2.2 \\
(0.5)\end{array}$ & $\begin{array}{c}\text { peneous, } \\
12.6 \\
(1.4) \\
0.2 \\
(-5.6) \\
1.1 \\
(-3.3) \\
3.5 \\
(0.6)\end{array}$ & $\begin{array}{c}\text { homosce } \\
26.9 \\
(-1.8) \\
10.2 \\
(0.1) \\
6.7 \\
(0.1) \\
2.1 \\
(0.1)\end{array}$ & $\begin{array}{c}\text { edastic } \\
19.6 \\
(-0.6) \\
7.5 \\
(0.6) \\
5.0 \\
(0.5) \\
1.7 \\
(0.3)\end{array}$ & $\begin{array}{c}15.0 \\
(0.8) \\
7.0 \\
(1.0) \\
5.5 \\
(0.8) \\
3.2 \\
(0.3)\end{array}$ \\
\hline 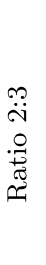 & IPW 3 & $\begin{array}{c}15.1 \\
(0.0) \\
6.0 \\
(-0.4) \\
5.1 \\
(-0.2) \\
4.3 \\
(0.0)\end{array}$ & $\begin{array}{l}\text { homos } \\
10.6 \\
(0.0) \\
3.2 \\
(-0.5) \\
2.9 \\
(-0.3) \\
3.0 \\
(0.0)\end{array}$ & $\begin{array}{c}\text { eneous, } \\
7.2 \\
(0.0) \\
2.2 \\
(-0.5) \\
2.1 \\
(-0.2) \\
2.2 \\
(0.0)\end{array}$ & $\begin{array}{c}\text { heterosc } \\
17.0 \\
(-0.7) \\
6.2 \\
(-0.1) \\
5.2 \\
(0.0) \\
4.2 \\
(0.0)\end{array}$ & $\begin{array}{c}\text { edastic } \\
12.1 \\
(-0.6) \\
3.9 \\
(0.0) \\
3.4 \\
(0.0) \\
2.9 \\
(0.0)\end{array}$ & $\begin{array}{c}7.7 \\
(-0.5) \\
2.5 \\
(0.0) \\
2.3 \\
(0.0) \\
2.2 \\
(0.0)\end{array}$ & $\begin{array}{c}16.4 \\
(0.3) \\
4.5 \\
(-1.9) \\
4.2 \\
(-1.1) \\
4.5 \\
(0.2)\end{array}$ & $\begin{array}{c}\text { hetero } \\
12.0 \\
(0.7) \\
1.3 \\
(-2.4) \\
1.8 \\
(-1.3) \\
3.4 \\
(0.4)\end{array}$ & $\begin{array}{c}\text { eneous, } \\
8.4 \\
(0.9) \\
-0.5 \\
(-3.2) \\
0.5 \\
(-1.8) \\
2.5 \\
(0.4)\end{array}$ & $\begin{array}{c}\text { heterosc } \\
20.5 \\
(-1.2) \\
6.3 \\
(0.1) \\
5.3 \\
(0.1) \\
4.1 \\
(0.1)\end{array}$ & $\begin{array}{c}\text { edastic } \\
15.2 \\
(-0.4) \\
4.2 \\
(0.4) \\
3.7 \\
(0.3) \\
2.9 \\
(0.2)\end{array}$ & $\begin{array}{c}10.4 \\
(0.5) \\
3.2 \\
(0.6) \\
2.8 \\
(0.5) \\
2.3 \\
(0.2)\end{array}$ \\
\hline
\end{tabular}


Table A.7: Percentage improvement in MSE for the ATE if the shrunken propensity scores are used with trimming rule 2 instead of the conventional propensity scores with trimming rule 3 , fixed valued $\lambda$

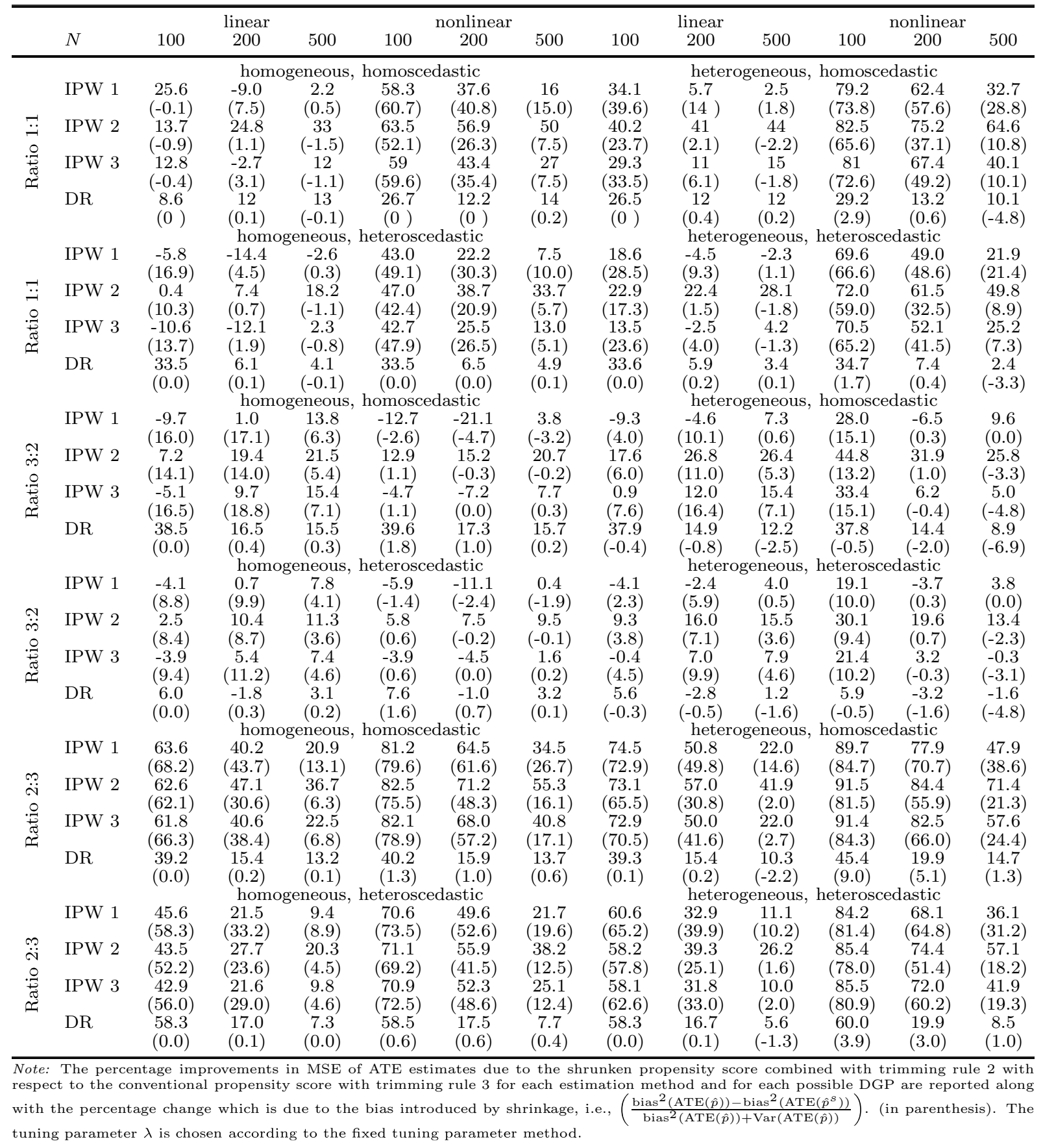


Table A.8: Percentage improvement in MSE for the ATE if the shrunken propensity scores are used with trimming rule 2 instead of the conventional propensity scores, $\operatorname{MSE}\left(\hat{p}_{i}^{s}\right)$-minimizing $\lambda$

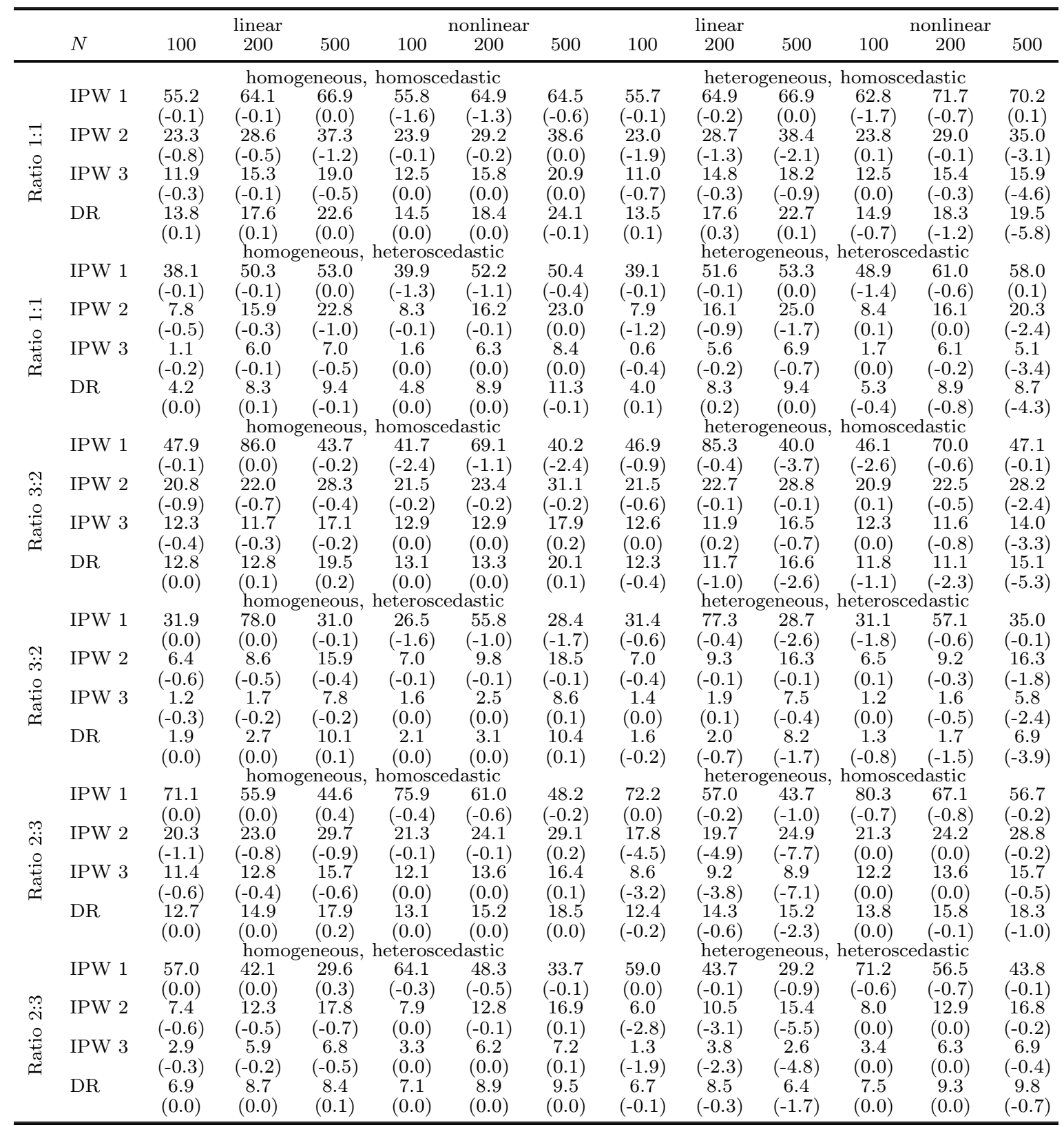

Note: The percentage improvements in MSE of ATE estimates due to the shrunken propensity score combined with trimming rule 2 with respect to the conventional propensity score for each estimation method and for each possible DGP are reported along with the percentage change which is due to the bias introduced by shrinkage, i.e., $\left(\frac{\operatorname{bias}^{2}(\operatorname{ATE}(\hat{p}))-\operatorname{bias}^{2}\left(\operatorname{ATE}\left(\hat{p}^{s}\right)\right)}{\operatorname{bias}^{2}(\operatorname{ATE}(\hat{p}))+\operatorname{Var}(\operatorname{ATE}(\hat{p}))}\right)$. (in parenthesis). The tuning parameter $\lambda$ is chosen according to the MSE minimizing tuning parameter method. 
Table A.9: Percentage improvement in MSE for the ATE if the shrunken propensity scores are used with trimming rule 2 instead of the conventional propensity scores with trimming rule 1 , $\operatorname{MSE}\left(\hat{p}_{i}^{s}\right)$-minimizing $\lambda$

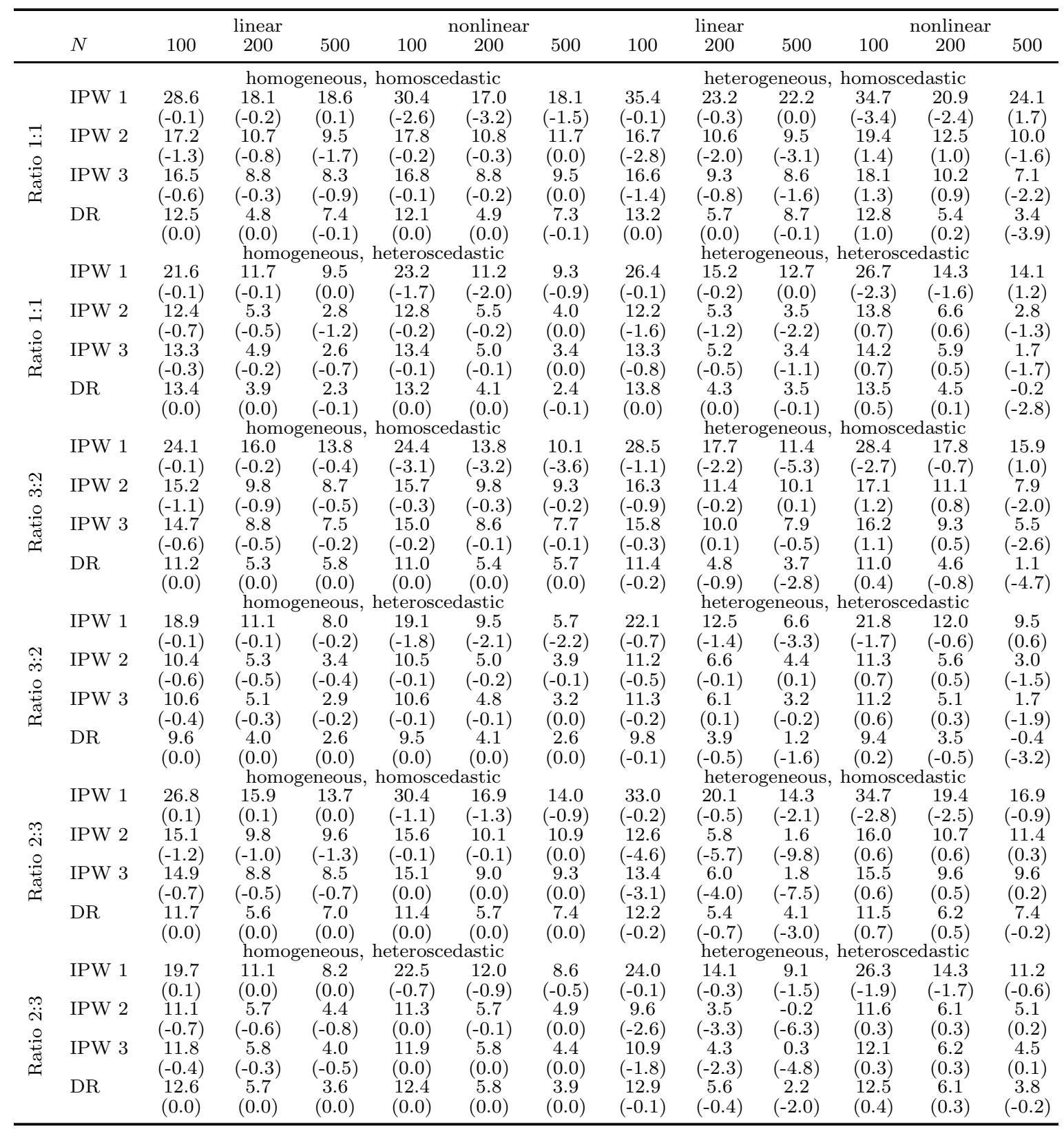

Note: The percentage improvements in MSE of ATE estimates due to the shrunken propensity score combined with trimming rule 2 with respect to the conventional propensity score combined with trimming rule 1 for each estimation method and for each possible DGP are reported along with the percentage change which is due to the bias introduced by shrinkage, i.e., $\left(\frac{\operatorname{bias}^{2}(\operatorname{ATE}(\hat{p}))-\operatorname{bias}\left(\operatorname{ATE}\left(\hat{p}^{s}\right)\right)}{\operatorname{bias}(\operatorname{ATE}(\hat{p}))+\operatorname{Var}(\operatorname{ATE}(\hat{p}))}\right) \cdot(\operatorname{in}$ parenthesis). The tuning parameter $\lambda$ is chosen according to the MSE minimizing tuning parameter method. 
Table A.10: Percentage improvement in MSE for the ATE if the shrunken propensity scores are used with trimming rule 2 instead of the conventional propensity scores with trimming rule $2, \operatorname{MSE}\left(\hat{p}_{i}^{s}\right)$-minimizing $\lambda$

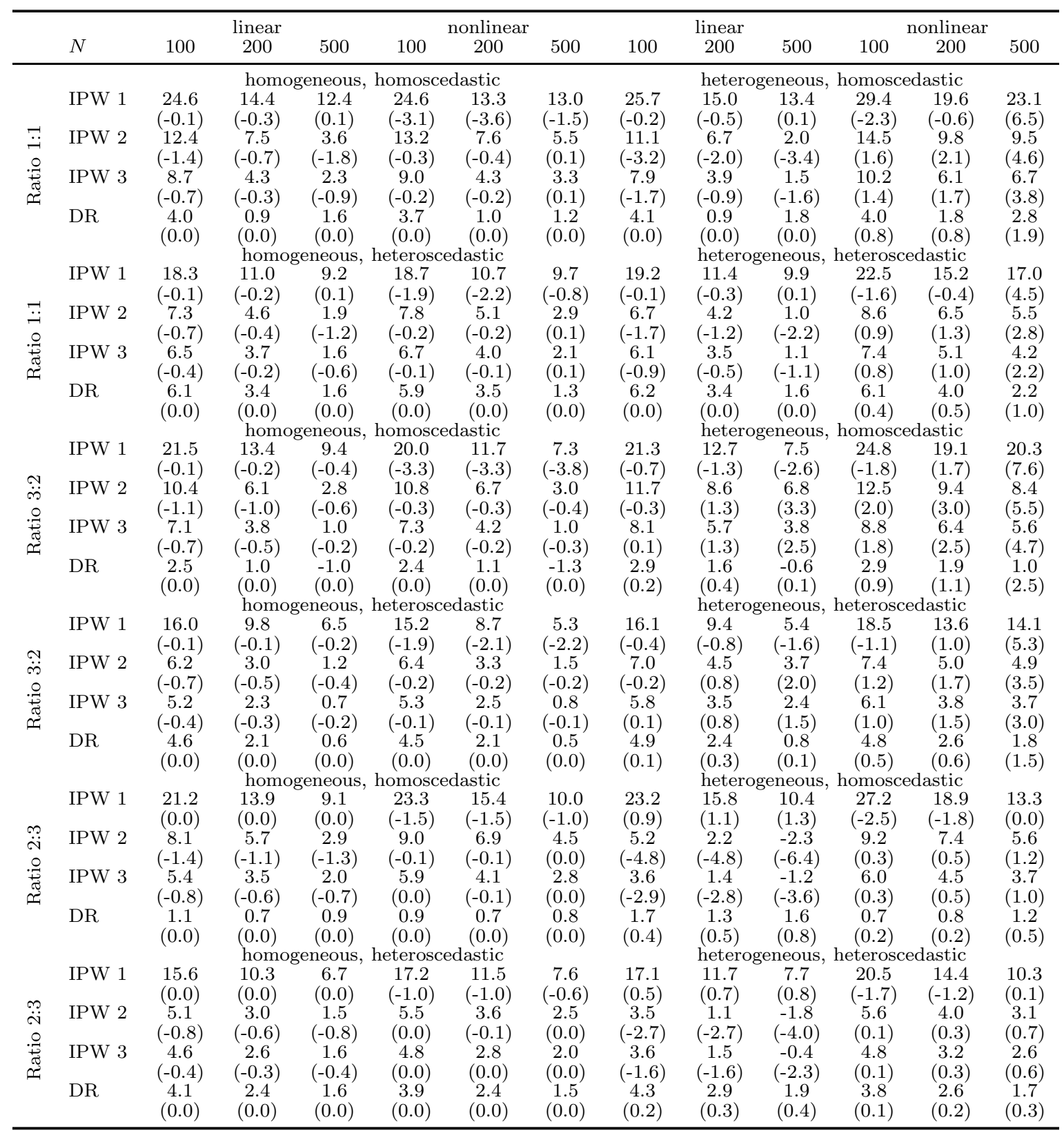

Note: The percentage improvements in MSE of ATE estimates due to the shrunken propensity score combined with trimming rule 2 with respect to the conventional propensity score combined with trimming rule 2 for each estimation method and for each possible DGP are reported along with the percentage change which is due to the bias introduced by shrinkage, i.e., $\left(\frac{\operatorname{bias}^{2}(\operatorname{ATE}(\hat{p}))-\operatorname{bias}\left(\operatorname{ATE}^{2}\left(\hat{p}^{s}\right)\right)}{\operatorname{bias}^{2}(\operatorname{ATE}(\hat{p}))+\operatorname{Var}(\operatorname{ATE}(\hat{p}))}\right) \cdot(\operatorname{in}$ parenthesis). The tuning parameter $\lambda$ is chosen according to the MSE minimizing tuning parameter method. 
Table A.11: Percentage improvement in MSE for the ATE if the shrunken propensity scores are used with trimming rule 2 instead of the conventional propensity scores with trimming rule $3, \operatorname{MSE}\left(\hat{p}_{i}^{s}\right)$ minimizing $\lambda$

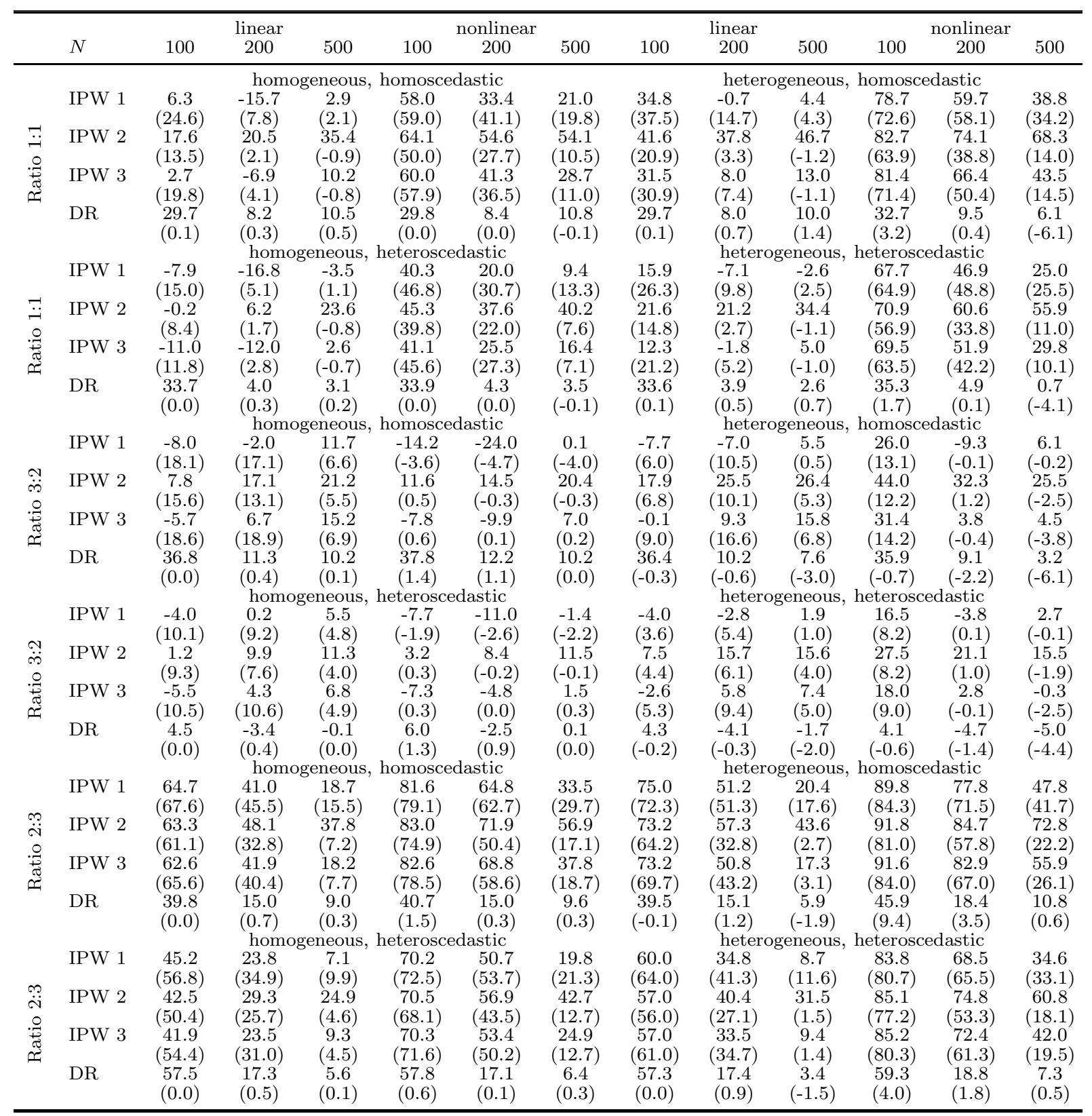

Note: The percentage improvements in MSE of ATE estimates due to the shrunken propensity score combined with trimming rule 2 with respect to the conventional propensity score combined with trimming rule 3 for each estimation method and for each possible DGP are reported along with the percentage change which is due to the bias introduced by shrinkage, i.e., $\left(\frac{\operatorname{bias}^{2}(\operatorname{ATE}(\hat{p}))-\operatorname{bias}^{2}\left(\operatorname{ATE}\left(\hat{p}^{s}\right)\right)}{\operatorname{bias}^{2}(\operatorname{ATE}(\hat{p}))+\operatorname{Var}(\operatorname{ATE}(\hat{p}))}\right) \cdot(\operatorname{in} \operatorname{parenthesis}) \cdot \operatorname{The}$ tuning parameter $\lambda$ is chosen according to the MSE minimizing tuning parameter method. 
Table A.12: Percentage improvement in MSE for the ATE if the shrunken propensity scores are used with trimming rule 2 instead of the conventional propensity scores, cross validated $\lambda$

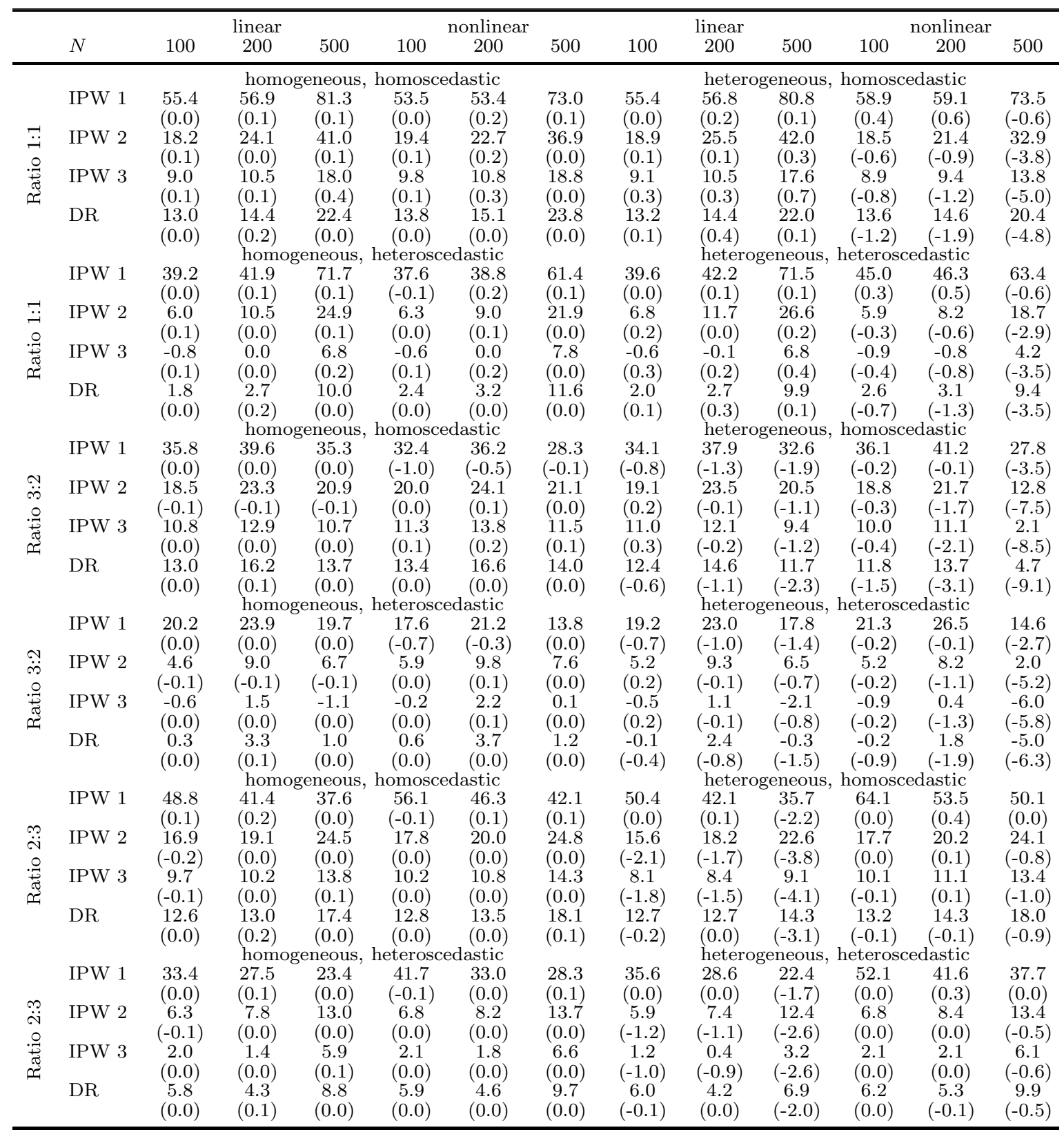

Note: The percentage improvements in MSE of ATE estimates due to the shrunken propensity score combined with trimming rule 2 (he conventional propensity score for each estimation method and for each possible DGP are reported along with the percentage change which is due to the bias introduced by shrinkage, i.e., $\left(\frac{\operatorname{bias}^{2}(\operatorname{ATE}(\hat{p}))-\operatorname{bias}^{2}\left(\operatorname{ATE}\left(\hat{p}^{s}\right)\right)}{\operatorname{bias}^{2}(\operatorname{ATE}(\hat{p}))+\operatorname{Var}(\operatorname{ATE}(\hat{p}))}\right)$. (in parenthesis). The tuning parameter $\lambda$ is chosen according to the cross validated tuning parameter method. 
Table A.13: Percentage improvement in MSE for the ATE if the shrunken propensity scores are used with trimming rule 2 instead of the conventional propensity scores with trimming rule 1 , cross-validated $\lambda$

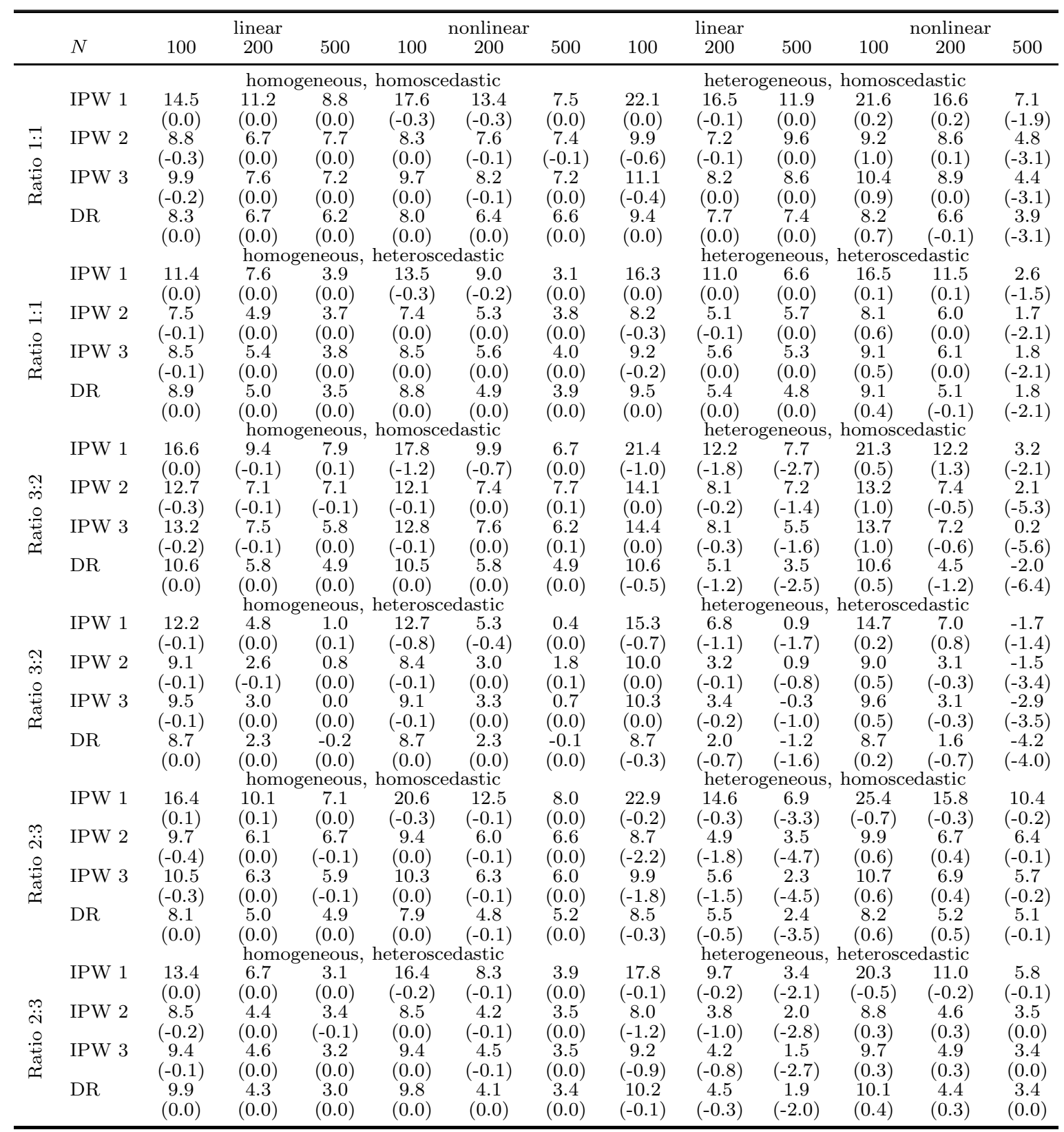

Note: The percentage improvements in MSE of ATE estimates due to the shrunken propensity score combined with trimming rule 2 with respect to the conventional propensity score combined with trimming rule 1 for each estimation method and for each possible DGP are reported along with the percentage change which is due to the bias introduced by shrinkage, i.e., $\left(\frac{\operatorname{bias}^{2}(\operatorname{ATE}(\hat{p}))-\operatorname{bias}^{2}\left(\operatorname{ATE}\left(\hat{p}^{s}\right)\right)}{\operatorname{bias}(\operatorname{ATE}(\hat{p}))+\operatorname{Var}(\operatorname{ATE}(\hat{p}))}\right) \cdot(\operatorname{in}$ parenthesis). The tuning parameter $\lambda$ is chosen according to the cross validated tuning parameter method. 
Table A.14: Percentage improvement in MSE for the ATE if the shrunken propensity scores are used with trimming rule 2 instead of the conventional propensity scores with trimming rule 2 , cross-validated $\lambda$

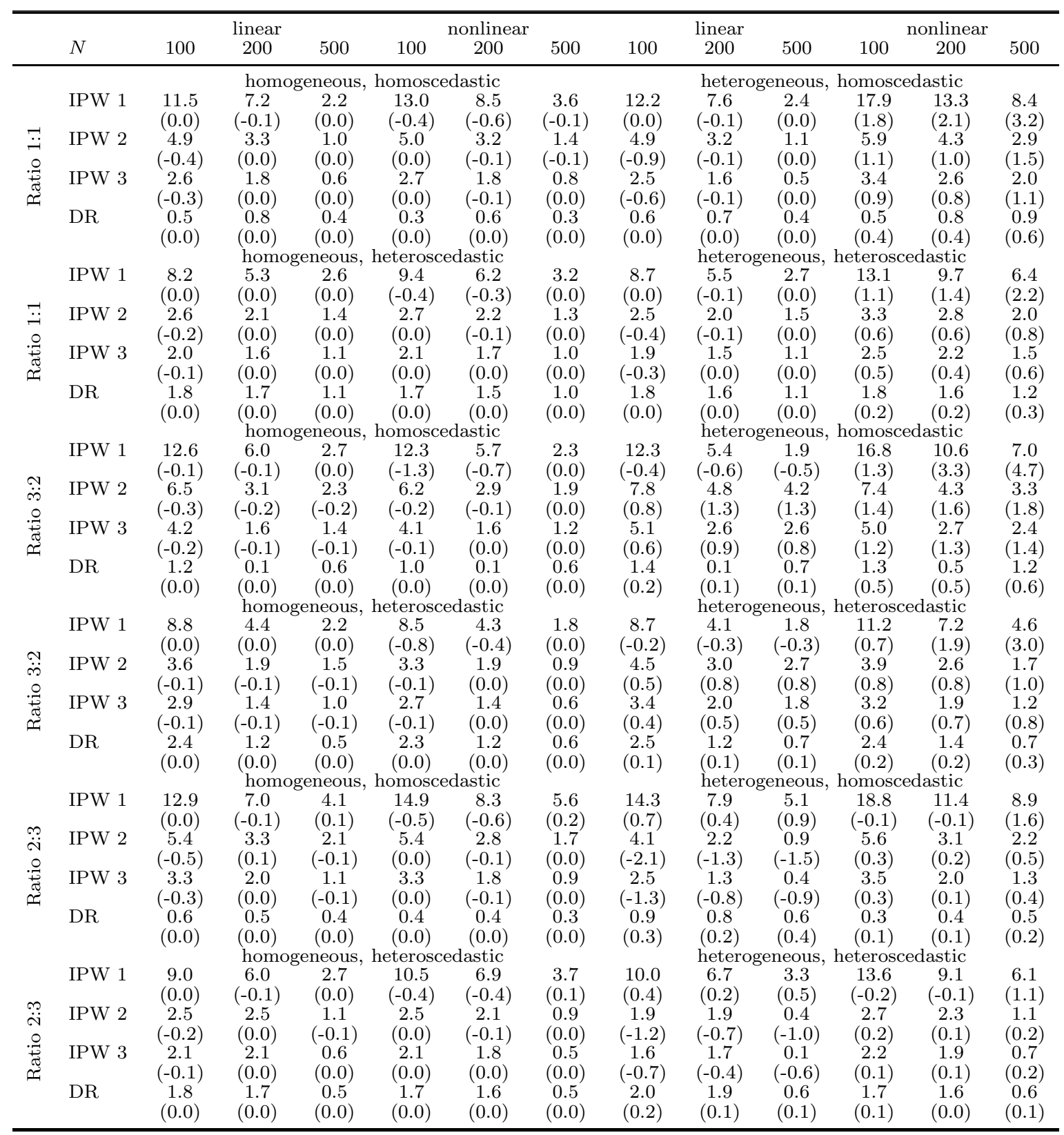

Note: The percentage improvements in MSE of ATE estimates due to the shrunken propensity score combined with trimming rule 2 with respect to the conventional propensity score combined with trimming rule 2 for each estimation method and for each possible DGP are reported along with the percentage change which is due to the bias introduced by shrinkage, i.e., $\left(\frac{\operatorname{bias}^{2}(\operatorname{ATE}(\hat{p}))-\operatorname{bias}^{2}\left(\operatorname{ATE}\left(\hat{p}^{\mathcal{S}}\right)\right)}{\operatorname{bias}^{2}(\operatorname{ATE}(\hat{p}))+\operatorname{Var}(\operatorname{ATE}(\hat{p}))}\right) \cdot(\operatorname{in}$ parenthesis). The tuning parameter $\lambda$ is chosen according to the cross validated tuning parameter method. 
Table A.15: Percentage improvement in MSE for the ATE if the shrunken propensity scores are used with trimming rule 2 instead of the conventional propensity scores with trimming rule 3 , crossvalidated $\lambda$

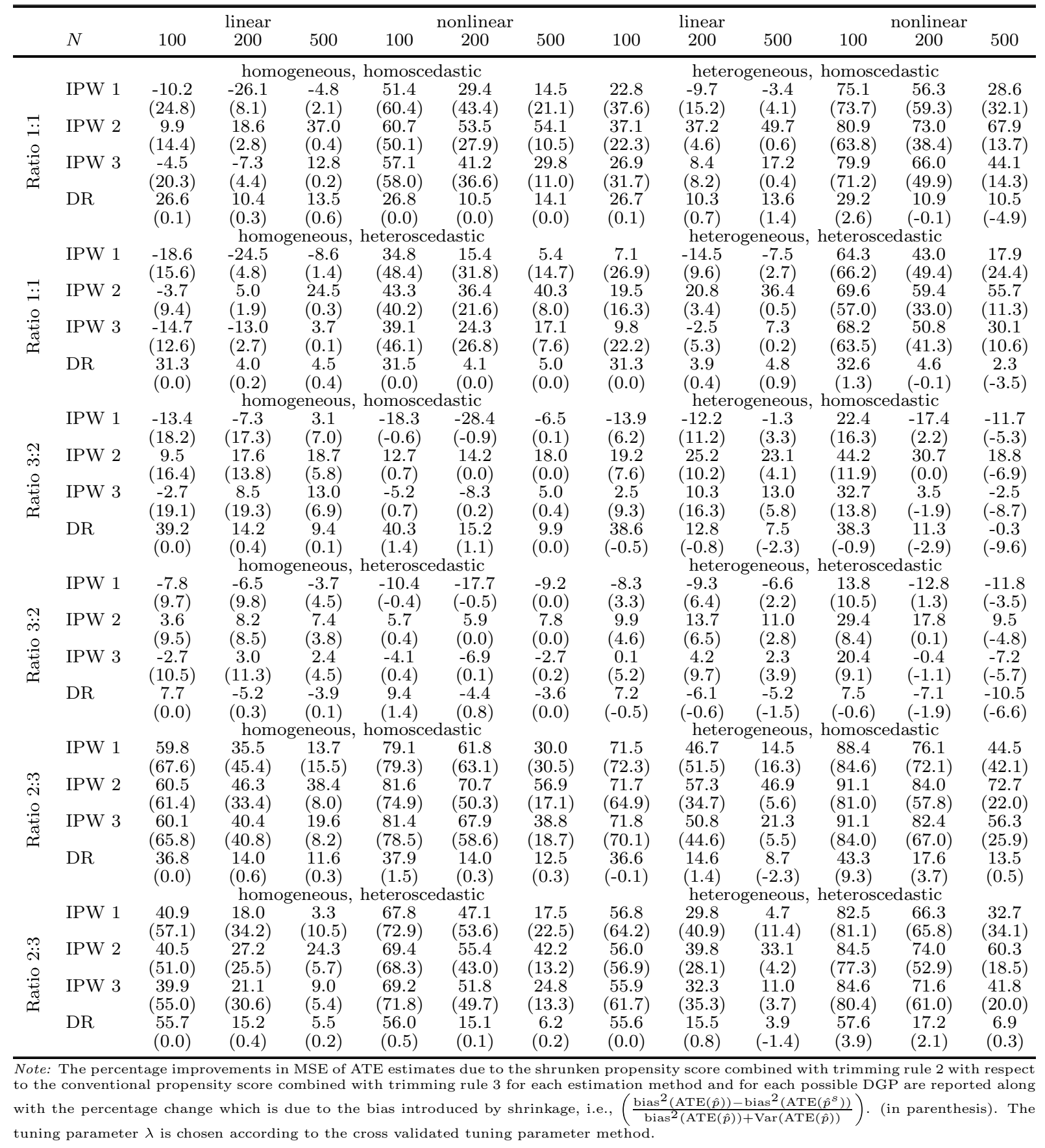


Table A.16: Details for the simulations with many variables.

\begin{tabular}{|c|c|c|c|c|c|c|c|c|c|c|c|c|c|c|c|}
\hline \multicolumn{16}{|c|}{ Empirical Variance-Covariance Matrix $(\Sigma)$} \\
\hline 2.56 & & & & & & & & & & & & & & & \\
\hline 1.19 & 1.68 & & & & & & & & & & & & & & \\
\hline-0.64 & -0.79 & 38.61 & & & & & & & & & & & & & \\
\hline-0.30 & -0.94 & 26.81 & 29.82 & & & & & & & & & & & & \\
\hline-0.05 & 0.01 & -0.29 & -0.26 & 0.22 & & & & & & & & & & & \\
\hline-0.07 & -0.05 & -0.03 & -0.10 & -0.02 & 0.15 & & & & & & & & & & \\
\hline-0.26 & -0.13 & 0.83 & 0.69 & -0.13 & 0.23 & 2.83 & & & & & & & & & \\
\hline 0.27 & 0.25 & 0.01 & 0.09 & 0.04 & -0.05 & -0.20 & 2.52 & & & & & & & & \\
\hline 0.36 & 0.25 & 0.01 & 0.01 & 0.03 & -0.07 & -0.41 & 1.44 & 2.26 & & & & & & & \\
\hline 0.53 & 0.42 & 0.20 & 0.23 & 0.03 & -0.10 & -0.38 & 1.04 & 1.13 & 2.70 & & & & & & \\
\hline 0.50 & 0.38 & 0.56 & 0.58 & 0.03 & -0.11 & -0.52 & 0.87 & 1.07 & 2.16 & 2.74 & & & & & \\
\hline 0.43 & 0.29 & 0.13 & 0.06 & 0.00 & -0.03 & -0.16 & 0.22 & 0.27 & 0.29 & 0.29 & 1.11 & & & & \\
\hline-1.07 & -0.62 & -0.21 & -0.33 & 0.02 & 0.05 & 0.36 & -0.30 & -0.40 & -0.45 & -0.47 & -0.34 & 2.86 & & & \\
\hline-0.07 & -0.03 & 0.02 & -0.08 & 0.00 & 0.02 & 0.13 & 0.32 & 0.25 & 0.00 & 0.03 & -0.01 & 0.14 & 2.10 & & \\
\hline-0.27 & -0.20 & 0.10 & 0.08 & -0.01 & 0.04 & 0.20 & 0.30 & 0.21 & -0.11 & -0.12 & -0.10 & 0.24 & 0.78 & 1.28 & \\
\hline 0.26 & 0.27 & 0.46 & 0.09 & -0.01 & -0.05 & -0.09 & -0.06 & 0.15 & 0.39 & 0.18 & -0.11 & -0.04 & 0.08 & -0.15 & 9.85 \\
\hline
\end{tabular}
Note: Details for the simulations with many variables. The sample var
matrix for the $X$ vector in Eq. (17) drawn from multivariate normal. 
Table A.17: Percentage improvement in MSE for the ATE if the shrunken propensity scores are used instead of the conventional propensity scores, fixed valued $\lambda$ for many $X$

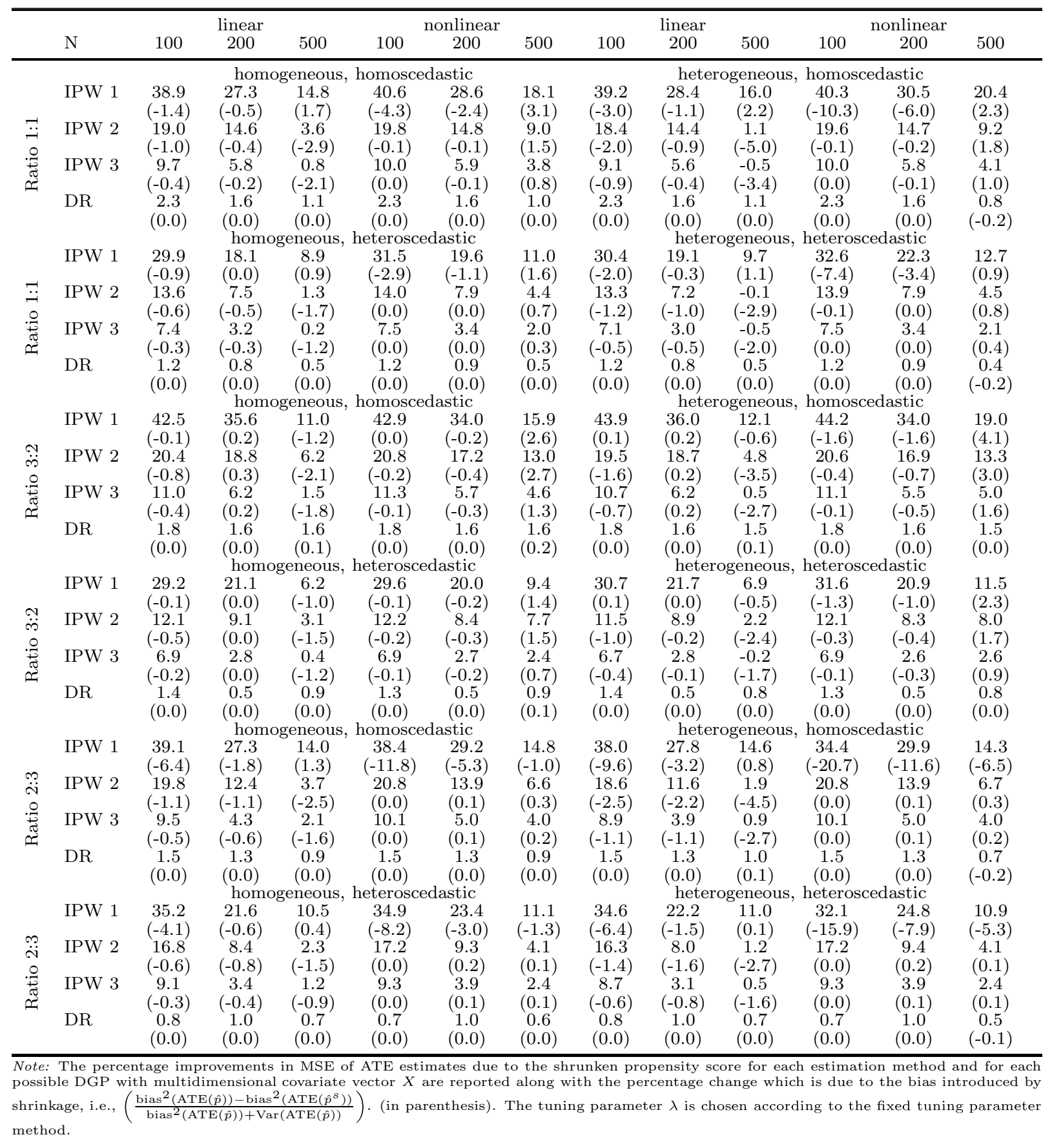


Table A.18: Percentage improvement in MSE for the ATE if the shrunken propensity scores are used instead of the conventional propensity scores, $\operatorname{MSE}\left(\hat{p}_{i}^{s}\right)$-minimizing $\lambda$, for many $X$.

\begin{tabular}{|c|c|c|c|c|c|c|c|c|c|c|c|c|c|}
\hline & & & linear & & & nonlinear & & & linear & & & nonlinear & \\
\hline & $\mathrm{N}$ & 100 & 200 & 500 & 100 & 200 & 500 & 100 & 200 & 500 & 100 & 200 & 500 \\
\hline & & & hom & geneous, & homosce & lastic & & & hete & geneous & homosce & lastic & \\
\hline & IPW 1 & 54.6 & 34.0 & 20.7 & 49.3 & 26.4 & 10.3 & 54.2 & 34.0 & 20.3 & 41.3 & 14.9 & -5.6 \\
\hline & & $(-1.9)$ & $(-1.9)$ & $(-1.5)$ & $(-9.8)$ & $(-13.1)$ & $(-13.9)$ & $(-4.0)$ & $(-3.6)$ & $(-2.7)$ & $(-23.2)$ & $(-30.7)$ & $(-33.1)$ \\
\hline$\vec{ت}$ & IPW 2 & 30.5 & 16.6 & 11.9 & 32.4 & 18.3 & 13.6 & 27.1 & 12.8 & 8.4 & 32.0 & 17.7 & 12.9 \\
\hline 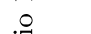 & & $(-3.1)$ & $(-2.3)$ & $(-1.5)$ & $(-0.4)$ & $(-1.1)$ & $(-1.3)$ & $(-6.9)$ & $(-6.2)$ & $(-5.0)$ & $(-0.8)$ & $(-1.7)$ & $(-1.9)$ \\
\hline 索 & IPW 3 & 22.4 & 13.4 & 9.0 & 24.4 & 14.2 & 8.6 & 19.7 & 10.8 & 7.0 & 24.1 & 13.8 & 8.2 \\
\hline 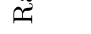 & & $(-2.3)$ & $(-1.3)$ & $(-0.6)$ & $(-0.2)$ & $(-0.8)$ & $(-0.9)$ & $(-5.1)$ & $(-3.9)$ & $(-2.8)$ & $(-0.5)$ & $(-1.2)$ & $(-1.3)$ \\
\hline & DR & $\begin{array}{c}3.1 \\
(0.0)\end{array}$ & $\begin{array}{c}4.2 \\
(0.0)\end{array}$ & $\begin{array}{c}2.9 \\
(0.0)\end{array}$ & $\begin{array}{c}3.2 \\
(0.0)\end{array}$ & $\begin{array}{c}4.2 \\
(0.0)\end{array}$ & $\begin{array}{l}2.9 \\
(0.0)\end{array}$ & $\begin{array}{c}3.1 \\
(0.0)\end{array}$ & $\begin{array}{c}4.3 \\
(0.0)\end{array}$ & $\begin{array}{c}2.9 \\
(0.0)\end{array}$ & $\begin{array}{c}3.2 \\
(0.0)\end{array}$ & $\begin{array}{c}4.3 \\
(0.0)\end{array}$ & $\begin{array}{c}3.0 \\
(0.1)\end{array}$ \\
\hline & & & hom & geneous, & heterosc & dastic & & & hete & geneous & heterosce & dastic & \\
\hline & IPW 1 & $\begin{array}{c}42.2 \\
(-1.1)\end{array}$ & $\begin{array}{c}23.5 \\
(-1.1)\end{array}$ & $\begin{array}{l}13.9 \\
(-0.8)\end{array}$ & $\begin{array}{c}39.0 \\
(-6.4)\end{array}$ & $\begin{array}{c}18.9 \\
(-8.3)\end{array}$ & $\begin{array}{c}8.5 \\
(-7.6)\end{array}$ & $\begin{array}{c}42.6 \\
(-2.5)\end{array}$ & $\begin{array}{c}23.7 \\
(-2.2)\end{array}$ & $\begin{array}{c}14.1 \\
(-1.4)\end{array}$ & $\begin{array}{c}34.5 \\
(-16.4)\end{array}$ & $\begin{array}{c}11.6 \\
(-20.5)\end{array}$ & $\begin{array}{c}-0.1 \\
(-18.8)\end{array}$ \\
\hline$\ddot{ت}$ & IPW 2 & 20.4 & 8.6 & 5.5 & 21.3 & 9.6 & 6.7 & 18.7 & 6.3 & 3.5 & 21.0 & 9.2 & 6.3 \\
\hline. & IPU 2 & $(-1.9)$ & $(-1.5)$ & $(-0.9)$ & $(-0.2)$ & $(-0.6)$ & $(-0.7)$ & $(-4.1)$ & $(-4.0)$ & $(-2.9)$ & $(-0.4)$ & $(-1.0)$ & $(-1.0)$ \\
\hline 苞 & IPW 3 & $\begin{array}{l}15.3 \\
(-1.4)\end{array}$ & $\begin{array}{c}7.5 \\
(-0.9)\end{array}$ & $\begin{array}{c}4.3 \\
(-0.5)\end{array}$ & $\begin{array}{c}16.4 \\
(-0.1)\end{array}$ & $\begin{array}{c}7.9 \\
(-0.4)\end{array}$ & $\begin{array}{c}4.0 \\
(-0.5)\end{array}$ & $\begin{array}{c}13.9 \\
(-3.0)\end{array}$ & $\begin{array}{c}5.9 \\
(-2.5)\end{array}$ & $\begin{array}{c}3.3 \\
(-1.6)\end{array}$ & $\begin{array}{c}16.2 \\
(-0.2)\end{array}$ & $\begin{array}{c}7.6 \\
(-0.7)\end{array}$ & $\begin{array}{c}3.7 \\
(-0.7)\end{array}$ \\
\hline & DR & 1.4 & 2.2 & 2.0 & 1.4 & 2.2 & 2.0 & 1.4 & 2.2 & 2.0 & 1.5 & 2.3 & 2.1 \\
\hline & & $(0.0)$ & $\begin{array}{c}(0.0) \\
\text { hom }\end{array}$ & $\begin{array}{l}(0.0) \\
\text { geneous }\end{array}$ & $\begin{array}{c}(0.0) \\
\text { homosce }\end{array}$ & $\begin{array}{l}(0.0) \\
\text { lastic }\end{array}$ & $(0.0)$ & $(0.0)$ & $\begin{array}{l}(0.0) \\
\text { hete }\end{array}$ & $\begin{array}{l}(0.0) \\
\text { geneous }\end{array}$ & $\begin{array}{c}(0.0) \\
\text { homosce }\end{array}$ & $\begin{array}{l}(0.0) \\
\text { lastic }\end{array}$ & $(0.0)$ \\
\hline & IPW 1 & 67.9 & 52.8 & 24.8 & 65.1 & 47.9 & 22.0 & 68.8 & 53.6 & 25.5 & 62.4 & 43.5 & 16.5 \\
\hline \& & & $(-0.3)$ & $(-0.3)$ & $(-0.2)$ & $(-0.8)$ & $(-2.0)$ & $(-2.8)$ & $(0.0)$ & $(0.1)$ & $(0.1)$ & $(-5.3)$ & $(-8.3)$ & $(-10.1)$ \\
\hline - & IPW 2 & $\begin{array}{c}29.2 \\
(-3.3)\end{array}$ & $\begin{array}{c}26.1 \\
(-2.0)\end{array}$ & $\begin{array}{c}14.5 \\
(-1.2)\end{array}$ & $\begin{array}{c}31.3 \\
(-0.8)\end{array}$ & $\begin{array}{c}25.4 \\
(-2.3)\end{array}$ & $\begin{array}{c}13.6 \\
(-2.8)\end{array}$ & $\begin{array}{c}26.3 \\
(-6.1)\end{array}$ & $\begin{array}{c}23.6 \\
(-4.6)\end{array}$ & $\begin{array}{c}12.1 \\
(-3.5)\end{array}$ & $\begin{array}{c}30.5 \\
(-1.6)\end{array}$ & $\begin{array}{c}24.0 \\
(-3.6)\end{array}$ & $\begin{array}{c}12.3 \\
(-4.2)\end{array}$ \\
\hline 20 & $(-1.9)$ & & & & & & & & & & & & \\
\hline & IPW 3 & 23.6 & 17.1 & 11.2 & 25.9 & 17.0 & 9.8 & 21.5 & 15.3 & 9.6 & 25.4 & 15.9 & 8.8 \\
\hline & & $(-2.4)$ & $(-1.2)$ & $(-0.5)$ & $(-0.5)$ & $(-1.8)$ & $(-1.9)$ & $(-4.5)$ & $(-3.1)$ & $(-1.9)$ & $(-1.0)$ & $(-2.8)$ & $(-2.9)$ \\
\hline ) & $(-0.7)$ & 4.9 & & & & & & & & & & & \\
\hline & & $(0.0)$ & $(0.0)$ & $(0.0)$ & $(0.0)$ & $\begin{array}{l}0.0 \\
(0.0)\end{array}$ & $\begin{array}{l}5.0 \\
(0.0)\end{array}$ & $\begin{array}{l}4.9 \\
(0.0)\end{array}$ & $\begin{array}{l}0.0 \\
(0.0)\end{array}$ & $\begin{array}{l}4.0 \\
(0.0)\end{array}$ & $\begin{array}{l}4.9 \\
(0.0)\end{array}$ & $\begin{array}{l}3.6 \\
(0.0)\end{array}$ & $\begin{array}{l}3.8 \\
(0.1)\end{array}$ \\
\hline & & & hom & jeneous, & heterosc & dastic & & & hete & geneous & heterosce & dastic & \\
\hline & IPW 1 & $\begin{array}{c}48.4 \\
(-0.2)\end{array}$ & $\begin{array}{c}33.8 \\
(-0.4)\end{array}$ & $\begin{array}{l}14.3 \\
(0.0)\end{array}$ & $\begin{array}{c}45.2 \\
(-0.5)\end{array}$ & $\begin{array}{c}29.9 \\
(-1.3)\end{array}$ & $\begin{array}{c}12.5 \\
(-1.6)\end{array}$ & $\begin{array}{l}49.5 \\
(0.0)\end{array}$ & $\begin{array}{c}34.6 \\
(-0.1)\end{array}$ & $\begin{array}{l}14.8 \\
(0.1)\end{array}$ & $\begin{array}{c}44.2 \\
(-4.0)\end{array}$ & $\begin{array}{c}27.7 \\
(-5.8)\end{array}$ & $\begin{array}{c}9.5 \\
(-6.0)\end{array}$ \\
\hline 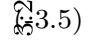 & & & & & & & & & & & & & \\
\hline$\stackrel{\circ}{\rightleftarrows}$ & IPW 2 & $\begin{array}{c}17.0 \\
(-2.0)\end{array}$ & $\begin{array}{c}13.2 \\
(-1.5)\end{array}$ & $\begin{array}{c}7.2 \\
(-0.6)\end{array}$ & $\begin{array}{c}17.5 \\
(-0.5)\end{array}$ & $\begin{array}{c}13.0 \\
(-1.4)\end{array}$ & $\begin{array}{c}6.5 \\
(-1.7)\end{array}$ & $\begin{array}{c}15.4 \\
(-3.7)\end{array}$ & $\begin{array}{c}11.4 \\
(-3.3)\end{array}$ & $\begin{array}{c}5.9 \\
(-1.8)\end{array}$ & $\begin{array}{c}16.9 \\
(-0.9)\end{array}$ & $\begin{array}{c}12.1 \\
(-2.2)\end{array}$ & $\begin{array}{c}5.7 \\
(-24)\end{array}$ \\
\hline & IPUW 2 & & & & & & & & & & & & \\
\hline & IPW 3 & $\begin{array}{l}13.5 \\
(-1.4)\end{array}$ & $\begin{array}{c}8.3 \\
(-0.9)\end{array}$ & $\begin{array}{c}5.1 \\
(-0.2)\end{array}$ & $\begin{array}{l}14.4 \\
(-0.3)\end{array}$ & $\begin{array}{c}8.2 \\
(-1.0)\end{array}$ & $(-1.1)$ & $\begin{array}{c}12.3 \\
(-2.7)\end{array}$ & $\begin{array}{c}7.0 \\
(-2.2)\end{array}$ & $\begin{array}{c}4.3 \\
(-0.9)\end{array}$ & $\begin{array}{c}14.1 \\
(-0.6)\end{array}$ & $\begin{array}{c}7.6 \\
(-1.6)\end{array}$ & $\begin{array}{c}3.5 \\
(-1.7)\end{array}$ \\
\hline & DR & 3.2 & 1.8 & 2.2 & 3.2 & 1.8 & 2.1 & 3.2 & 1.8 & 2.2 & 3.2 & 1.8 & 2.1 \\
\hline & & $(0.0)$ & $(0.0)$ & $(0.0)$ & $(0.0)$ & $(0.0)$ & $(0.0)$ & $(0.0)$ & $(0.0)$ & $(0.0)$ & $(0.0)$ & $(0.0)$ & $(0.0)$ \\
\hline & & & hom & geneous & homosce & dastic & & & hete & geneous & homosce & lastic & \\
\hline & IPW 1 & 56.0 & 28.3 & 12.4 & 52.3 & 7.5 & -5.5 & 54.8 & 22.7 & 10.1 & 46.5 & -21.8 & -34.9 \\
\hline$m$ & & $(-10.1)$ & $(-11.4)$ & $(-7.5)$ & $(-20.2)$ & $(-33.7)$ & $(-29.5)$ & $(-13.8)$ & $(-16.4)$ & $(-11.0)$ & $(-31.9)$ & $(-67.5)$ & $(-65.0)$ \\
\hline & IPW 2 & 34.7 & 26.7 & 4.8 & 36.5 & 27.4 & 10.4 & 31.1 & 24.0 & -0.9 & 36.4 & 27.5 & 10.6 \\
\hline 莺 & & $(-2.5)$ & $(-1.8)$ & $(-5.1)$ & $(-0.1)$ & $(-0.1)$ & $(0.2)$ & $(-6.5)$ & $(-6.0)$ & $(-11.6)$ & $(-0.1)$ & $(-0.1)$ & $(0.2)$ \\
\hline$\approx$ & IPW 3 & $\begin{array}{c}27.1 \\
(-1.8)\end{array}$ & $\begin{array}{l}13.0 \\
(-1.2)\end{array}$ & $\begin{array}{c}4.3 \\
(-3.4)\end{array}$ & $\begin{array}{l}28.5 \\
(0.0)\end{array}$ & $\begin{array}{l}14.3 \\
(-0.2)\end{array}$ & $\begin{array}{l}7.5 \\
(0.2)\end{array}$ & $\begin{array}{c}24.3 \\
(-4.6)\end{array}$ & $\begin{array}{c}9.8 \\
(-4.2)\end{array}$ & $\begin{array}{c}0.4 \\
-7.5)\end{array}$ & $\begin{array}{l}28.5 \\
(0.0)\end{array}$ & $\begin{array}{l}14.2 \\
(-0.2)\end{array}$ & $\begin{array}{l}7.6 \\
(0.2)\end{array}$ \\
\hline & DR & $\begin{array}{c}(-1.0) \\
4.0\end{array}$ & 4.0 & 2.1 & 4.0 & 4.0 & 2.2 & 4.0 & 4.0 & 2.1 & 4.0 & 4.1 & 2.1 \\
\hline & & $(0.0)$ & $(0.0)$ & $(0.0)$ & $(0.0)$ & $(0.0)$ & $(0.0)$ & $(0.0)$ & $(0.0)$ & $(0.0)$ & $(0.0)$ & $(0.0)$ & $(-0.2)$ \\
\hline & & & & seneous, & heterosc & dastic & & & hete & geneous, & heterosce & dastic & \\
\hline & IPW 1 & 48.2 & 27.1 & 11.3 & 46.5 & 12.7 & 1.6 & 48.0 & 23.1 & 10.5 & 43.0 & -9.7 & -15.3 \\
\hline & & $(-6.7)$ & $(-6.5)$ & $(-3.9)$ & $(-14.8)$ & $(-20.4)$ & $(-16.2)$ & $(-9.7)$ & $(-9.5)$ & $(-5.9)$ & $(-25.8)$ & $(-44.6)$ & $(-37.8)$ \\
\hline 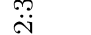 & IPW 2 & 26.5 & 18.9 & 0.8 & 27.2 & 19.1 & 3.9 & 24.8 & 17.7 & -2.3 & 27.2 & 19.2 & 3.9 \\
\hline$\therefore$ & & $(-1.3)$ & $(-1.2)$ & $(-2.8)$ & $(0.0)$ & $(0.0)$ & $(0.1)$ & $(-3.5)$ & $(-3.8)$ & $(-6.4)$ & $(0.0)$ & $(0.0)$ & $(0.1)$ \\
\hline 苋 & IPW 3 & 21.6 & 8.8 & 1.7 & 22.2 & 9.5 & 3.2 & 20.4 & 7.2 & -0.3 & 22.2 & 9.5 & 3.2 \\
\hline & & $(-0.9)$ & $(-0.8)$ & $(-1.8)$ & $(0.0)$ & $(-0.1)$ & $(0.1)$ & $(-2.4)$ & $(-2.5)$ & $(-4.1)$ & $(0.0)$ & $(-0.1)$ & $(0.1)$ \\
\hline & DR & 2.1 & 3.4 & 1.7 & 2.1 & 3.4 & 1.8 & 2.1 & 3.4 & 1.7 & 2.1 & 3.5 & 1.8 \\
\hline & & $(0.0)$ & $(0.0)$ & $(0.0)$ & $(0.0)$ & $(0.0)$ & $(0.0)$ & $(0.0)$ & $(0.0)$ & $(0.0)$ & $(0.0)$ & $(0.0)$ & $(-0.1)$ \\
\hline
\end{tabular}


Table A.19: Percentage improvement in MSE for the ATE if the shrunken propensity scores are used instead of the conventional propensity scores, cross validated $\lambda$, for many $X$.

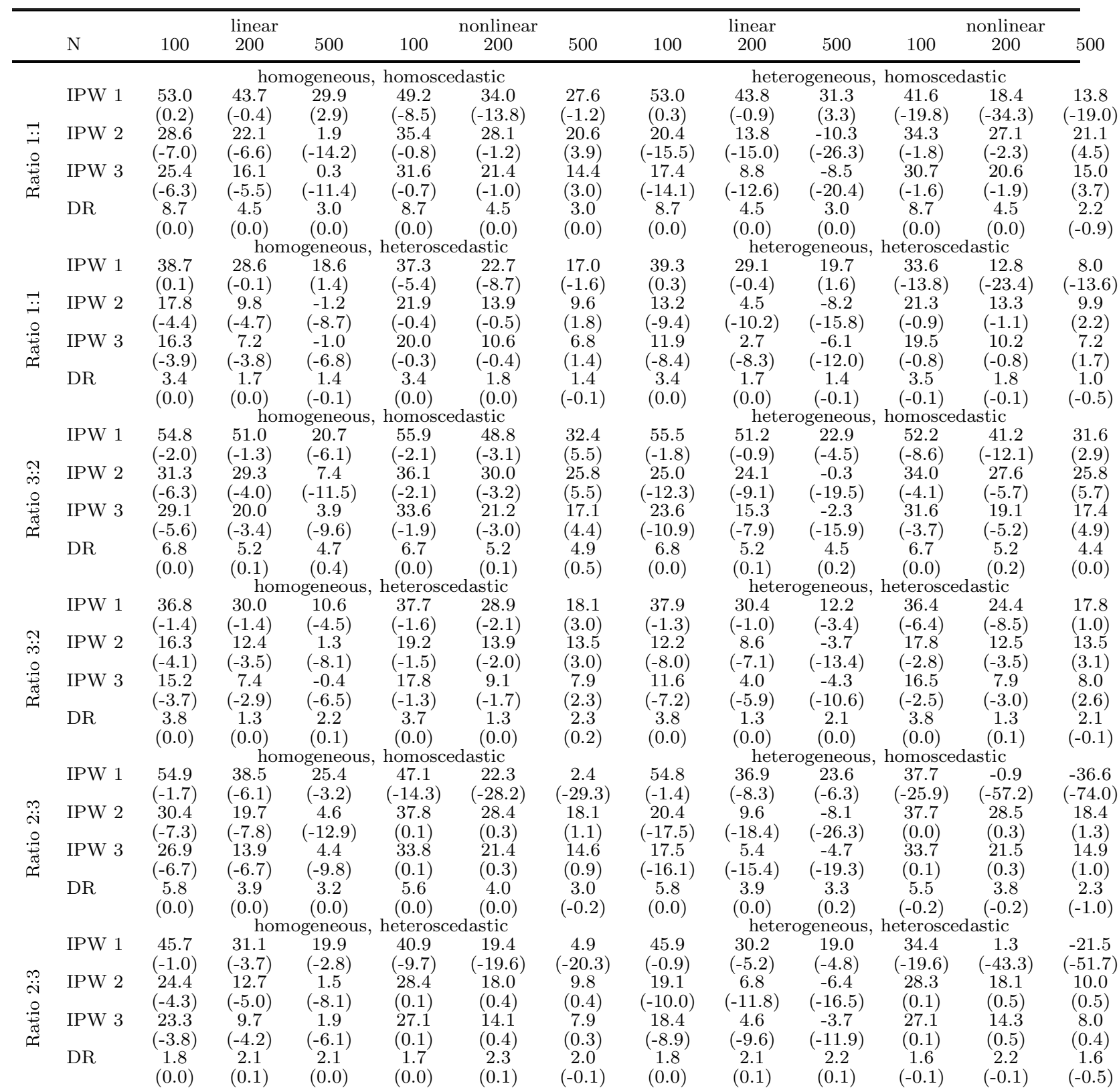

Note: The percentage improvements in MSE of ATE estimates due to the shrunken propensity score for each estimation method and for each possible DGP with multidimensional covariate vector $X$ are reported along with the percentage change which is due to the bias introduced by shrinkage, i.e., $\left(\frac{\operatorname{bias}^{2}(\operatorname{ATE}(\hat{p}))-\operatorname{bias}^{2}\left(\operatorname{ATE}\left(\hat{p}^{s}\right)\right)}{\operatorname{bias}^{2}(\operatorname{ATE}(\hat{p}))+\operatorname{Var}(\operatorname{ATE}(\hat{p}))}\right)$. (in parenthesis). The tuning parameter $\lambda$ is chosen according to the fixed tuning parameter method. 
Table A.20: Percentage improvement in MSE for the ATE if the shrunken propensity scores are used with trimming rule 2 instead of the conventional propensity scores, fixed valued $\lambda$, many $X$

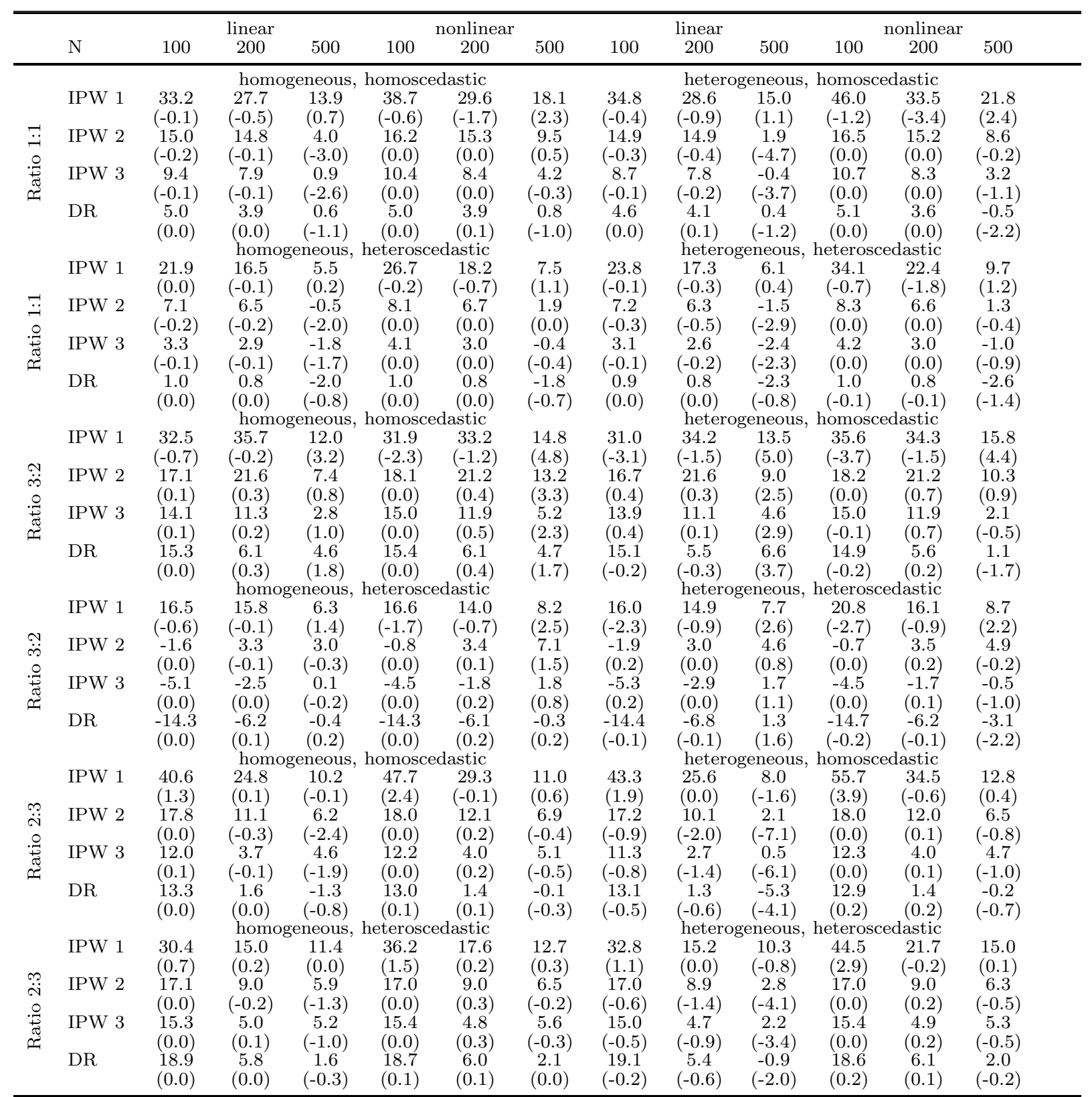

Note: The percentage improvements in MSE of ATE estimates due to the shrunken propensity score for each estimation method and for each possible DGP with multidimensional covariate vector $X$ are reported along with the percentage change which is due to the bias introduced by shrinkage, i.e., $\left(\frac{\operatorname{bias}^{2}(\operatorname{ATE}(\hat{p}))-\operatorname{bias}^{2}\left(\operatorname{ATE}\left(\hat{p}^{s}\right)\right)}{\operatorname{bias}^{2}(\operatorname{ATE}(\hat{p}))+\operatorname{Var}(\operatorname{ATE}(\hat{p}))}\right)$. (in parenthesis). The tuning parameter $\lambda$ is chosen according to the fixed tuning parameter method. 
Table A.21: Percentage improvement in MSE for the ATE if the shrunken propensity scores are used with trimming rule 2 instead of the conventional propensity scores with trimming rule 1, fixed valued $\lambda$, many $X$

\begin{tabular}{|c|c|c|c|c|c|c|c|c|c|c|c|c|c|}
\hline & & & linear & & & tonlinea & & & linear & & & tonlinea & \\
\hline & $\mathrm{N}$ & 100 & 200 & 500 & 100 & 200 & 500 & 100 & 200 & 500 & 100 & 200 & 500 \\
\hline & & & homo & eneous & homosce & lastic & & & heter & geneous & homosce & dastic & \\
\hline & IPW 1 & $\begin{array}{c}29.3 \\
(-0.4)\end{array}$ & $\begin{array}{c}14.7 \\
(-0.5)\end{array}$ & $\begin{array}{c}6.9 \\
(0.4)\end{array}$ & $\begin{array}{c}32.5 \\
(-1.3)\end{array}$ & $\begin{array}{c}17.2 \\
(-2.0)\end{array}$ & $\begin{array}{l}10.2 \\
(2.0)\end{array}$ & $\begin{array}{r}33.2 \\
(-0.9)\end{array}$ & $\begin{array}{c}18.7 \\
(-1.0)\end{array}$ & $\begin{array}{l}10.0 \\
(0.8)\end{array}$ & $\begin{array}{c}36.1 \\
(-3.1\end{array}$ & $\begin{array}{c}19.9 \\
(-4.1)\end{array}$ & $\begin{array}{l}14.1 \\
(3.4)\end{array}$ \\
\hline$ت$ & IPW 2 & 15.7 & 5.7 & -1.4 & 15.8 & 5.9 & 1.8 & 14.8 & 5.7 & -2.7 & 15.6 & 5.9 & 2.7 \\
\hline.$\subsetneq$ & & $(-0.3)$ & $(-0.2)$ & $(-3.6)$ & $(0.0)$ & $(-0.1)$ & $(-0.1)$ & $(-0.6)$ & $(-0.4)$ & $(-5.2)$ & $(0.1)$ & $(0.0)$ & (1.1) \\
\hline 氙 & IPW 3 & 14.7 & 4.6 & -1.5 & 14.8 & 4.9 & 0.8 & 14.1 & 4.8 & -2.3 & 14.5 & 4.8 & 1.5 \\
\hline & & & $(0.0)$ & $(-3.0)$ & $(0.0)$ & $(0.0)$ & $(-0.4)$ & $(-0.3)$ & $(-0.2)$ & $(-4.2)$ & $(0.1)$ & $(0.0)$ & $(0.6)$ \\
\hline & DR & $\begin{array}{l}14.0 \\
(0.0)\end{array}$ & $\begin{array}{c}0.7 \\
(0.0)\end{array}$ & $\begin{array}{c}-1.9 \\
(-1.5)\end{array}$ & $\begin{array}{l}13.7 \\
(0.0)\end{array}$ & $\begin{array}{c}0.4 \\
(0.0)\end{array}$ & $\begin{array}{l}-2.0 \\
(-1.6)\end{array}$ & $\begin{array}{l}13.7 \\
(0.0)\end{array}$ & $\begin{array}{c}1.2 \\
(0.0)\end{array}$ & $\begin{array}{l}-1.5 \\
(-1.5)\end{array}$ & $\begin{array}{l}13.6 \\
(0.1)\end{array}$ & $\begin{array}{c}0.1 \\
(0.0)\end{array}$ & $\begin{array}{l}-1.7 \\
(-1.0)\end{array}$ \\
\hline & & & homo & neous, & heterosc & dastic & & & heter & eneous, & heterosc & dastic & \\
\hline & IPW 1 & $\begin{array}{c}25.4 \\
(-0.2)\end{array}$ & $\begin{array}{c}16.2 \\
(-0.1)\end{array}$ & $\begin{array}{c}6.4 \\
(0.5)\end{array}$ & $\begin{array}{c}27.4 \\
(-0.7)\end{array}$ & $\begin{array}{c}18.8 \\
(-0.8)\end{array}$ & $\begin{array}{c}8.1 \\
(1.3)\end{array}$ & $\begin{array}{c}28.3 \\
(-0.4)\end{array}$ & $\begin{array}{c}19.3 \\
(-0.3)\end{array}$ & $\begin{array}{c}8.0 \\
(0.8)\end{array}$ & $\begin{array}{c}30.4 \\
(-1.8)\end{array}$ & $\begin{array}{c}21.9 \\
(-1.9)\end{array}$ & $\begin{array}{l}10.3 \\
(2.1)\end{array}$ \\
\hline$\ddot{ت}$ & IPW 2 & 14.7 & 6.3 & 1.5 & 14.6 & 7.4 & 3.2 & 14.7 & 6.0 & 0.7 & 14.8 & 7.5 & 3.8 \\
\hline$\therefore$ & & $(-0.2)$ & $(-0.3)$ & $(-1.5)$ & $(0.0)$ & $(0.0)$ & $(0.3)$ & $(-0.4)$ & $(-0.5)$ & $(-2.4)$ & $(0.1)$ & (0.1) & (1.0) \\
\hline 莺 & IPW 3 & $\begin{array}{c}13.2 \\
(-0.1)\end{array}$ & $\begin{array}{c}5.7 \\
(-0.2)\end{array}$ & $\begin{array}{c}1.7 \\
(-1.2)\end{array}$ & $\begin{array}{l}13.2 \\
(0.0)\end{array}$ & $\begin{array}{c}6.6 \\
(0.0)\end{array}$ & $\begin{array}{c}2.9 \\
(0.1)\end{array}$ & $\begin{array}{c}13.3 \\
(-0.2)\end{array}$ & $\begin{array}{c}5.6 \\
(-0.3)\end{array}$ & $\begin{array}{c}1.2 \\
(-1.8)\end{array}$ & $\begin{array}{l}13.2 \\
(0.1)\end{array}$ & $\begin{array}{l}6.6 \\
(0.1)\end{array}$ & $\begin{array}{l}3.4 \\
(0.7)\end{array}$ \\
\hline & DR & 14.0 & 5.4 & 2.2 & 13.9 & 5.0 & 2.3 & 14.0 & $\begin{array}{c}(-0.0) \\
5.8\end{array}$ & $\begin{array}{c}(-1.0) \\
2.3\end{array}$ & $\begin{array}{l}(0.1) \\
13.8\end{array}$ & $\begin{array}{l}(0.1) \\
4.7\end{array}$ & $\begin{array}{l}(0.7) \\
2.6\end{array}$ \\
\hline & & $(0.0)$ & $(0.0)$ & $(-0.4)$ & $(0.0)$ & $(0.0)$ & $(-0.5)$ & $(0.0)$ & $(0.0)$ & $(-0.4)$ & $(0.0)$ & $(0.0)$ & $(-0.1)$ \\
\hline & & & hom & eneous & homosce & dastic & & & heter & geneous & homosce & dastic & \\
\hline & IPW 1 & $\begin{array}{c}22.5 \\
(-11\end{array}$ & $\begin{array}{l}11.7 \\
(-0.5)\end{array}$ & $\begin{array}{c}2.9 \\
(0.4)\end{array}$ & $\begin{array}{c}23.3 \\
(-27\end{array}$ & 11.3 & 4.8 & $\begin{array}{c}23.4 \\
(-36)\end{array}$ & $\begin{array}{l}13.0 \\
(-2)\end{array}$ & $\begin{array}{c}5.9 \\
(1.5\end{array}$ & 25.1 & $\begin{array}{l}12.8 \\
(-2.3)\end{array}$ & $\begin{array}{c}6.5 \\
(3.5)\end{array}$ \\
\hline$\stackrel{\sim}{\ddot{m}}$ & IPW 2 & 18.0 & 6.0 & $\begin{array}{l}(0.4) \\
-1.1\end{array}$ & 18.3 & $\begin{array}{c}(-2.0) \\
5.1\end{array}$ & $\begin{array}{l}2.0) \\
1.2\end{array}$ & $\begin{array}{c}(-3.0) \\
18.5\end{array}$ & $\begin{array}{c}(-2.2) \\
6.8\end{array}$ & $\begin{array}{c}(1.0) \\
0.9\end{array}$ & $\begin{array}{c}(-4.0) \\
18.5\end{array}$ & $\begin{array}{c}(-2 .) \\
5.2\end{array}$ & $\begin{array}{c}(3.5) \\
0.6\end{array}$ \\
\hline 0 & & $(-0.2)$ & $(0.0)$ & $(-1.7)$ & $(0.0)$ & $(-0.3)$ & $(1.2)$ & $(0.0)$ & $(0.1)$ & $(-0.7)$ & $(0.2)$ & $(0.2)$ & $(1.1)$ \\
\hline 䓠 & IPW 3 & 18.0 & 5.5 & -1.1 & 18.4 & 4.7 & 0.7 & 18.5 & 6.2 & 0.9 & 18.5 & 4.6 & -0.1 \\
\hline & & $(-0.1)$ & $(0.0)$ & $(-1.2)$ & $(0.0)$ & $(-0.2)$ & $(1.0)$ & $(0.0)$ & $(0.0)$ & $(-0.1)$ & $(0.1)$ & $(0.2)$ & $(0.7)$ \\
\hline & DR & 31.1 & 3.0 & 0.7 & 30.9 & 2.8 & 0.5 & 31.2 & 2.9 & 2.5 & 30.6 & 2.4 & -1.0 \\
\hline & & & homo & $\begin{array}{l}(0.5) \\
\text { eneous, }\end{array}$ & heterosc & dastic & & & $\begin{array}{l}(-0.4) \\
\text { heter }\end{array}$ & $\begin{array}{l}(1.6) \\
\text { eneous, }\end{array}$ & heterosc & $\begin{array}{l}\text { (U.1) } \\
\text { dastic }\end{array}$ & \\
\hline & IPW 1 & 21.9 & 13.2 & 3.0 & 22.7 & 13.4 & 3.9 & 22.7 & 14.3 & 5.2 & 24.0 & 14.5 & 4.3 \\
\hline & IPW 2 & $\begin{array}{c}(-0.6) \\
14.7\end{array}$ & $\begin{array}{c}(-0.1) \\
7.1\end{array}$ & $(0.1)$ & $(-1.6)$ & $\begin{array}{l}(-0.7) \\
60\end{array}$ & $(1.1)$ & $(-2.2)$ & $(-0.9)$ & $(0.9)$ & $(-2.5)$ & $\begin{array}{l}(-0.8) \\
69\end{array}$ & $(2.1)$ \\
\hline 3 & $11 \mathrm{~W} 2$ & $(-0.1)$ & $(-0.1)$ & $\begin{array}{c}0.3 \\
(-1.2)\end{array}$ & $\begin{array}{l}15.0 \\
(0.0)\end{array}$ & $\begin{array}{l}0.9 \\
(0.0)\end{array}$ & $\begin{array}{l}1.5 \\
(0.6)\end{array}$ & $\begin{array}{l}10.0 \\
(0.0)\end{array}$ & $(0.0)$ & $\begin{array}{c}2.0 \\
(-0.6)\end{array}$ & $\begin{array}{l}15.1 \\
(0.1)\end{array}$ & $\begin{array}{c}6.9 \\
(0.1)\end{array}$ & $\begin{array}{c}0.4 \\
(0.5)\end{array}$ \\
\hline 范 & IPW 3 & 12.8 & 7.0 & 0.3 & 13.2 & 6.8 & 1.1 & 13.1 & 7.5 & 1.9 & 13.2 & 6.7 & 0.1 \\
\hline$\approx$ & & $(-0.1)$ & $(-0.1)$ & $(-0.9)$ & $(0.0)$ & $(0.0)$ & $(0.5)$ & $(0.0)$ & $(0.0)$ & $(-0.2)$ & $(0.1)$ & $(0.1)$ & $(0.3)$ \\
\hline & DR & 12.4 & 4.8 & 0.8 & 12.0 & 4.7 & 0.8 & 12.6 & 4.9 & 2.3 & 11.6 & $4.3^{\prime}$ & -0.7 \\
\hline & & & $\begin{array}{l}(0.0) \\
\text { homo }\end{array}$ & $\begin{array}{l}\text { (0.1) } \\
\text { eneous }\end{array}$ & $\begin{array}{c}(0.0) \\
\text { homosce }\end{array}$ & $\begin{array}{l}(0.0) \\
\text { dastic }\end{array}$ & $(0.1)$ & $(0.0)$ & $\begin{array}{c}(-0.1) \\
\text { heter }\end{array}$ & $\begin{array}{c}(0.9) \\
\text { seneous }\end{array}$ & $\begin{array}{c}(-0.1) \\
\text { homosce }\end{array}$ & $\begin{array}{r}(0.0) \\
\text { dastic }\end{array}$ & $(-0.6)$ \\
\hline & IPW 1 & 24.9 & 14.9 & 10.8 & 28.9 & 16.7 & 12.2 & 30.0 & 18.1 & 12.4 & 34.2 & 19.4 & 14.8 \\
\hline & & $(0.0)$ & $(0.1)$ & $(2.2)$ & $(0.0)$ & $(-0.1)$ & $(3.2)$ & $(-0.1)$ & $(0.3)$ & (1.9) & $(-0.2)$ & $(-0.5)$ & $(4.3)$ \\
\hline$\ddot{\sim}$ & IPW 2 & 15.6 & 7.2 & 3.0 & 15.5 & 7.5 & 4.1 & 15.8 & 6.0 & -1.2 & 15.7 & 7.5 & 4.6 \\
\hline$\stackrel{\oplus}{\oplus}$ & IPW 3 & & $(-0.6)$ & $(-2.0)$ & $(0.1)$ & $(0.0)$ & $(0.2)$ & $(-0.9)$ & $(-2.0)$ & $(-6.1)$ & $(0.2)$ & $(0.2)$ & $(0.9)$ \\
\hline 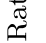 & $1 P W 3$ & $\begin{array}{c}14.6 \\
(-0.1)\end{array}$ & $\begin{array}{c}6.3 \\
(-0.4)\end{array}$ & $\begin{array}{c}3.1 \\
(-1.5)\end{array}$ & $\begin{array}{l}14.4 \\
(0.1)\end{array}$ & $\begin{array}{c}6.4 \\
(0.0)\end{array}$ & $\begin{array}{c}3.7 \\
(0.2)\end{array}$ & $\begin{array}{c}14.9 \\
(-0.7)\end{array}$ & $\begin{array}{c}5.5 \\
(-1.6)\end{array}$ & $\begin{array}{c}-0.4 \\
(-4.9)\end{array}$ & $\begin{array}{l}14.6 \\
(0.2)\end{array}$ & $\begin{array}{c}6.3 \\
(0.2)\end{array}$ & $\begin{array}{c}4.2 \\
(0.9)\end{array}$ \\
\hline & DR & 30.4 & 5.0 & -0.2 & 30.5 & 4.6 & -0.5 & 30.6 & 5.1 & -1.8 & 30.7 & 4.6 & -0.1 \\
\hline & & $(0.0)$ & $(0.0)$ & $(0.2)$ & $(0.0)$ & $(0.0)$ & $(0.1)$ & $(-0.1)$ & $(-0.3)$ & $(-1.6)$ & $(0.1)$ & $(0.2)$ & $(0.7)$ \\
\hline & & & homo & eneous, & heterosc & dastic & & & heterc & eneous, & heterosc & dastic & \\
\hline & IPW 1 & 23.7 & 15.1 & 9.7 & 26.6 & 16.8 & $\begin{array}{c}9.5 \\
(18)\end{array}$ & $\begin{array}{l}27.6 \\
(0.0)\end{array}$ & 17.4 & 9.8 & $\begin{array}{c}30.8 \\
(-0.1)\end{array}$ & $\begin{array}{l}19.2 \\
(0.0)\end{array}$ & $\begin{array}{l}10.1 \\
(2.5)\end{array}$ \\
\hline & IPW 2 & $\begin{array}{l}(0.0) \\
16.2\end{array}$ & 8.0 & 6.3 & 16.0 & 8.8 & 6.4 & 16.8 & 7.2 & 3.4 & $\begin{array}{c}-0.1) \\
15.9\end{array}$ & 8.9 & 6.5 \\
\hline 0 & & $(-0.1)$ & $(-0.6)$ & $(-1.0)$ & $(0.1)$ & $(-0.1)$ & $(0.1)$ & $(-0.5)$ & $(-1.6)$ & $(-3.3)$ & $(0.2)$ & $(0.1)$ & $(0.6)$ \\
\hline 氮 & IPW 3 & 16.0 & 7.8 & 6.1 & 15.7 & 8.3 & 6.0 & 16.7 & 7.2 & 3.4 & 15.7 & 8.4 & 6.1 \\
\hline & & $(0.0)$ & $(-0.5)$ & $(-0.7)$ & $(0.1)$ & $(-0.1)$ & $(0.1)$ & $(-0.3)$ & $(-1.3)$ & $(-2.7)$ & $(0.2)$ & $(0.0)$ & $(0.5)$ \\
\hline & DR & $\begin{array}{l}38.0 \\
(0.0)\end{array}$ & $\begin{array}{c}9.4 \\
(-0.1)\end{array}$ & $\begin{array}{c}2.6 \\
(0.1)\end{array}$ & $\begin{array}{l}38.0 \\
(0.0)\end{array}$ & $\begin{array}{c}9.2 \\
(-0.1)\end{array}$ & $\begin{array}{l}2.5 \\
(0.1)\end{array}$ & $\begin{array}{c}38.2 \\
(-0.1)\end{array}$ & $\begin{array}{c}9.6 \\
(-0.5)\end{array}$ & $\begin{array}{c}0.9 \\
(-0.8)\end{array}$ & $\begin{array}{l}38.1 \\
(0.0)\end{array}$ & $\begin{array}{c}9.1 \\
(0.0)\end{array}$ & $\begin{array}{c}2.7 \\
(0.5)\end{array}$ \\
\hline
\end{tabular}

Note: The percentage improvements in MSE of ATE estimates due to the shrunken propensity score for each estimation method and for each possible DGP with multidimensional covariate vector $X$ are reported along with the percentage change which is due to the bias introduced by shrinkage, i.e., $\left(\frac{\operatorname{bias}^{2}(\operatorname{ATE}(\hat{p}))-\operatorname{bias}^{2}\left(\operatorname{ATE}\left(\hat{p}^{s}\right)\right)}{\operatorname{bias}^{2}(\operatorname{ATE}(\hat{p}))+\operatorname{Var}(\operatorname{ATE}(\hat{p}))}\right)$. (in parenthesis). The tuning parameter $\lambda$ is chosen according to the fixed tuning parameter method. 
Table A.22: Percentage improvement in MSE for the ATE if the shrunken propensity scores are used with trimming rule 2 instead of the conventional propensity scores with trimming rule 2, fixed valued $\lambda$, many $X$

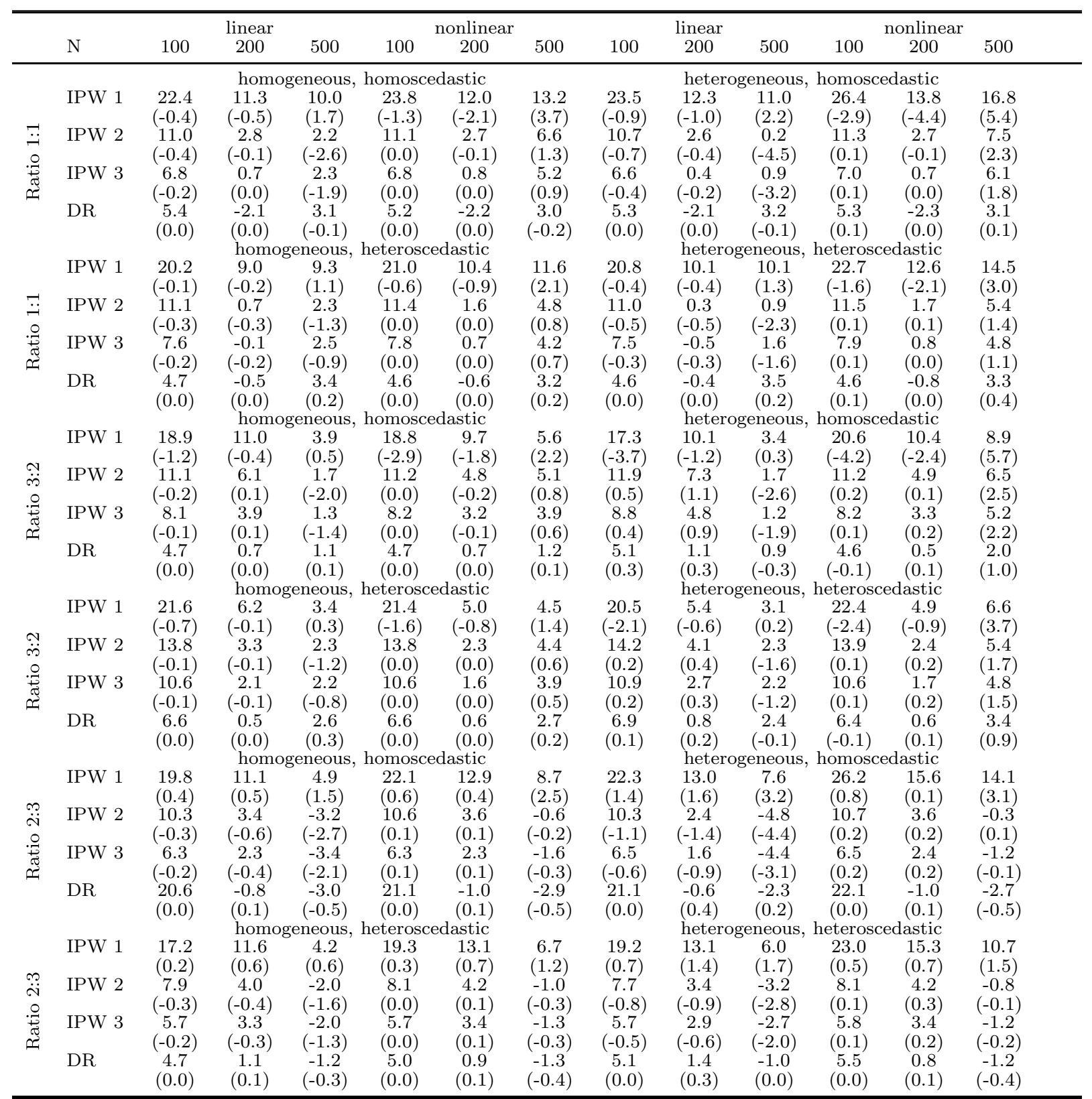

Note: The percentage improvements in MSE of ATE estimates due to the shrunken propensity score for each estimation method and for each possible DGP with multidimensional covariate vector $X$ are reported along with the percentage change which is due to the bias introduced by shrinkage, i.e., $\left(\frac{\operatorname{bias}^{2}(\operatorname{ATE}(\hat{p}))-\operatorname{bias}^{2}\left(\operatorname{ATE}\left(\hat{p}^{s}\right)\right)}{\operatorname{bias}^{2}(\operatorname{ATE}(\hat{p}))+\operatorname{Var}(\operatorname{ATE}(\hat{p}))}\right)$. (in parenthesis). The tuning parameter $\lambda$ is chosen according to the fixed tuning parameter method. 
Table A.23: Percentage improvement in MSE for the ATE if the shrunken propensity scores are used with trimming rule 2 instead of the conventional propensity scores with trimming rule 3 , fixed valued $\lambda$

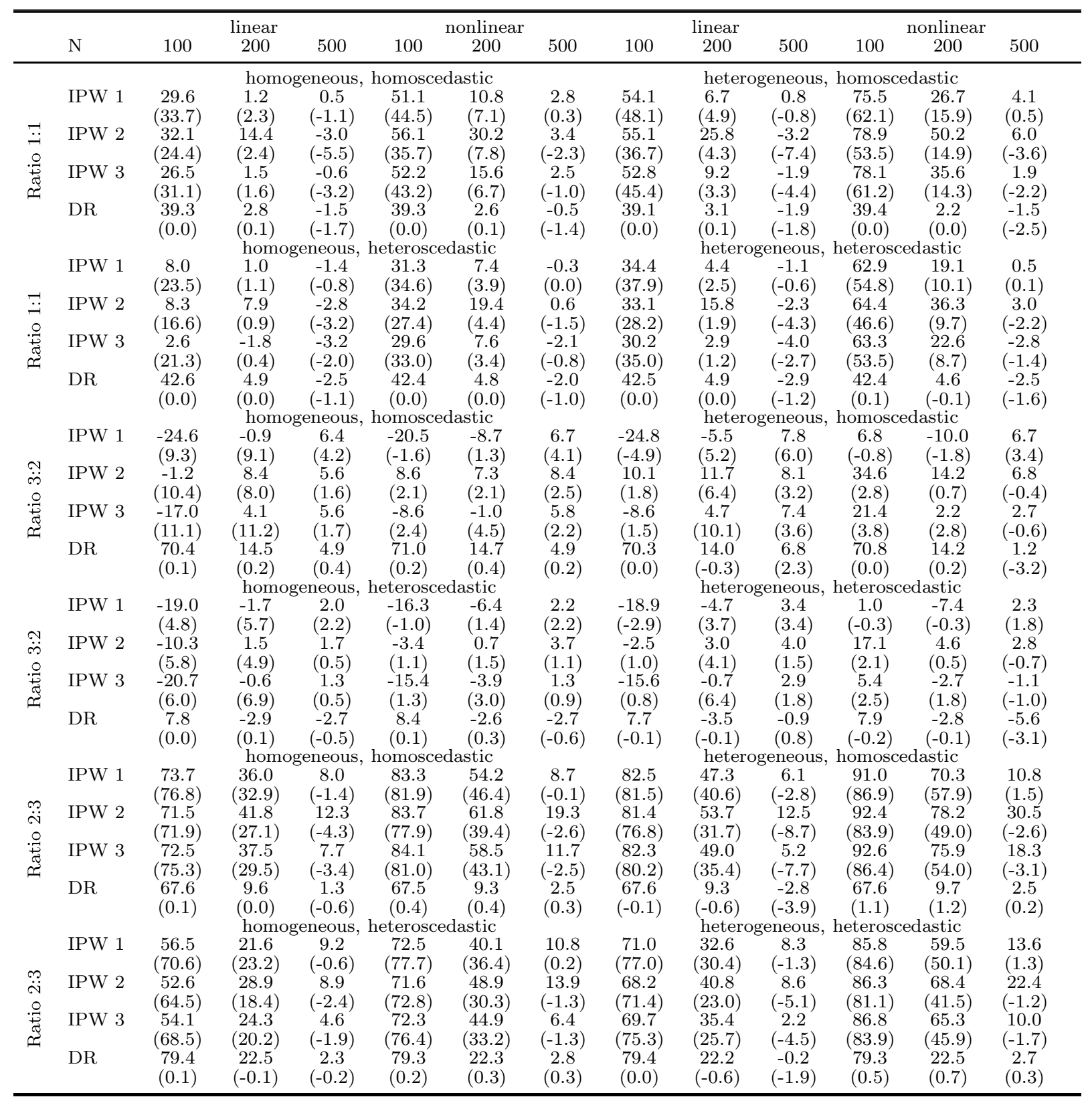
Note: The percentage improvements in MSE of ATE estimates due to the shrunken propensity score for each estimation method and for each shrinkage, i.e., $\left(\frac{\operatorname{bias}^{2}(\operatorname{ATE}(\hat{p}))-\operatorname{bias}^{2}\left(\operatorname{ATE}\left(\hat{p}^{s}\right)\right)}{\operatorname{bias}^{2}(\operatorname{ATE}(\hat{p}))+\operatorname{Var}(\operatorname{ATE}(\hat{p}))}\right)$, (in parentheses). The tuning parameter $\lambda$ is chosen according to the fixed tuning parameter method. 
Table A.24: MSE of ATE estimators based on conventional propensity score

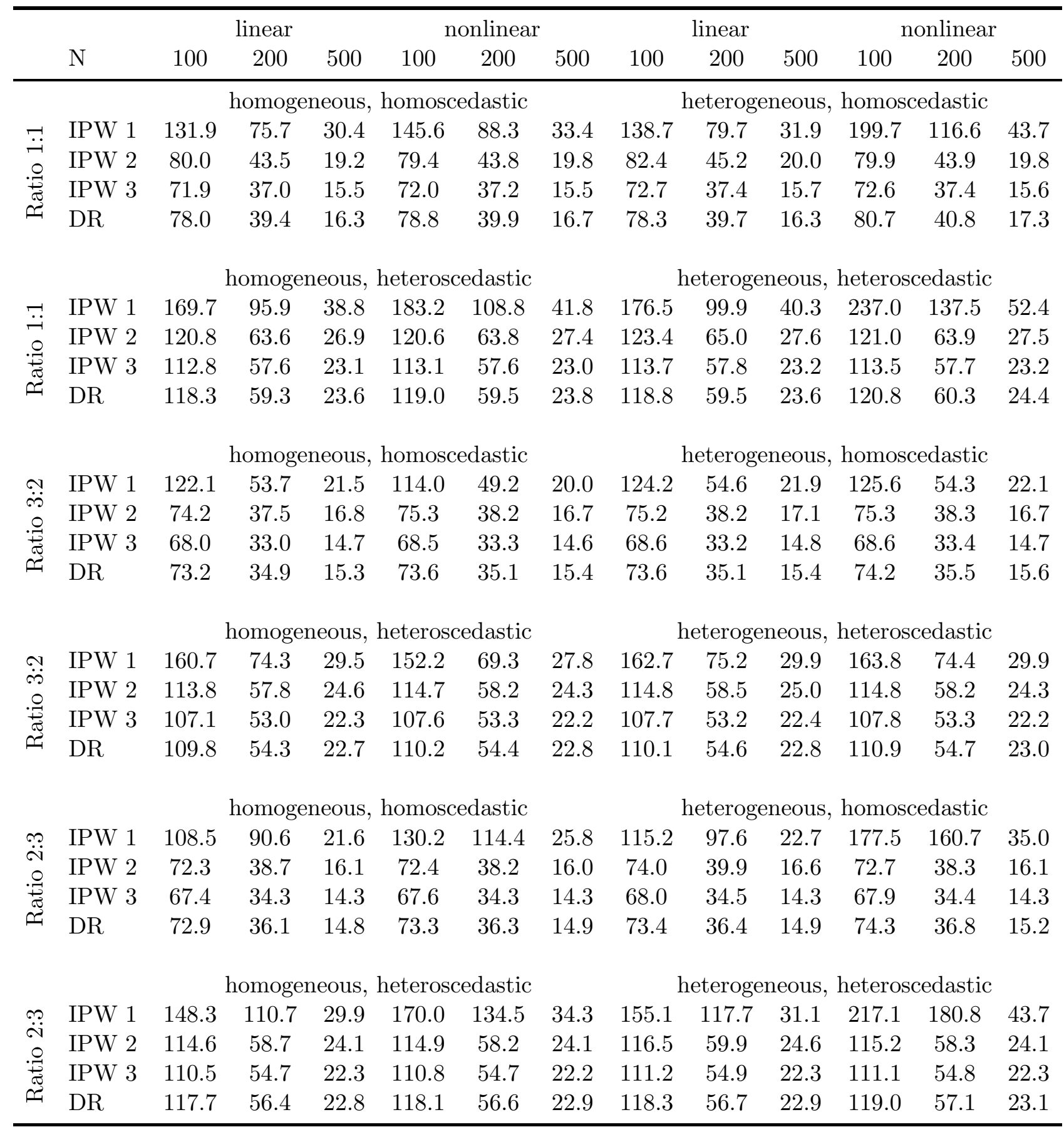

Note: Reported values are Monte Carlo MSE $\times 10^{4}$ of ATE estimators based on the four different method: IPW1, IPW2, IPW3 and DR which are explained in detailed in Section 2. The ATE is estimated for 10000, 5000 and 2000 Monte Carlo samples with sample sizes 100, 200 and 500, respectively. Ratio refers to the treated-to-control ratio. Linear and nonlinear refer to the relation between propensity score and outcome variable. Homogeneous or heterogenous describes treatment homogeneity or heterogeneity. Homoscedastic and heteroscedastic describe the error term structure of the outcome variable. 
Table A.25: MSE of ATE estimators based on propensity score trimmed by trimming rule 1

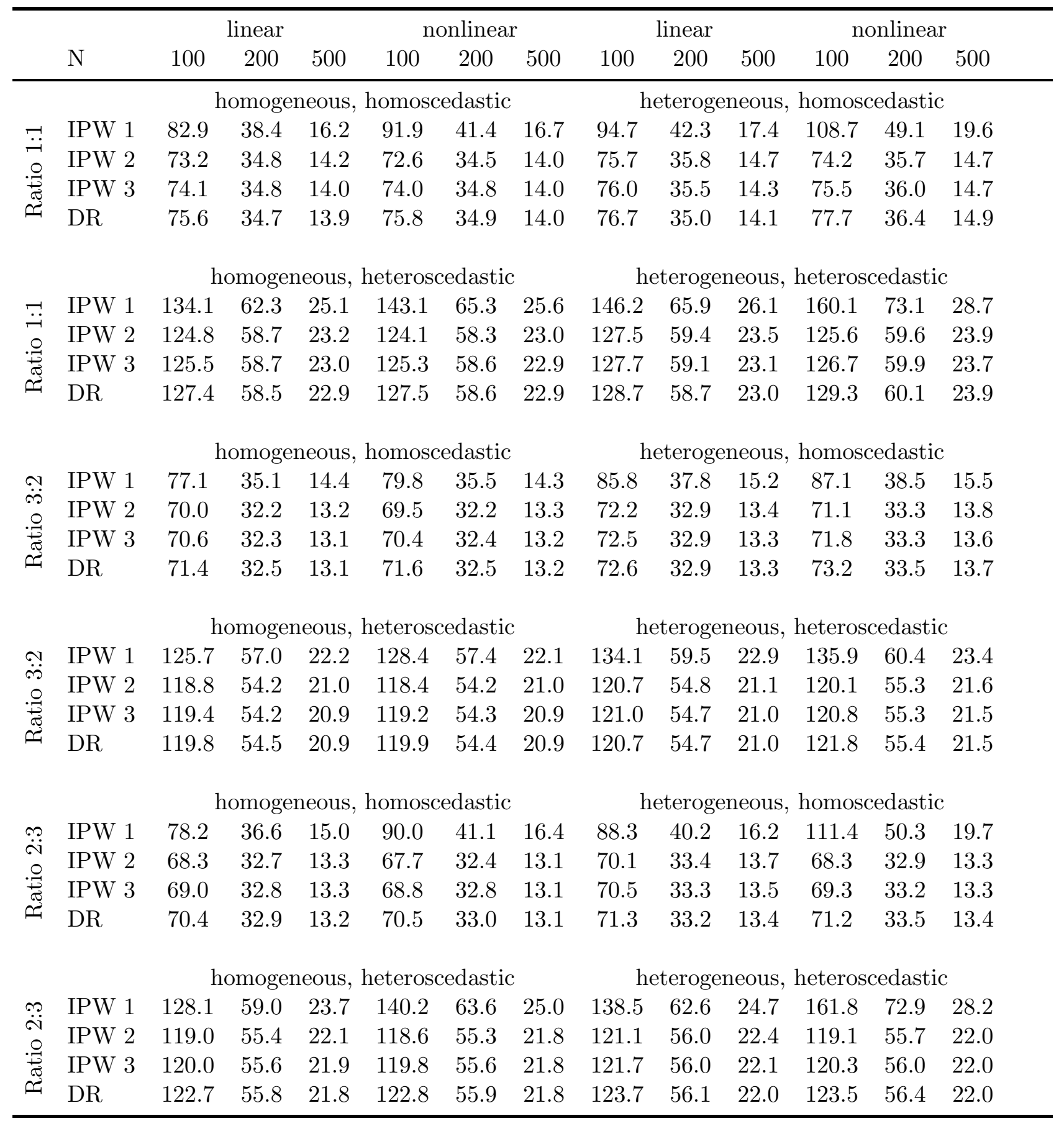

Note: Reported values are Monte Carlo MSE $\times 10^{4}$ of ATE estimators based on the four different propensity score methods method: IPW1, IPW2, IPW3 and DR which are explained in detailed in Section 2. Propensity score is trimmed according to the first rule explained in the text. The ATE is estimated for 10000, 5000 and 2000 Monte Carlo samples with sample sizes 100, 200 and 500, respectively. Ratio refers to the treated-to-control ratio. Linear and nonlinear refer to the relation between propensity score and outcome variable. Homogeneous or heterogenous describes treatment homogeneity or heterogeneity. Homoscedastic and heteroscedastic describe the error term structure of the outcome variable. 
Table A.26: MSE of ATE estimators based on propensity score trimmed by trimming rule 2

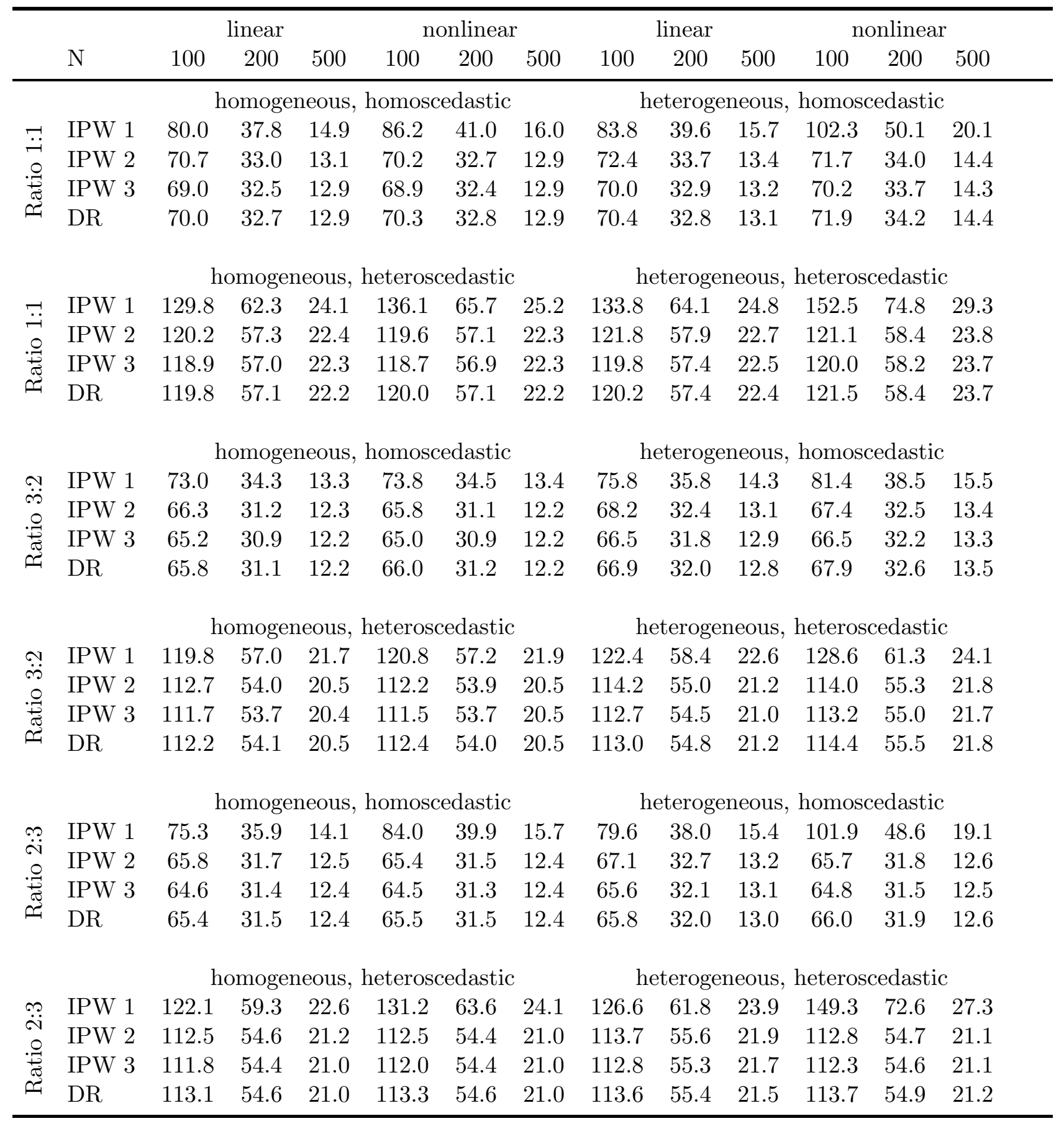

Note: Reported values are Monte Carlo MSE $\times 10^{4}$ of ATE estimators based on the four different propensity score methods method: IPW1, IPW2, IPW3 and DR which are explained in detailed in Section 2. Propensity score is trimmed according to the second rule explained in the text. The ATE is estimated for 10000, 5000 and 2000 Monte Carlo samples with sample sizes 100, 200 and 500, respectively. Ratio refers to the treated-to-control ratio. Linear and nonlinear refer to the relation between propensity score and outcome variable. Homogeneous or heterogenous describes treatment homogeneity or heterogeneity. Homoscedastic and heteroscedastic describe the error term structure of the outcome variable. 
Table A.27: MSE of ATE estimators based on propensity score trimmed by trimming rule by HLW

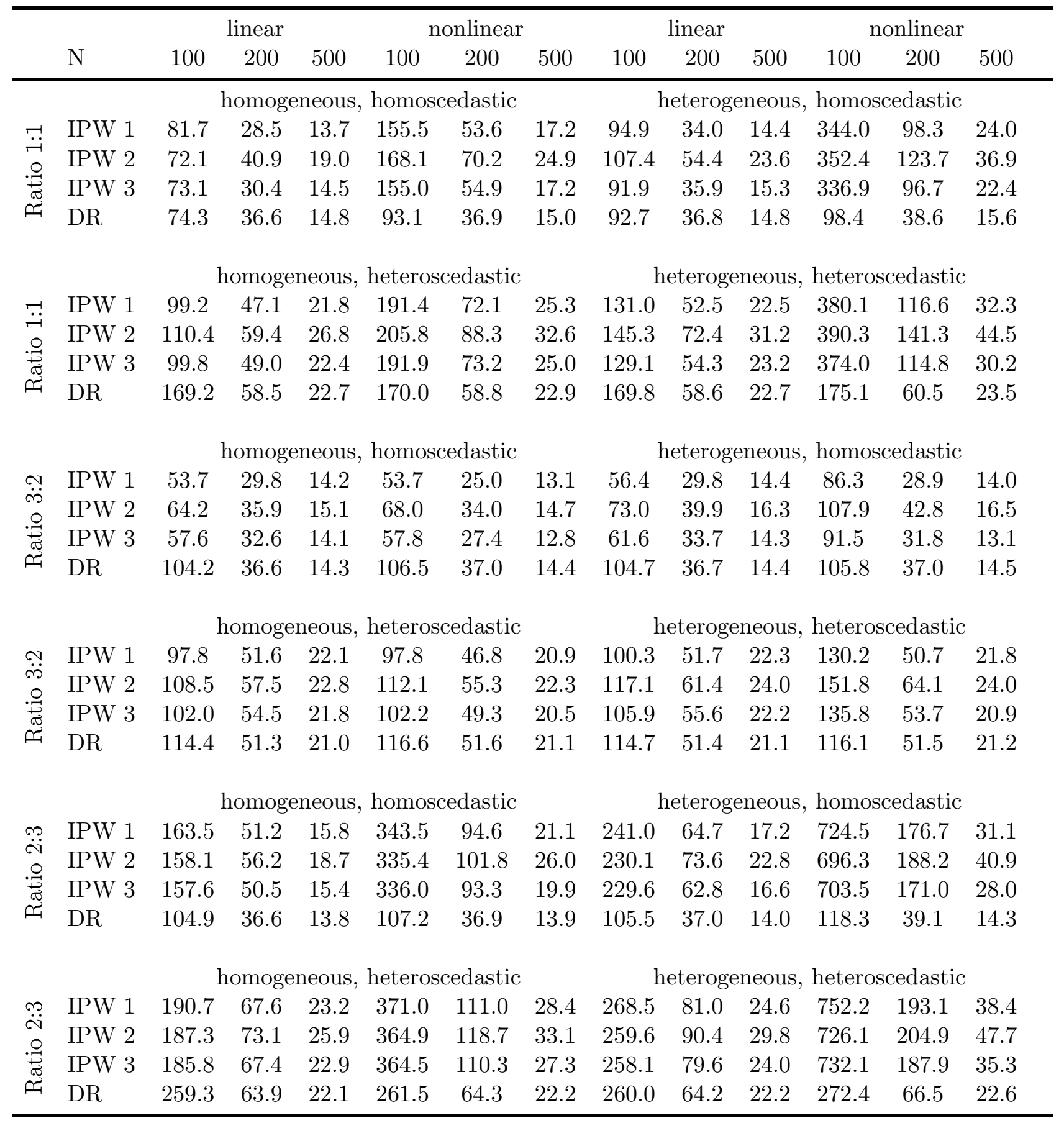

Note: Reported values are Monte Carlo MSE $\times 10^{4}$ of ATE estimators based on the four different propensity score methods method: IPW1, IPW2, IPW3 and DR which are explained in detailed in Section 2. Propensity score is trimmed according to the rule by HLW. The ATE is estimated for 10000, 5000 and 2000 Monte Carlo samples with sample sizes 100, 200 and 500, respectively. Ratio refers to the treated-to-control ratio. Linear and nonlinear refer to the relation between propensity score and outcome variable. Homogeneous or heterogenous describes treatment homogeneity or heterogeneity. Homoscedastic and heteroscedastic describe the error term structure of the outcome variable. 
Table A.28: $\quad$ MSE of ATE estimators based on shrunken propensity score with fixed valued $\lambda$

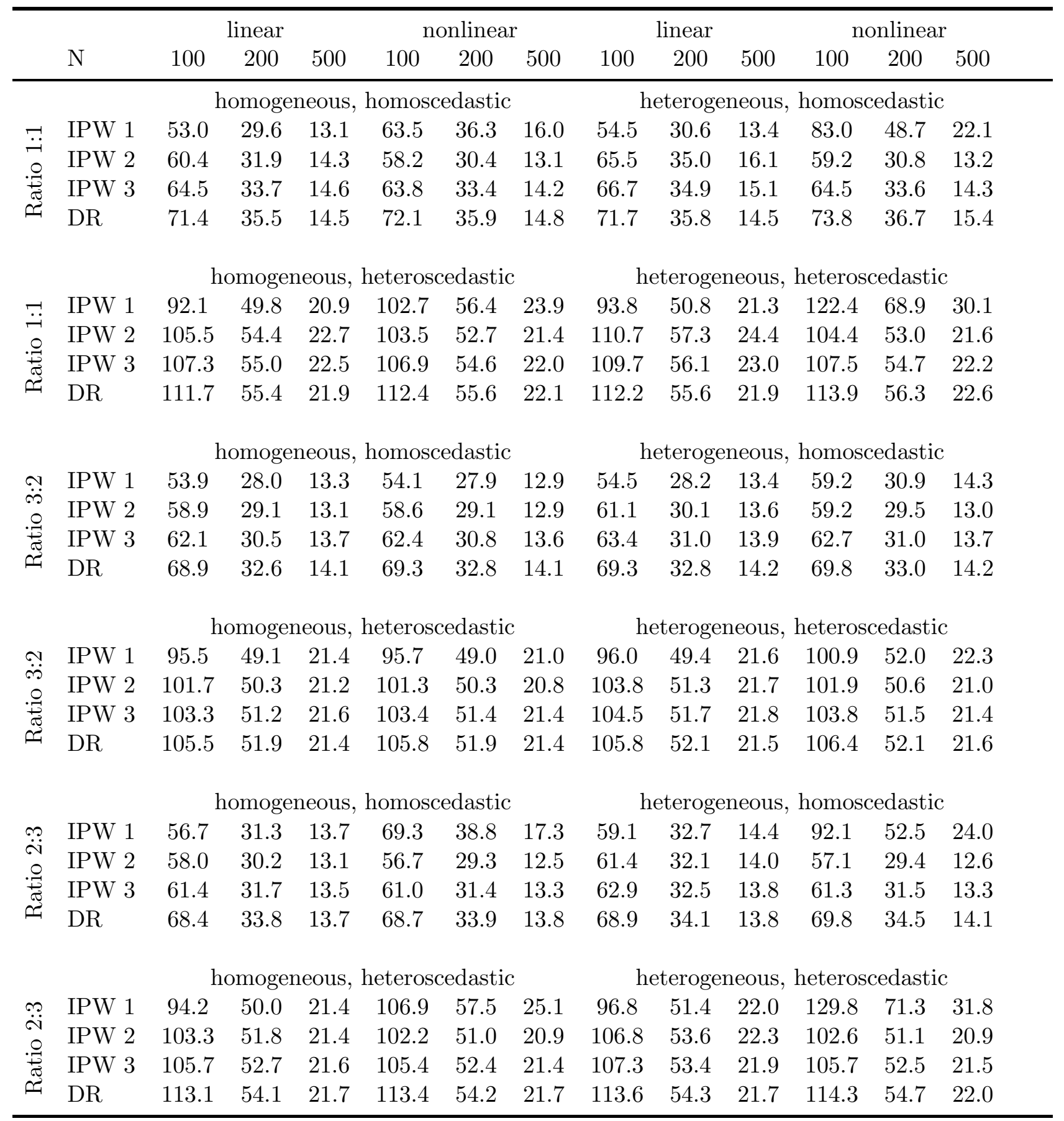

Note: Reported values are Monte Carlo MSE $\times 10^{4}$ of ATE estimators based on the four different propensity score methods method: IPW1, IPW2, IPW3 and DR which are explained in detailed in Section 2. Propensity score is shrunken with the fixed valued $\lambda$. The ATE is estimated for 10000, 5000 and 2000 Monte Carlo samples with sample sizes 100, 200 and 500, respectively. Ratio refers to the treated-to-control ratio. Linear and nonlinear refer to the relation between propensity score and outcome variable. Homogeneous or heterogenous describes treatment homogeneity or heterogeneity. Homoscedastic and heteroscedastic describe the error term structure of the outcome variable. 
Table A.29: MSE of ATE estimators based on shrunken propensity score with MSE-minimizing $\lambda$

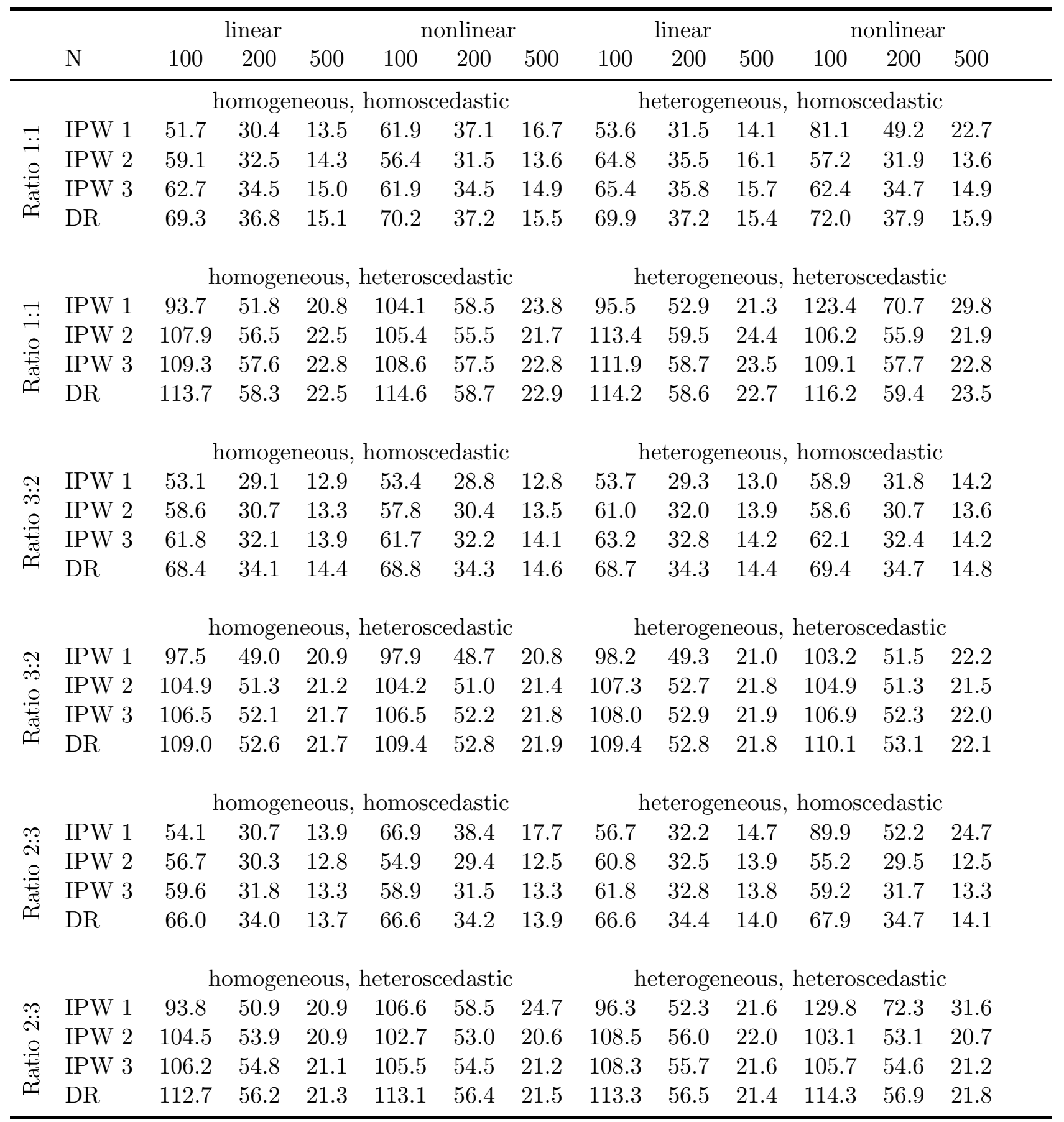

Note: Reported values are Monte Carlo MSE $\times 10^{4}$ of ATE estimators based on the four different propensity score methods method: IPW1, IPW2, IPW3 and DR which are explained in detailed in Section 2. Propensity score is shrunken with the MSE-minimizing $\lambda$. The ATE is estimated for 10000, 5000 and 2000 Monte Carlo samples with sample sizes 100, 200 and 500, respectively. Ratio refers to the treated-to-control ratio. Linear and nonlinear refer to the relation between propensity score and outcome variable. Homogeneous or heterogenous describes treatment homogeneity or heterogeneity. Homoscedastic and heteroscedastic describe the error term structure of the outcome variable. 
Table A.30: MSE of ATE estimators based on shrunken propensity score with data driven $\lambda$

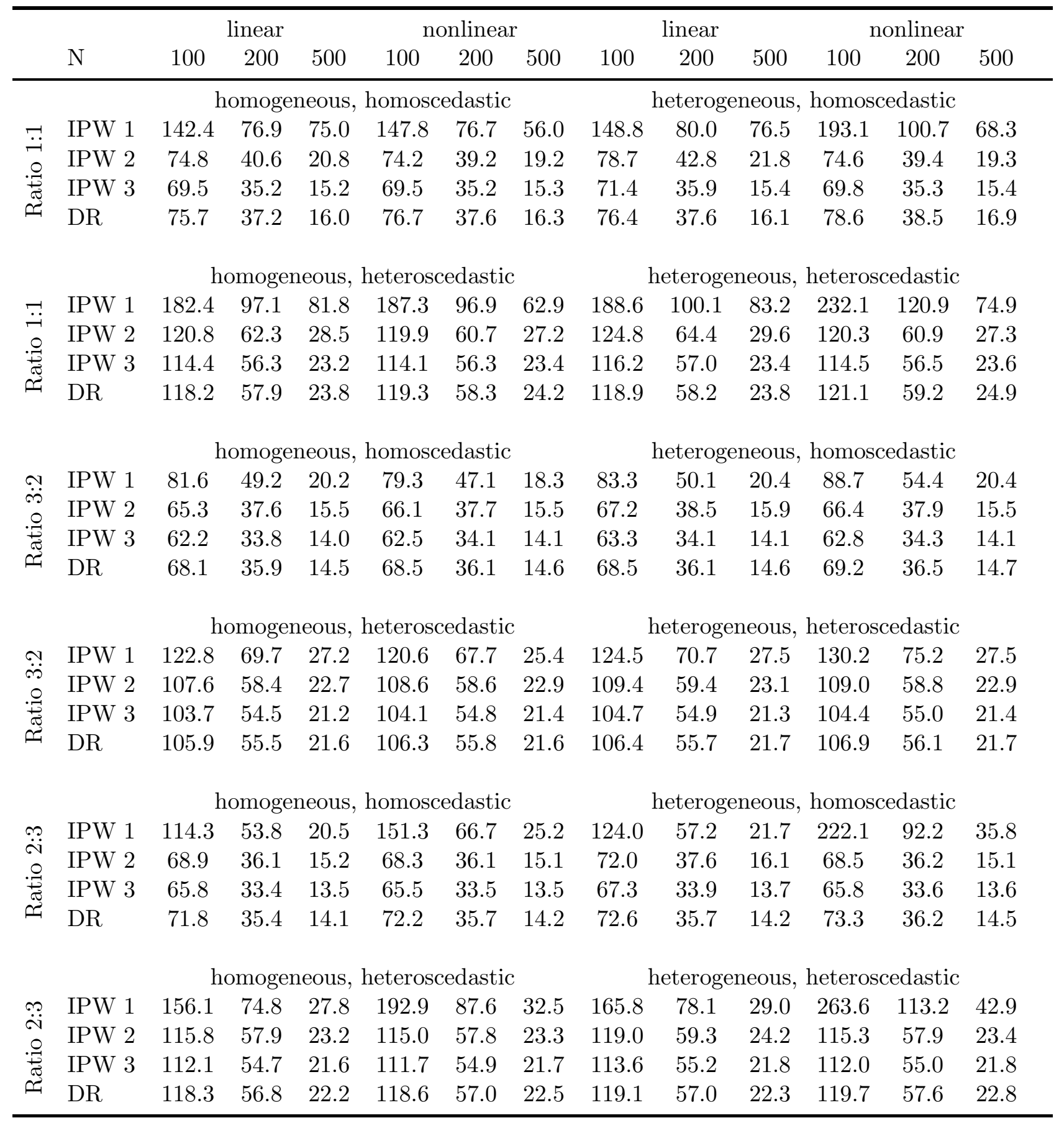

Note: Reported values are Monte Carlo MSE $\times 10^{4}$ of ATE estimators based on the four different propensity score methods method: IPW1, IPW2, IPW3 and DR which are explained in detailed in Section 2. Propensity score is shrunken with the data-driven $\lambda$. The ATE is estimated for 10000, 5000 and 2000 Monte Carlo samples with sample sizes 100, 200 and 500, respectively. Ratio refers to the treated-to-control ratio. Linear and nonlinear refer to the relation between propensity score and outcome variable. Homogeneous or heterogenous describes treatment homogeneity or heterogeneity. Homoscedastic and heteroscedastic describe the error term structure of the outcome variable. 
Table A.31: MSE of ATE estimators based on shrunken propensity score with trimming rule 2, fixed valued $\lambda$

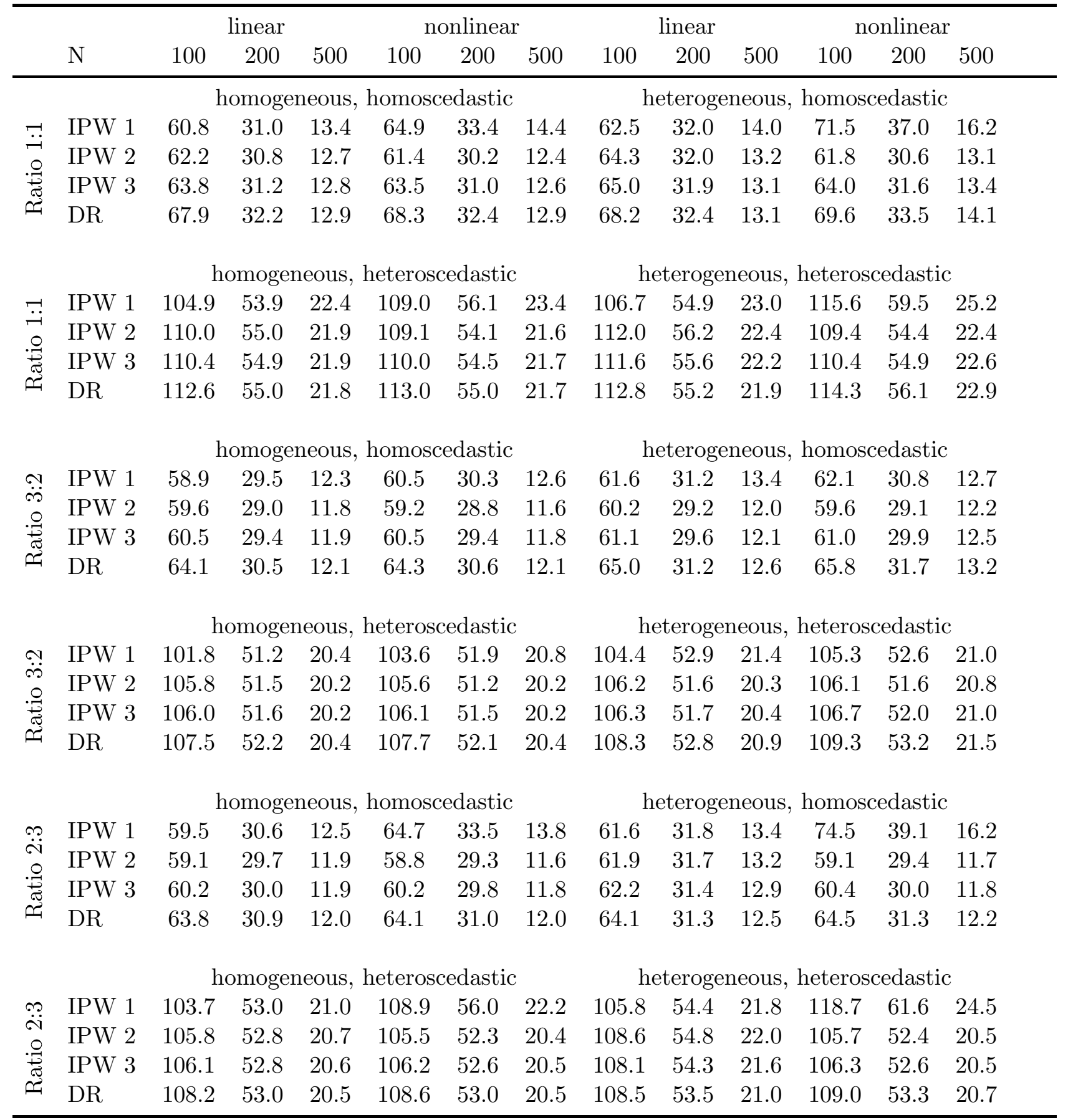

Note: Reported values are Monte Carlo MSE $\times 10^{4}$ of ATE estimators based on the four different propensity score methods method: IPW1, IPW2, IPW3 and DR which are explained in detailed in Section 2. Propensity score is shrunken with the fixed valued $\lambda$ combined with the second trimming rule. The ATE is estimated for 10000, 5000 and 2000 Monte Carlo samples with sample sizes 100, 200 and 500, respectively. Ratio refers to the treated-to-control ratio. Linear and nonlinear refer to the relation between propensity score and outcome variable. Homogeneous or heterogenous describes treatment homogeneity or heterogeneity. Homoscedastic and heteroscedastic describe the error term structure of the outcome variable. 
Table A.32: MSE of ATE estimators based on shrunken propensity score with trimming rule 2, MSE-minimizing $\lambda$

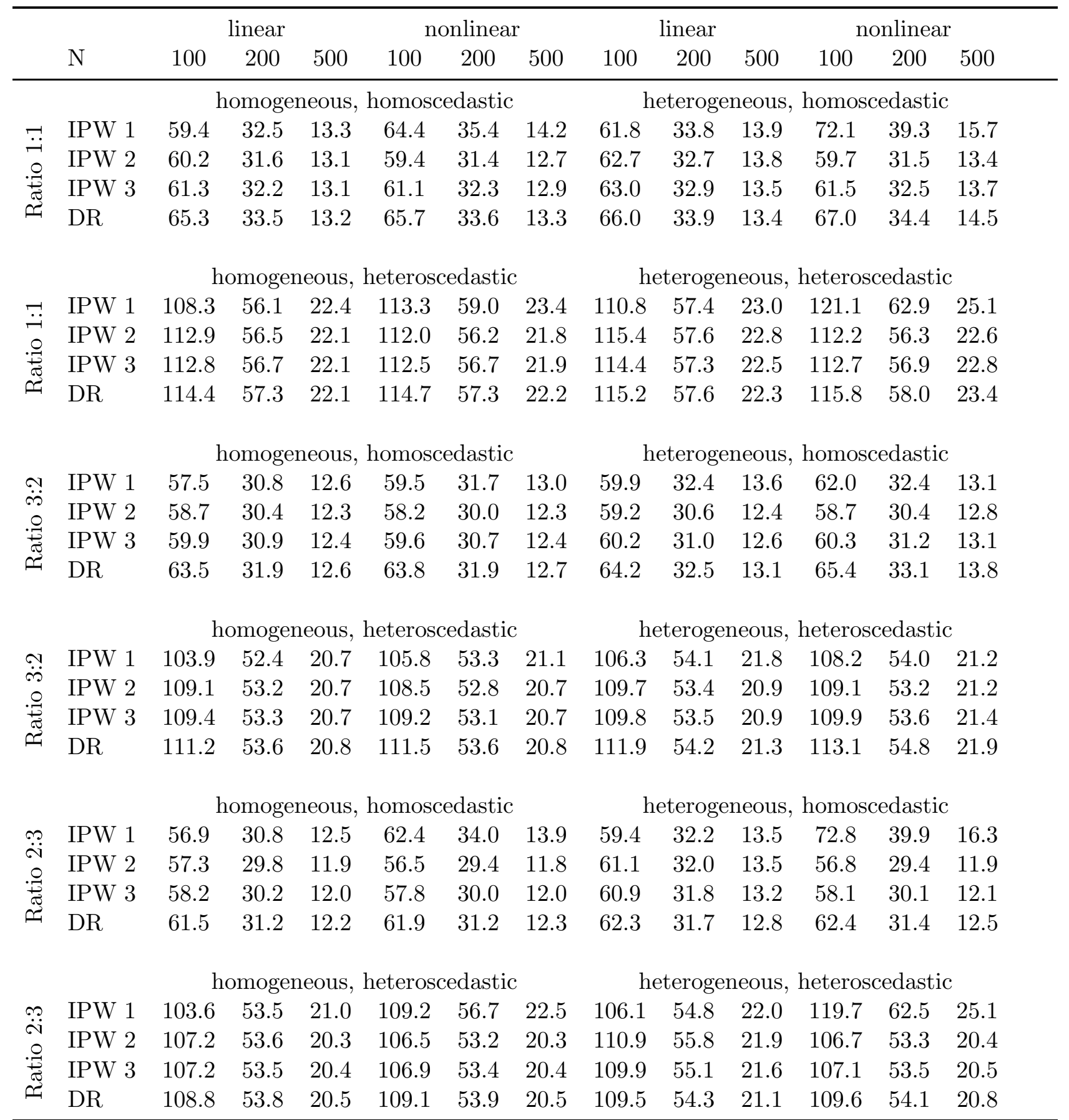

Note: Reported values are Monte Carlo MSE $\times 10^{4}$ of ATE estimators based on the four different propensity score methods method: IPW1, IPW2, IPW3 and DR which are explained in detailed in Section 2. Propensity score is shrunken with the MSE-minimizing $\lambda$ combined with the second trimming rule. The ATE is estimated for 10000, 5000 and 2000 Monte Carlo samples with sample sizes 100, 200 and 500, respectively. Ratio refers to the treated-to-control ratio. Linear and nonlinear refer to the relation between propensity score and outcome variable. Homogeneous or heterogenous describes treatment homogeneity or heterogeneity. Homoscedastic and heteroscedastic describe the error term structure of the outcome variable. 
Table A.33: MSE of ATE estimators based on shrunken propensity score with trimming rule 2, data driven $\lambda$

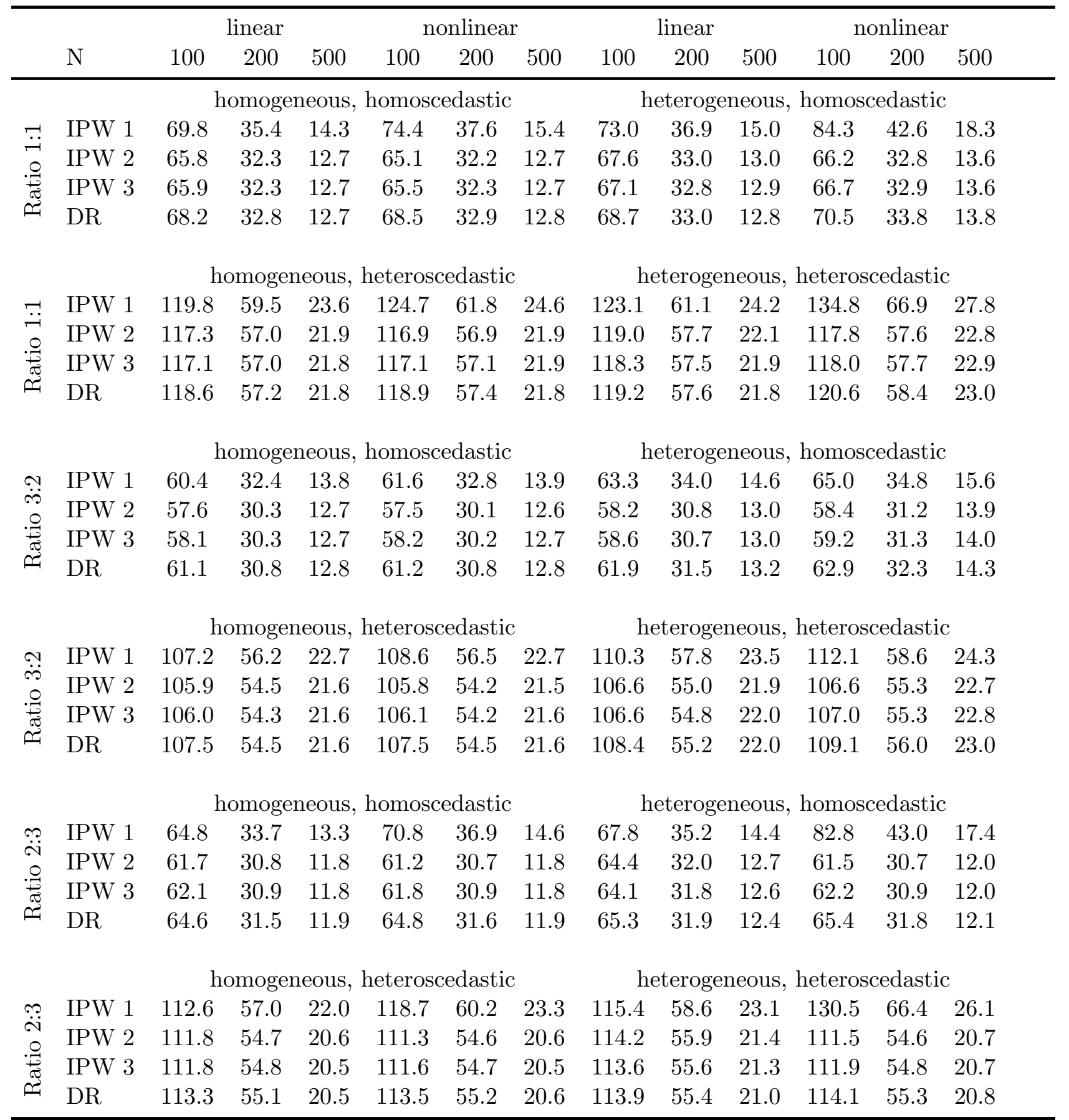

Note: Reported values are Monte Carlo MSE $\times 10^{4}$ of ATE estimators based on the four different propensity score methods method: IPW1, IPW2, IPW3 and DR which are explained in detailed in Section 2. Propensity score is shrunken with the data-driven $\lambda$ combined with the second trimming rule. The ATE is estimated for 10000, 5000 and 2000 Monte Carlo samples with sample sizes 100, 200 and 500, respectively. Ratio refers to the treated-to-control ratio. Linear and nonlinear refer to the relation between propensity score and outcome variable. Homogeneous or heterogenous describes treatment homogeneity or heterogeneity. Homoscedastic and heteroscedastic describe the error term structure of the outcome variable. 
Table A.34: MSE of ATE estimators based on shrunken propensity score with trimming rule 1, fixed valued $\lambda$

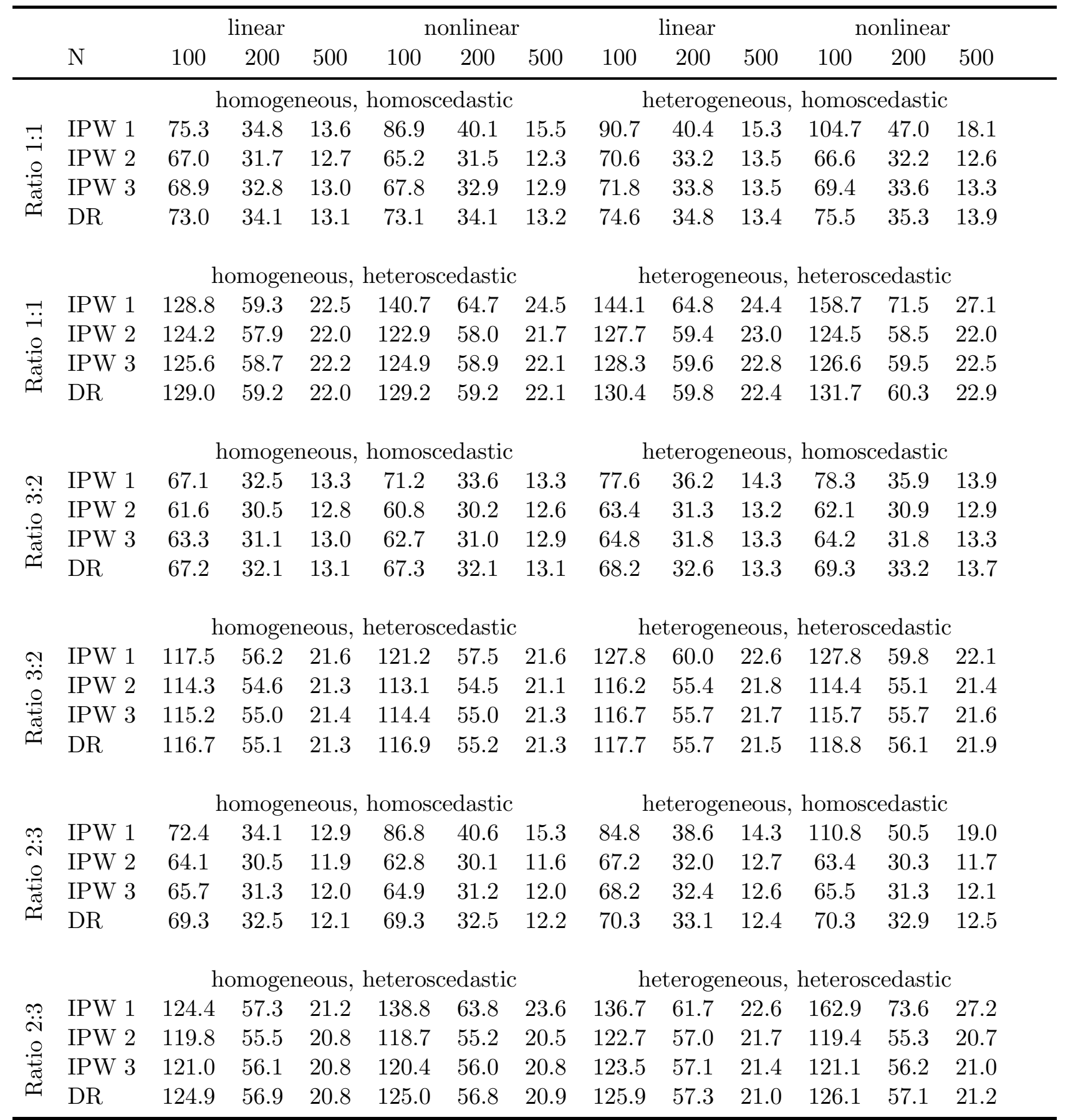

Note: Reported values are Monte Carlo MSE $\times 10^{4}$ of ATE estimators based on the four different propensity score methods method: IPW1, IPW2, IPW3 and DR which are explained in detailed in Section 2. Propensity score is shrunken with the fixed valued $\lambda$ combined with the first trimming rule. The ATE is estimated for 10000, 5000 and 2000 Monte Carlo samples with sample sizes 100, 200 and 500, respectively. Ratio refers to the treated-to-control ratio. Linear and nonlinear refer to the relation between propensity score and outcome variable. Homogeneous or heterogenous describes treatment homogeneity or heterogeneity. Homoscedastic and heteroscedastic describe the error term structure of the outcome variable. 
Table A.35: MSE of ATE estimators based on shrunken propensity score with trimming rule 1, MSE-minimizing $\lambda$

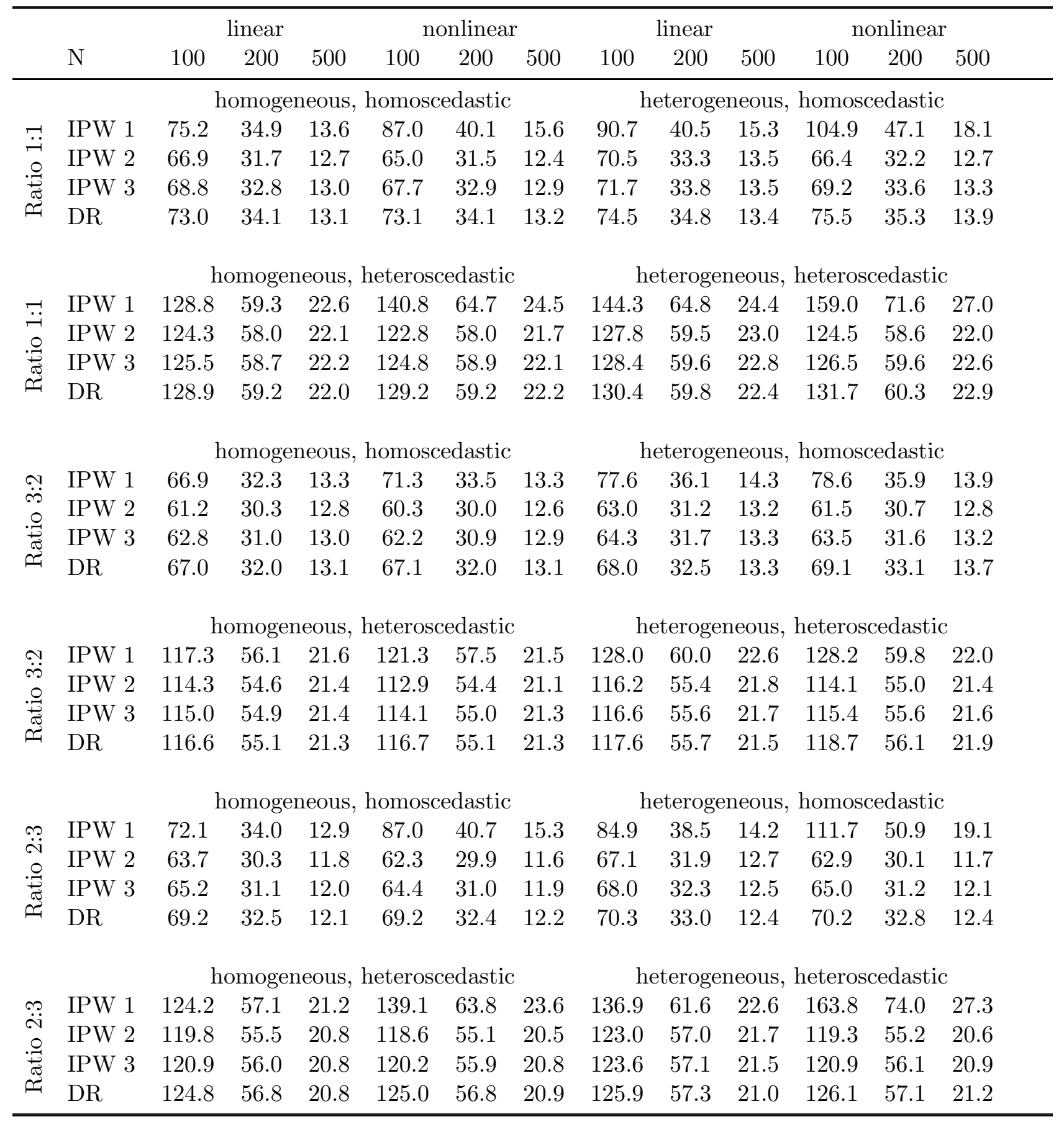

Note: Reported values are Monte Carlo MSE $\times 10^{4}$ of ATE estimators based on the four different propensity score methods method: IPW1, IPW2, IPW3 and DR which are explained in detailed in Section 2. Propensity score is shrunken with the MSE-minimizing $\lambda$ combined with the first trimming rule. The ATE is estimated for 10000, 5000 and 2000 Monte Carlo samples with sample sizes 100, 200 and 500, respectively. Ratio refers to the treated-to-control ratio. Linear and nonlinear refer to the relation between propensity score and outcome variable. Homogeneous or heterogenous describes treatment homogeneity or heterogeneity. Homoscedastic and heteroscedastic describe the error term structure of the outcome variable. 
Table A.36: $\quad$ MSE of ATE estimators based on shrunken propensity score with trimming rule 1, data-driven $\lambda$

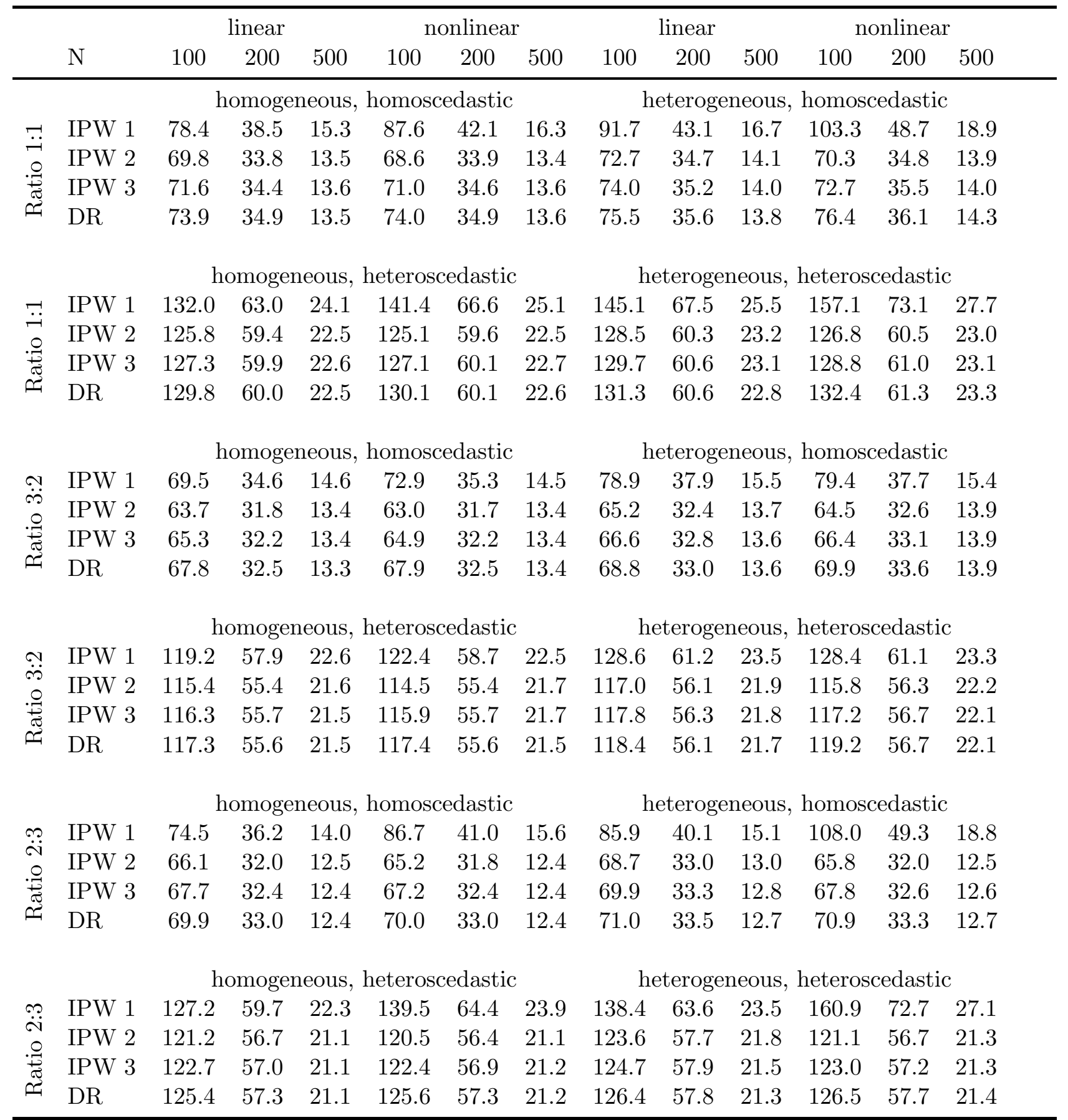

Note: Reported values are Monte Carlo MSE $\times 10^{4}$ of ATE estimators based on the four different propensity score methods method: IPW1, IPW2, IPW3 and DR which are explained in detailed in Section 2. Propensity score is shrunken with the data-driven $\lambda$ combined with the first trimming rule. The ATE is estimated for 10000, 5000 and 2000 Monte Carlo samples with sample sizes 100, 200 and 500, respectively. Ratio refers to the treated-to-control ratio. Linear and nonlinear refer to the relation between propensity score and outcome variable. Homogeneous or heterogenous describes treatment homogeneity or heterogeneity. Homoscedastic and heteroscedastic describe the error term structure of the outcome variable. 
Table A.37: Percentage improvement in MSE for the ATE if the shrunken propensity scores are used with trimming rule 1 instead of the conventional propensity scores, fixed $\lambda$

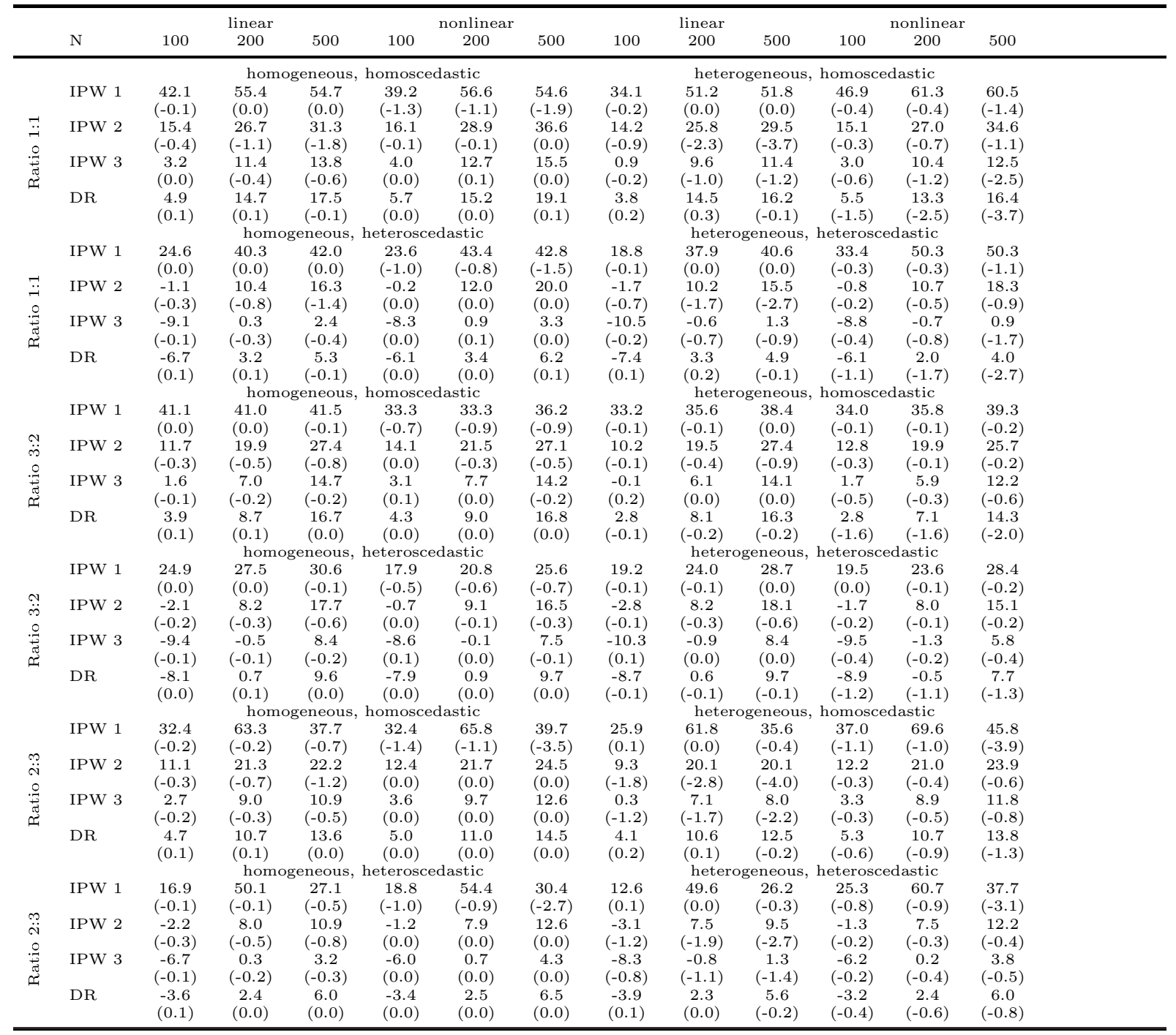

Note: Percentage change which is due to the bias $\left(\frac{\operatorname{bias}^{2}(\operatorname{ATE}(\hat{p}))-\operatorname{bias}^{2}\left(\operatorname{ATE}\left(\hat{p}^{s}\right)\right)}{\operatorname{bias}^{2}(\operatorname{ATE}(\hat{p}))+\operatorname{Var}(\operatorname{ATE}(\hat{p}))}\right)$ is given in brackets. 
Table A.38: Percentage improvement in MSE for the ATE if the shrunken propensity scores are used with trimming rule 1 instead of the conventional propensity scores with trimming rule 1 , fixed $\lambda$

\begin{tabular}{|c|c|c|c|c|c|c|c|c|c|c|c|c|c|}
\hline & $\mathrm{N}$ & 100 & $\begin{array}{c}\text { linear } \\
200\end{array}$ & 500 & 100 & $\begin{array}{c}\text { nonlinear } \\
200\end{array}$ & 500 & 100 & $\begin{array}{c}\text { linear } \\
200\end{array}$ & 500 & 100 & $\begin{array}{l}\text { onlinea } \\
200\end{array}$ & 500 \\
\hline 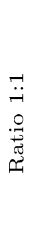 & $\begin{array}{l}\text { IPW } 2 \\
\text { IPW } 3\end{array}$ & $\begin{array}{c}7.9 \\
(-0.1) \\
7.6 \\
(-0.7) \\
6.1 \\
(-0.3) \\
1.9 \\
(0.0)\end{array}$ & $\begin{array}{c}\text { hom } \\
12.1 \\
(0.0) \\
8.2 \\
(-1.5) \\
5.8 \\
(-0.7) \\
3.1 \\
(0.0)\end{array}$ & $\begin{array}{c}\text { geneous, } \\
14.9 \\
(0.1) \\
7.3 \\
(-3.1) \\
4.3 \\
(-1.3) \\
3.5 \\
(0.0)\end{array}$ & $\begin{array}{c}\text { homosce } \\
3.7 \\
(-2.2) \\
8.2 \\
(-0.2) \\
6.5 \\
(-0.1) \\
1.9 \\
(0.0)\end{array}$ & $\begin{array}{c}\text { lastic } \\
7.6 \\
(-2.6) \\
9.6 \\
(-0.2) \\
6.5 \\
(-0.1) \\
3.1 \\
(0.0)\end{array}$ & $\begin{array}{c}9.4 \\
(-3.9) \\
10.7 \\
(0.1) \\
6.0 \\
(0.2) \\
3.6 \\
(0.0)\end{array}$ & $\begin{array}{c}3.5 \\
(-0.2) \\
6.5 \\
(-1.6) \\
5.3 \\
(-0.8) \\
1.8 \\
(0.0)\end{array}$ & $\begin{array}{c}\text { heter } \\
8.1 \\
(-0.1) \\
6.3 \\
(-3.2) \\
4.7 \\
(-1.5) \\
3.0 \\
(0.0)\end{array}$ & $\begin{array}{c}\text { geneous } \\
11.4 \\
(0.0) \\
4.0 \\
(-6.1) \\
2.9 \\
(-2.5) \\
3.4 \\
(0.1)\end{array}$ & $\begin{array}{c}\text { homosce } \\
2.4 \\
(-1.6) \\
8.6 \\
(0.6) \\
6.7 \\
(0.5) \\
1.7 \\
(-0.1)\end{array}$ & $\begin{array}{c}\text { astic } \\
8.2 \\
(-0.7) \\
10.4 \\
(1.2) \\
7.0 \\
(0.8) \\
2.7 \\
(-0.3)\end{array}$ & $\begin{array}{c}11.9 \\
(-1.1) \\
12.1 \\
(2.4) \\
6.8 \\
(1.5) \\
2.8 \\
(-0.5)\end{array}$ \\
\hline 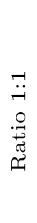 & IPW 3 & $\begin{array}{c}4.6 \\
(-0.1) \\
2.1 \\
(-0.4) \\
2.0 \\
(-0.2) \\
0.9 \\
(0.0)\end{array}$ & $\begin{array}{c}\text { hom } \\
8.1 \\
(0.0) \\
2.8 \\
(-0.9) \\
2.1 \\
(-0.4) \\
2.0 \\
(0.0)\end{array}$ & $\begin{array}{c}\text { eneous, } \\
10.2 \\
(0.1) \\
2.8 \\
(-2.0) \\
1.7 \\
(-0.8) \\
2.3 \\
(0.0)\end{array}$ & $\begin{array}{c}\text { heterosc } \\
2.1 \\
(-1.4) \\
2.6 \\
(-0.1) \\
2.3 \\
(-0.1) \\
1.0 \\
(0.0)\end{array}$ & $\begin{array}{c}\text { dastic } \\
5.6 \\
(-1.6) \\
3.8 \\
(-0.1) \\
2.6 \\
(0.0) \\
2.0 \\
(0.0)\end{array}$ & $\begin{array}{c}6.9 \\
(-2.4) \\
4.8 \\
(0.1) \\
2.7 \\
(0.1) \\
2.3 \\
(0.0)\end{array}$ & $\begin{array}{c}2.0 \\
(-0.1) \\
1.6 \\
(-1.0) \\
1.6 \\
(-0.5) \\
0.9 \\
(0.0)\end{array}$ & $\begin{array}{c}\text { heter } \\
5.8 \\
(0.0) \\
1.7 \\
(-2.0) \\
1.5 \\
(-1.0) \\
1.9 \\
(0.0)\end{array}$ & $\begin{array}{c}\text { seneous, } \\
8.2 \\
(0.0) \\
0.8 \\
(-3.9) \\
0.9 \\
(-1.6) \\
2.3 \\
(0.0)\end{array}$ & $\begin{array}{c}\text { eterosc } \\
1.4 \\
(-1.0) \\
2.9 \\
(0.4) \\
2.5 \\
(0.3) \\
0.9 \\
(-0.1)\end{array}$ & $\begin{array}{c}\text { lastic } \\
6.5 \\
(-0.4) \\
4.3 \\
(0.7) \\
3.0 \\
(0.5) \\
1.8 \\
(-0.2)\end{array}$ & $\begin{array}{c}9.0 \\
(-0.6) \\
5.8 \\
(1.5) \\
3.3 \\
(0.9) \\
1.9 \\
(-0.3)\end{array}$ \\
\hline 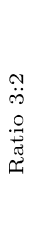 & IPW 2 & $\begin{array}{c}6.9 \\
(0.0) \\
6.5 \\
(-0.4) \\
5.3 \\
(-0.2) \\
1.5 \\
(0.0)\end{array}$ & $\begin{array}{c}\text { hom } \\
9.7 \\
(0.0) \\
6.5 \\
(-0.5) \\
4.9 \\
(-0.2) \\
1.8 \\
(0.0)\end{array}$ & $\begin{array}{c}\text { geneous, } \\
12.7 \\
(-0.2) \\
7.6 \\
(-1.1) \\
4.6 \\
(-0.4) \\
2.8 \\
(0.0)\end{array}$ & $\begin{array}{c}\text { homosce } \\
4.7 \\
(-1.0) \\
7.0 \\
(-0.2) \\
5.7 \\
(-0.1) \\
1.5 \\
(0.0)\end{array}$ & $\begin{array}{c}\text { lastic } \\
7.7 \\
(-1.3) \\
6.9 \\
(-0.5) \\
5.0 \\
(-0.3) \\
1.9 \\
(0.0)\end{array}$ & $\begin{array}{c}10.8 \\
(-1.3) \\
8.1 \\
(-0.6) \\
4.6 \\
(-0.3) \\
2.8 \\
(0.0)\end{array}$ & $\begin{array}{c}3.4 \\
(-0.1) \\
6.4 \\
(-0.3) \\
5.3 \\
(-0.1) \\
1.5 \\
(0.0)\end{array}$ & $\begin{array}{c}\text { heter } \\
7.0 \\
(0.1) \\
6.5 \\
(-0.3) \\
5.0 \\
(0.1) \\
1.8 \\
(0.0)\end{array}$ & $\begin{array}{c}\text { geneous } \\
11.0 \\
(0.2) \\
7.3 \\
(-1.1) \\
4.7 \\
(-0.1) \\
2.7 \\
(0.0)\end{array}$ & $\begin{array}{c}\text { homosce } \\
4.9 \\
(0.6) \\
7.6 \\
(0.8) \\
6.1 \\
(0.6) \\
1.4 \\
(0.0)\end{array}$ & $\begin{array}{c}\text { astic } \\
9.5 \\
(0.6) \\
7.9 \\
(1.0) \\
5.6 \\
(0.7) \\
1.7 \\
(-0.1)\end{array}$ & $\begin{array}{c}13.4 \\
(1.0) \\
9.6 \\
(1.4) \\
5.6 \\
(1.0) \\
2.6 \\
(-0.2)\end{array}$ \\
\hline 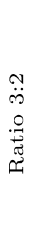 & $\begin{array}{l}\text { IPW } 3 \\
\text { DR }\end{array}$ & $\begin{array}{c}4.0 \\
(0.0) \\
2.1 \\
(-0.3) \\
1.8 \\
(-0.2) \\
0.9 \\
(0.0)\end{array}$ & $\begin{array}{c}\text { hom } \\
5.4 \\
(0.0) \\
2.1 \\
(-0.3) \\
1.7 \\
(-0.1) \\
1.0 \\
(0.0)\end{array}$ & $\begin{array}{c}\text { eneous, } \\
7.6 \\
(-0.1) \\
3.4 \\
(-0.7) \\
2.0 \\
(-0.2) \\
1.7 \\
(0.0)\end{array}$ & $\begin{array}{c}\text { heterosc } \\
2.7 \\
(-0.6) \\
2.4 \\
(-0.1) \\
2.0 \\
(-0.1) \\
0.9 \\
(0.0)\end{array}$ & $\begin{array}{c}\text { dastic } \\
4.4 \\
(-0.8) \\
2.4 \\
(-0.3) \\
1.8 \\
(-0.1) \\
1.0 \\
(0.0)\end{array}$ & $\begin{array}{c}6.2 \\
(-0.8) \\
3.5 \\
(-0.4) \\
1.9 \\
(-0.2) \\
1.7 \\
(0.0)\end{array}$ & $\begin{array}{c}1.9 \\
(-0.1) \\
2.2 \\
(-0.2) \\
1.9 \\
(-0.1) \\
0.9 \\
(0.0)\end{array}$ & $\begin{array}{c}\text { heter } \\
4.0 \\
(0.0) \\
2.1 \\
(-0.2) \\
1.8 \\
(0.1) \\
1.0 \\
(0.0)\end{array}$ & $\begin{array}{c}\text { eneous, } \\
6.6 \\
(0.1) \\
3.2 \\
(-0.7) \\
2.1 \\
(-0.1) \\
1.6 \\
(0.0)\end{array}$ & $\begin{array}{c}\text { eterosc } \\
2.9 \\
(0.4) \\
2.8 \\
(0.5) \\
2.3 \\
(0.4) \\
0.9 \\
(0.0)\end{array}$ & $\begin{array}{c}\text { lastic } \\
5.8 \\
(0.5) \\
3.1 \\
(0.6) \\
2.2 \\
(0.5) \\
0.9 \\
(-0.1)\end{array}$ & $\begin{array}{c}8.2 \\
(0.7) \\
4.5 \\
(0.9) \\
2.6 \\
(0.6) \\
1.5 \\
(-0.1)\end{array}$ \\
\hline 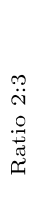 & $\begin{array}{l}\text { IPW } 3 \\
\text { DR }\end{array}$ & $\begin{array}{c}6.2 \\
(-0.3) \\
5.9 \\
(-0.5) \\
5.0 \\
(-0.3) \\
1.2 \\
(0.0)\end{array}$ & $\begin{array}{c}\text { hom } \\
9.3 \\
(-0.6) \\
6.8 \\
(-0.8) \\
5.1 \\
(-0.4) \\
2.1 \\
(0.0)\end{array}$ & $\begin{array}{c}\text { geneous, } \\
10.7 \\
(-1.0) \\
6.4 \\
(-1.5) \\
4.1 \\
(-0.7) \\
2.8 \\
(0.0)\end{array}$ & $\begin{array}{c}\text { homosce } \\
2.2 \\
(-2.1) \\
6.4 \\
(0.0) \\
5.3 \\
(0.0) \\
1.2 \\
(0.0)\end{array}$ & $\begin{array}{c}\text { lastic } \\
4.8 \\
(-3.3) \\
7.7 \\
(0.0) \\
5.6 \\
(0.0) \\
2.1 \\
(0.0)\end{array}$ & $\begin{array}{c}5.2 \\
(-5.7) \\
7.9 \\
(0.0) \\
4.9 \\
(0.1) \\
2.7 \\
(0.0)\end{array}$ & $\begin{array}{c}3.3 \\
(-0.2) \\
4.4 \\
(-1.8) \\
3.8 \\
(-1.2) \\
1.2 \\
(0.0)\end{array}$ & $\begin{array}{c}\text { heter } \\
7.1 \\
(-0.2) \\
4.6 \\
(-3.0) \\
3.6 \\
(-1.7) \\
2.1 \\
(0.0)\end{array}$ & $\begin{array}{c}\text { geneous } \\
9.5 \\
(-0.4) \\
3.0 \\
(-4.6) \\
2.4 \\
(-2.2) \\
2.8 \\
(0.1)\end{array}$ & $\begin{array}{c}\text { homosc } \\
-0.4 \\
(-2.6) \\
6.5 \\
(0.2) \\
5.4 \\
(0.1) \\
1.2 \\
(-0.1)\end{array}$ & $\begin{array}{c}\text { astic } \\
2.8 \\
(-3.8) \\
7.9 \\
(0.3) \\
5.6 \\
(0.2) \\
1.9 \\
(-0.2)\end{array}$ & $\begin{array}{c}3.4 \\
(-7.0) \\
8.1 \\
(0.5) \\
5.1 \\
(0.4) \\
2.3 \\
(-0.3)\end{array}$ \\
\hline 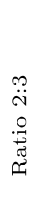 & $\begin{array}{l}\text { IPW } 3 \\
\text { DR }\end{array}$ & $\begin{array}{c}3.8 \\
(-0.2) \\
1.6 \\
(-0.3) \\
1.7 \\
(-0.2) \\
0.6 \\
(0.0)\end{array}$ & $\begin{array}{c}\text { hom } \\
6.4 \\
(-0.4) \\
2.4 \\
(-0.5) \\
2.0 \\
(-0.2) \\
1.3 \\
(0.0)\end{array}$ & $\begin{array}{c}\text { eneous, } \\
7.8 \\
(-0.7) \\
2.7 \\
(-0.9) \\
1.8 \\
(-0.4) \\
1.8 \\
(0.0)\end{array}$ & $\begin{array}{c}\text { neterosc } \\
1.5 \\
(-1.3) \\
1.9 \\
(0.0) \\
1.9 \\
(0.0) \\
0.6 \\
(0.0)\end{array}$ & $\begin{array}{c}\text { dastic } \\
3.7 \\
(-2.1) \\
3.0 \\
(0.0) \\
2.3 \\
(0.0) \\
1.3 \\
(0.0)\end{array}$ & $\begin{array}{c}4.5 \\
(-3.8) \\
3.6 \\
(0.0) \\
2.3 \\
(0.0) \\
1.7 \\
(0.0)\end{array}$ & $\begin{array}{c}2.1 \\
(-0.1) \\
0.8 \\
(-1.1) \\
1.0 \\
(-0.7) \\
0.6 \\
(0.0)\end{array}$ & $\begin{array}{c}\text { heter } \\
5.2 \\
(-0.1) \\
1.1 \\
(-1.8) \\
1.2 \\
(-1.0) \\
1.3 \\
(0.0)\end{array}$ & $\begin{array}{c}\text { seneous, } \\
7.2 \\
(-0.3) \\
0.6 \\
(-2.8) \\
0.8 \\
(-1.4) \\
1.9 \\
(0.1)\end{array}$ & $\begin{array}{c}\text { eterosc } \\
-0.3 \\
(-1.7) \\
2.0 \\
(0.1) \\
2.0 \\
(0.1) \\
0.6 \\
(0.0)\end{array}$ & $\begin{array}{c}\text { dastic } \\
2.5 \\
(-2.6) \\
3.1 \\
(0.2) \\
2.4 \\
(0.1) \\
1.2 \\
(-0.1)\end{array}$ & $\begin{array}{c}3.4 \\
(-4.9) \\
3.8 \\
(0.3) \\
2.4 \\
(0.2) \\
1.5 \\
(-0.2)\end{array}$ \\
\hline
\end{tabular}

Note: Percentage change which is due to the bias $\left(\frac{\operatorname{bias}^{2}(\operatorname{ATE}(\hat{p}))-\operatorname{bias}^{2}\left(\operatorname{ATE}\left(\hat{p}^{s}\right)\right)}{\operatorname{bias}^{2}(\operatorname{ATE}(\hat{p}))+\operatorname{Var}(\operatorname{ATE}(\hat{p}))}\right)$ is given in brackets. 
Table A.39: Percentage improvement in MSE for the ATE if the shrunken propensity scores are used with trimming rule 1 instead of the conventional propensity scores used with trimming rule 2 , fixed $\lambda$

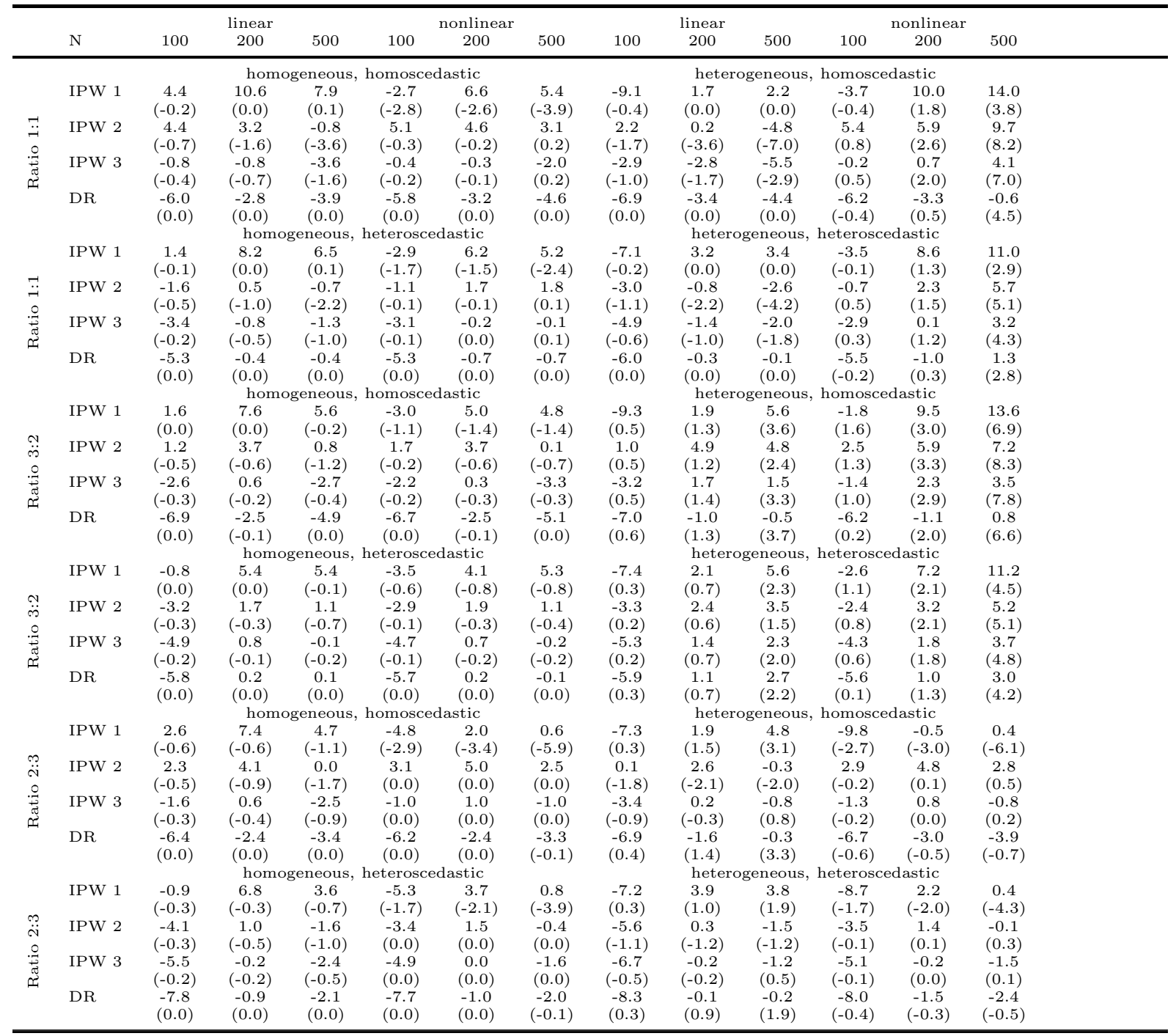

Note: Percentage change which is due to the $\operatorname{bias}\left(\frac{\operatorname{bias}^{2}(\operatorname{ATE}(\hat{p}))-\operatorname{bias}^{2}\left(\operatorname{ATE}\left(\hat{p}^{s}\right)\right)}{\operatorname{bias}^{2}(\operatorname{ATE}(\hat{p}))+\operatorname{Var}(\operatorname{ATE}(\hat{p}))}\right)$ is given in brackets. 
Table A.40: Percentage improvement in MSE for the ATE if the shrunken propensity scores are used with trimming rule 1 instead of the conventional propensity scores used with trimming rule by HLW, fixed $\lambda$

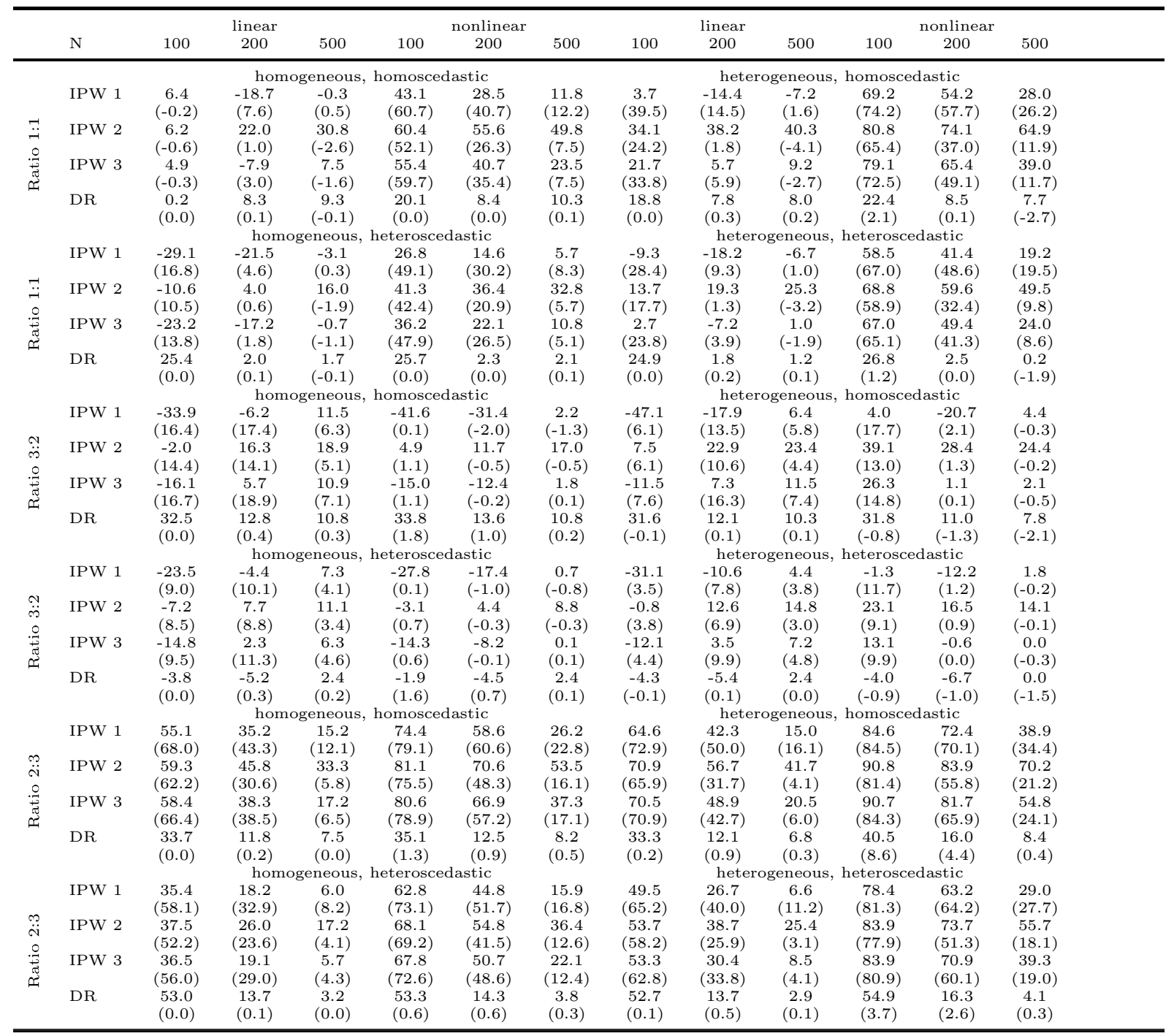

Note: Percentage change which is due to the bias $\left(\frac{\operatorname{bias}^{2}(\operatorname{ATE}(\hat{p}))-\operatorname{bias}^{2}\left(\operatorname{ATE}\left(\hat{p}^{s}\right)\right)}{\operatorname{bias}^{2}(\operatorname{ATE}(\hat{p}))+\operatorname{Var}(\operatorname{ATE}(\hat{p}))}\right)$ is given in brackets. 
Table A.41: Percentage improvement in MSE for the ATE if the shrunken propensity scores are used with trimming rule 1 instead of the conventional propensity scores, mse-minizing $\lambda$

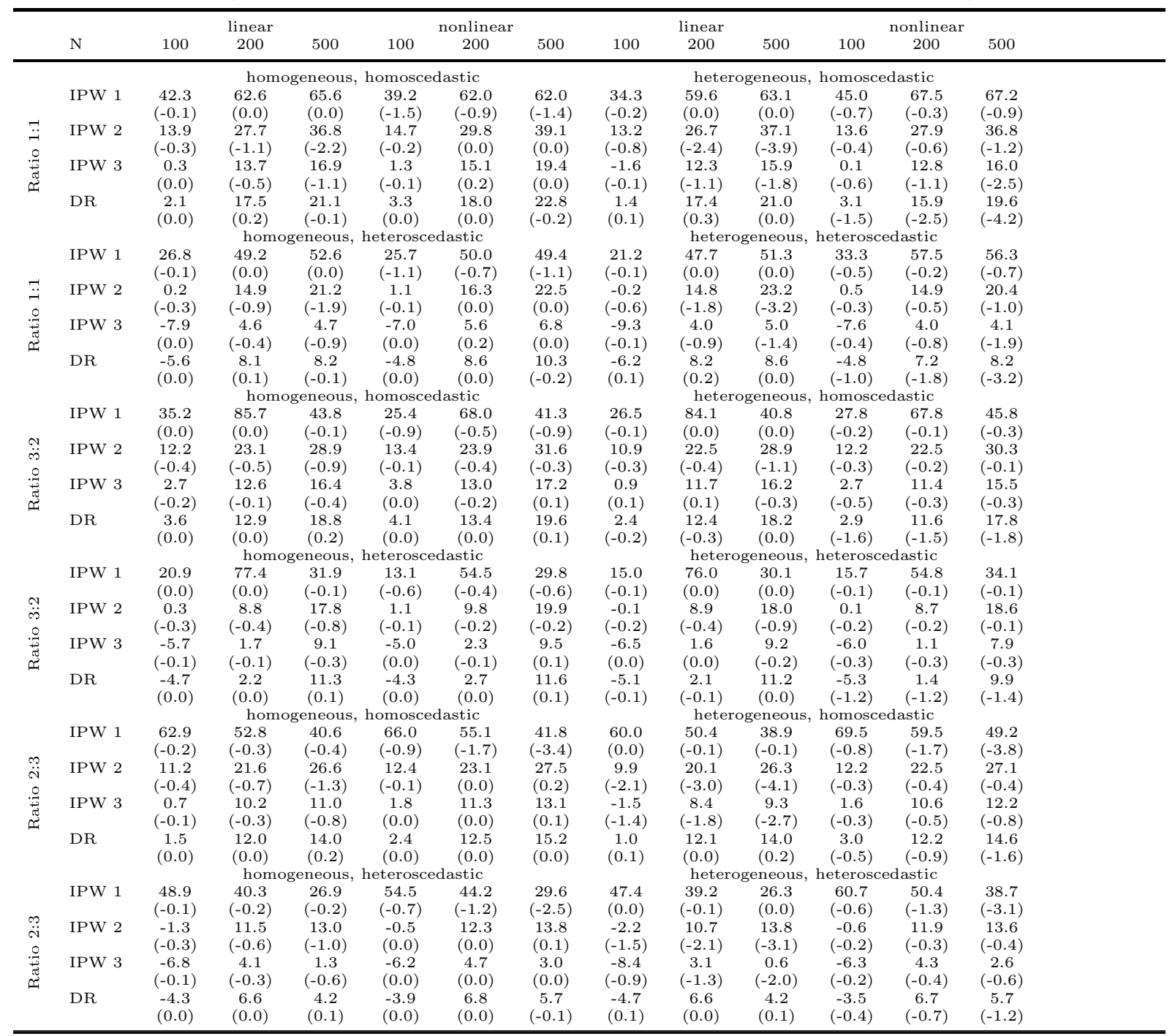

Note: Percentage change which is due to the bias $\left(\frac{\operatorname{bias}^{2}(\operatorname{ATE}(\hat{p}))-\operatorname{bias}^{2}\left(\operatorname{ATE}\left(\hat{p}^{s}\right)\right)}{\operatorname{bias}^{2}(\operatorname{ATE}(\hat{p}))+\operatorname{Var}(\operatorname{ATE}(\hat{p}))}\right)$ is given in brackets. 
Table A.42: Percentage improvement in MSE for the ATE if the shrunken propensity scores are used with trimming rule 1 instead of the conventional propensity scores with trimming rule 1 , mseminimizing $\lambda$

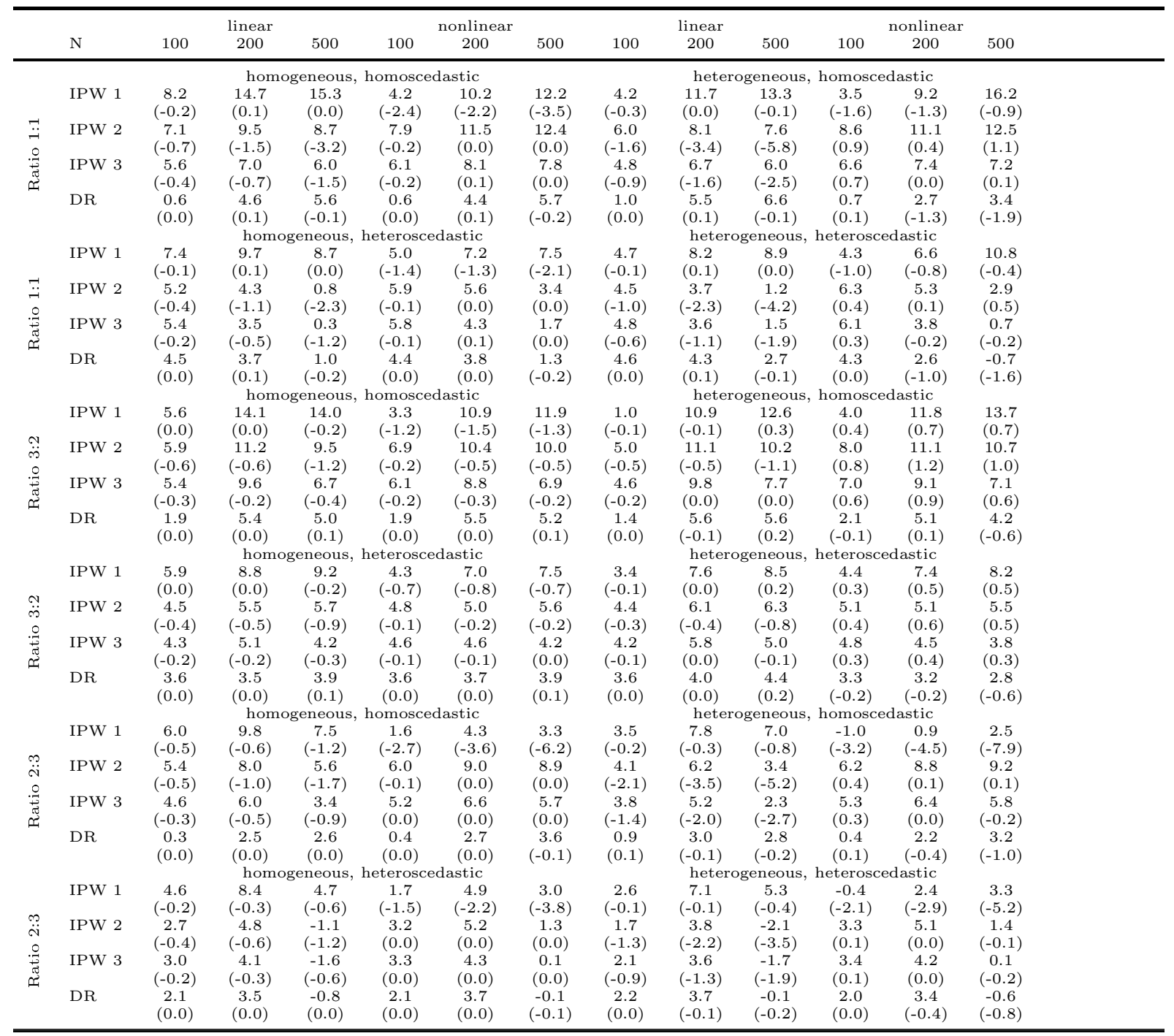

Note: Percentage change which is due to the bias $\left(\frac{\operatorname{bias}^{2}(\operatorname{ATE}(\hat{p}))-\operatorname{bias}^{2}\left(\operatorname{ATE}\left(\hat{p}^{s}\right)\right)}{\operatorname{bias}^{2}(\operatorname{ATE}(\hat{p}))+\operatorname{Var}(\operatorname{ATE}(\hat{p}))}\right)$ is given in brackets. 
Table A.43: Percentage improvement in MSE for the ATE if the shrunken propensity scores are used with trimming rule 1 instead of the conventional propensity scores used with trimming rule 2 , mse-minizing $\lambda$

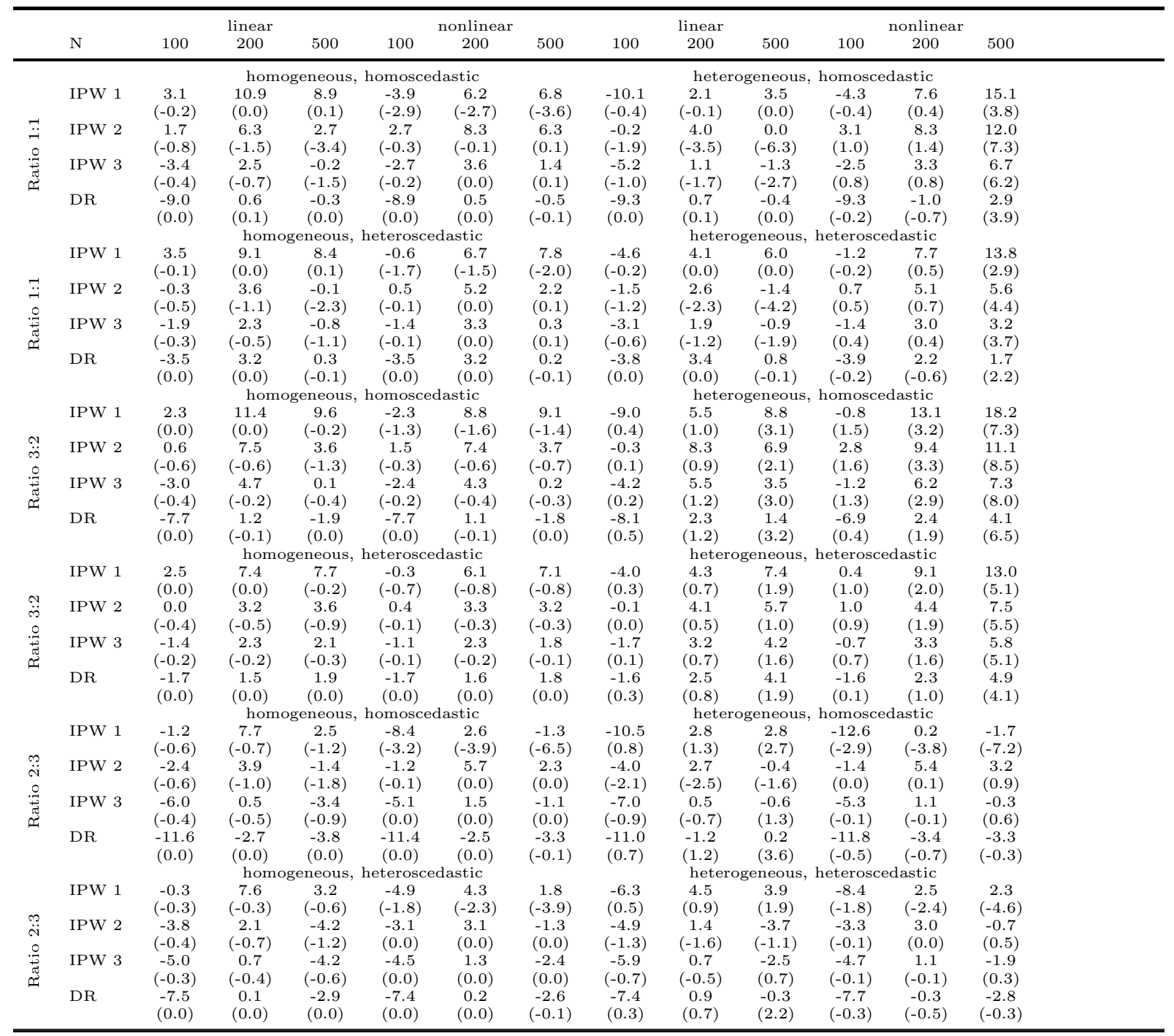

Note: Percentage change which is due to the bias $\left(\frac{\operatorname{bias}^{2}(\operatorname{ATE}(\hat{p}))-\operatorname{bias}^{2}\left(\operatorname{ATE}\left(\hat{p}^{s}\right)\right)}{\operatorname{bias}^{2}(\operatorname{ATE}(\hat{p}))+\operatorname{Var}(\operatorname{ATE}(\hat{p}))}\right)$ is given in brackets. 
Table A.44: Percentage improvement in MSE for the ATE if the shrunken propensity scores are used with trimming rule 1 instead of the conventional propensity scores used with trimming rule by HLW, mse-minimizing $\lambda$

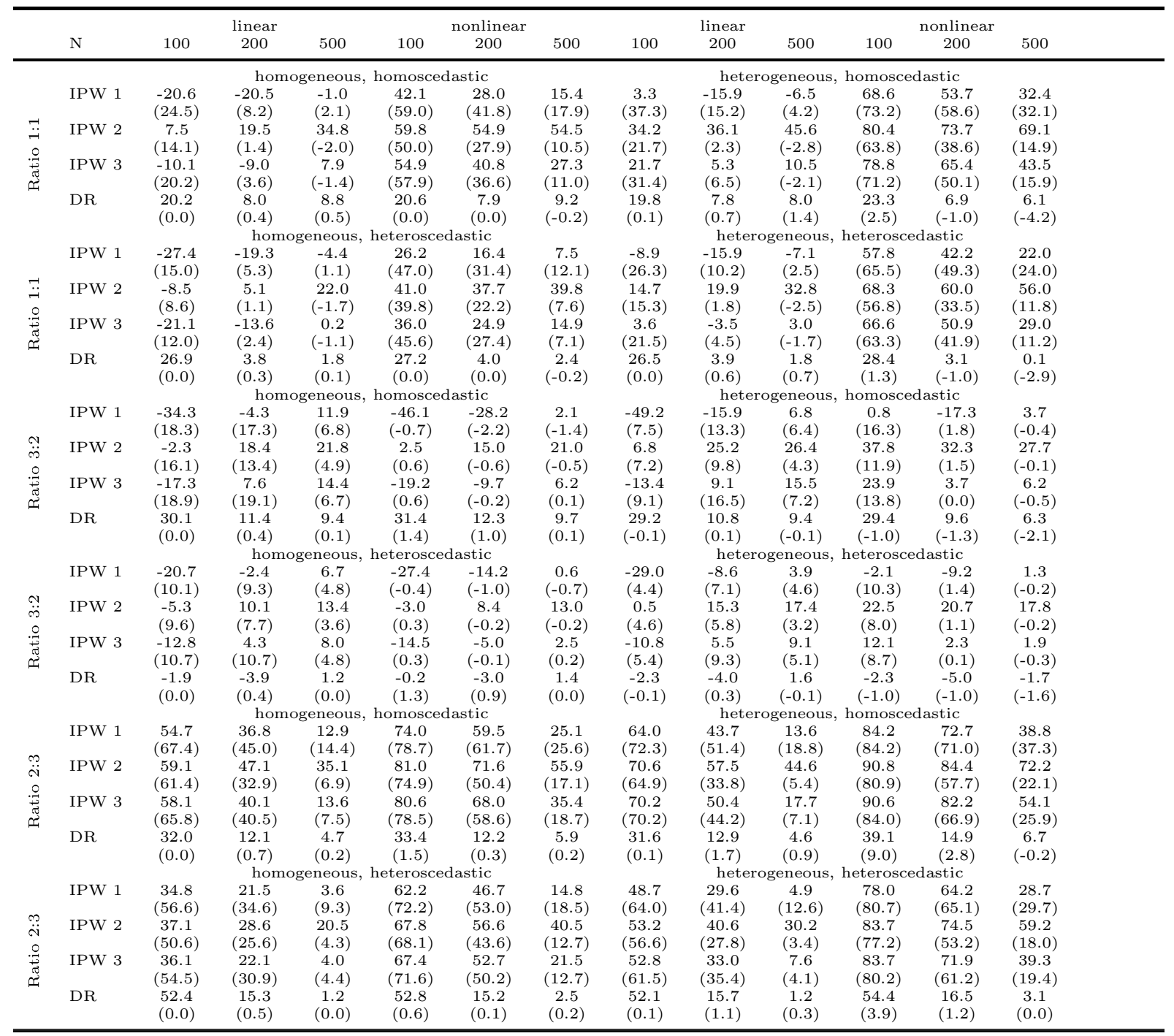

Note: Percentage change which is due to the bias $\left(\frac{\operatorname{bias}^{2}(\operatorname{ATE}(\hat{p}))-\operatorname{bias}^{2}\left(\operatorname{ATE}\left(\hat{p}^{s}\right)\right)}{\operatorname{bias}^{2}(\operatorname{ATE}(\hat{p}))+\operatorname{Var}(\operatorname{ATE}(\hat{p}))}\right)$ is given in brackets. 
Table A.45: Percentage improvement in MSE for the ATE if the shrunken propensity scores are used with trimming rule 1 instead of the conventional propensity scores, data driven $\lambda$

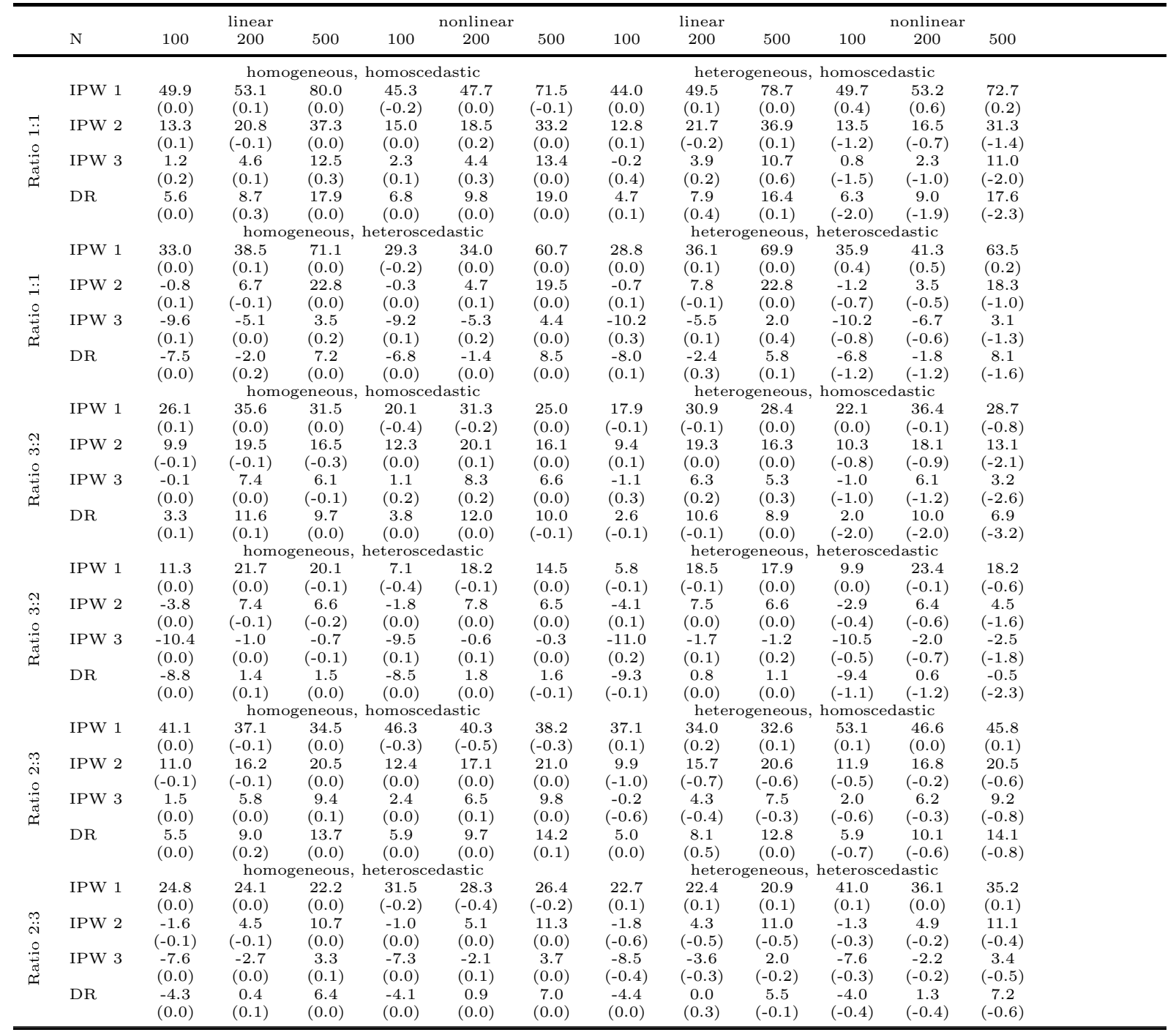

Note: Percentage change which is due to the bias $\left(\frac{\operatorname{bias}^{2}(\operatorname{ATE}(\hat{p}))-\operatorname{bias}^{2}\left(\operatorname{ATE}\left(\hat{p}^{s}\right)\right)}{\operatorname{bias}^{2}(\operatorname{ATE}(\hat{p}))+\operatorname{Var}(\operatorname{ATE}(\hat{p}))}\right)$ is given in brackets. 
Table A.46: Percentage improvement in MSE for the ATE if the shrunken propensity scores are used with trimming rule 1 instead of the conventional propensity scores with trimming rule 1, data-driven $\lambda$

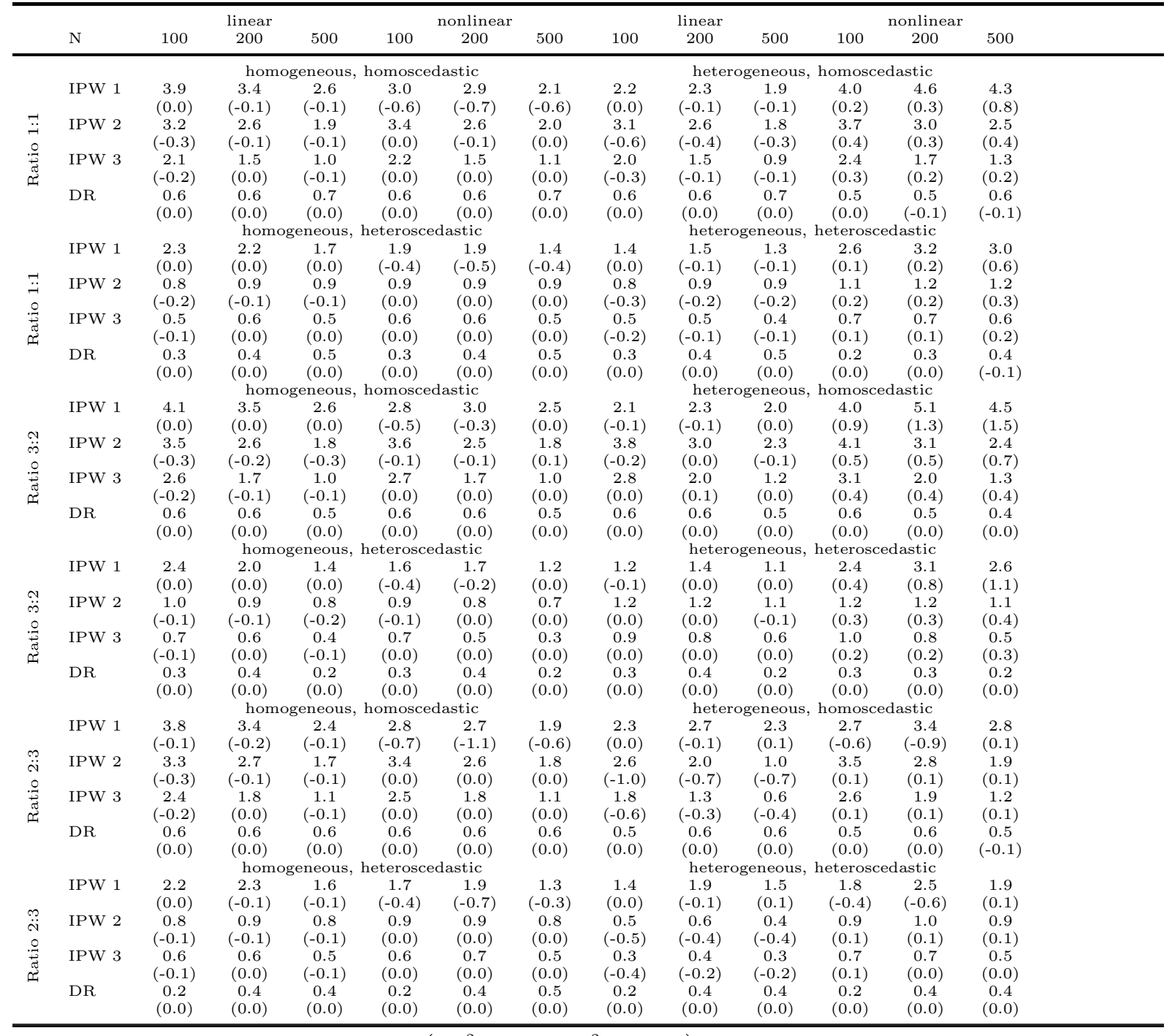
Note: Percentage change which is due to the bias $\left(\frac{\operatorname{bias}^{2}(\operatorname{ATE}(\hat{p}))-\operatorname{bias}^{2}\left(\operatorname{ATE}\left(\hat{p}^{s}\right)\right)}{\operatorname{bias}^{2}(\operatorname{ATE}(\hat{p}))+\operatorname{Var}(\operatorname{ATE}(\hat{p}))}\right)$ is given in brackets. 
Table A.47: Percentage improvement in MSE for the ATE if the shrunken propensity scores are used with trimming rule 1 instead of the conventional propensity scores used with trimming rule 2 , data-driven $\lambda$

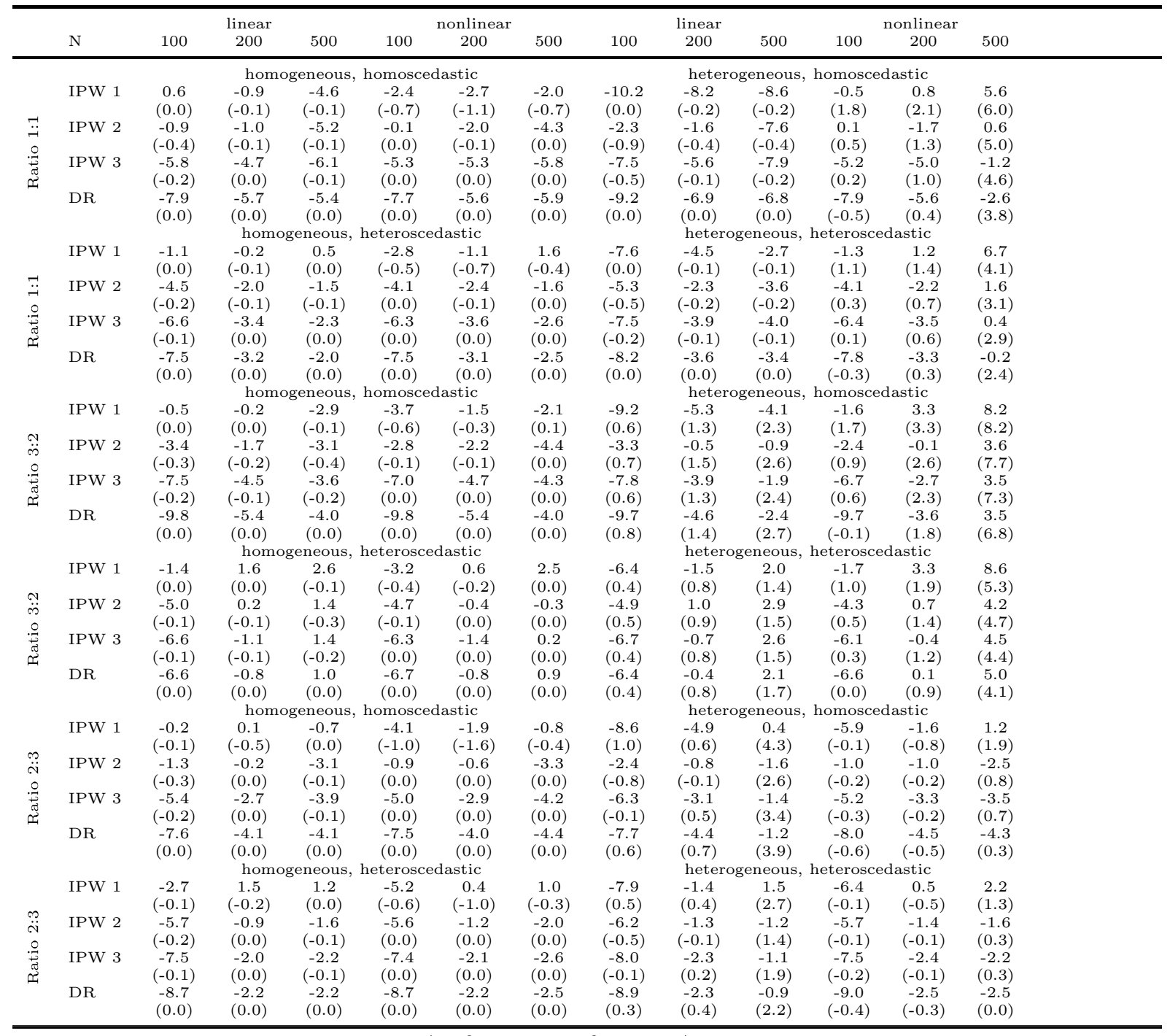

Note: Percentage change which is due to the $\operatorname{bias}\left(\frac{\operatorname{bias}^{2}(\operatorname{ATE}(\hat{p}))-\operatorname{bias}^{2}\left(\operatorname{ATE}\left(\hat{p}^{s}\right)\right)}{\operatorname{bias}^{2}(\operatorname{ATE}(\hat{p}))+\operatorname{Var}(\operatorname{ATE}(\hat{p}))}\right)$ is given in brackets. 
Table A.48: Percentage improvement in MSE for the ATE if the shrunken propensity scores are used with trimming rule 1 instead of the conventional propensity scores used with trimming rule by HLW, data-driven $\lambda$

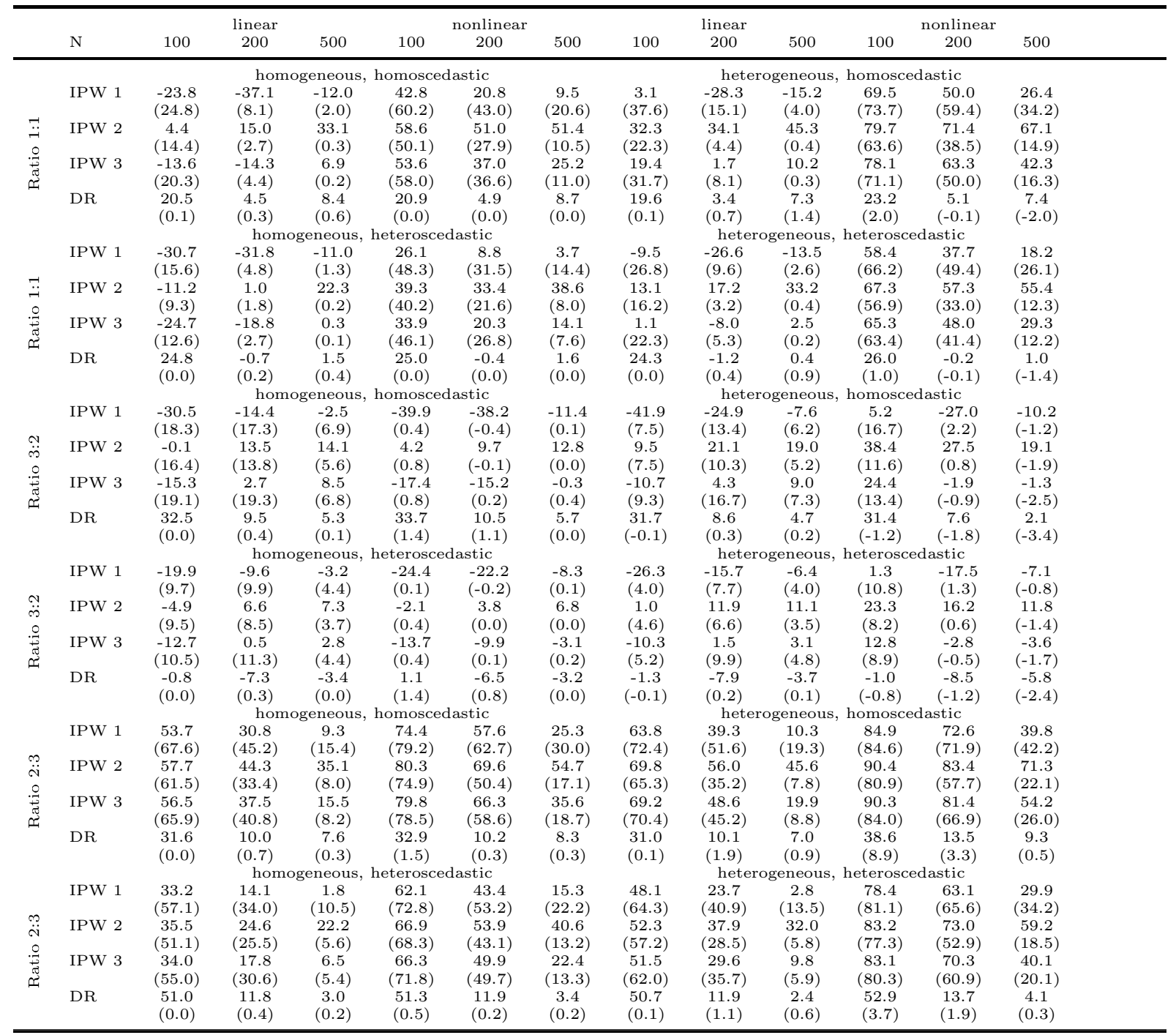

Note: Percentage change which is due to the bias $\left(\frac{\operatorname{bias}^{2}(\operatorname{ATE}(\hat{p}))-\operatorname{bias}^{2}\left(\operatorname{ATE}\left(\hat{p}^{s}\right)\right)}{\operatorname{bias}^{2}(\operatorname{ATE}(\hat{p}))+\operatorname{Var}(\operatorname{ATE}(\hat{p}))}\right)$ is given in brackets. 


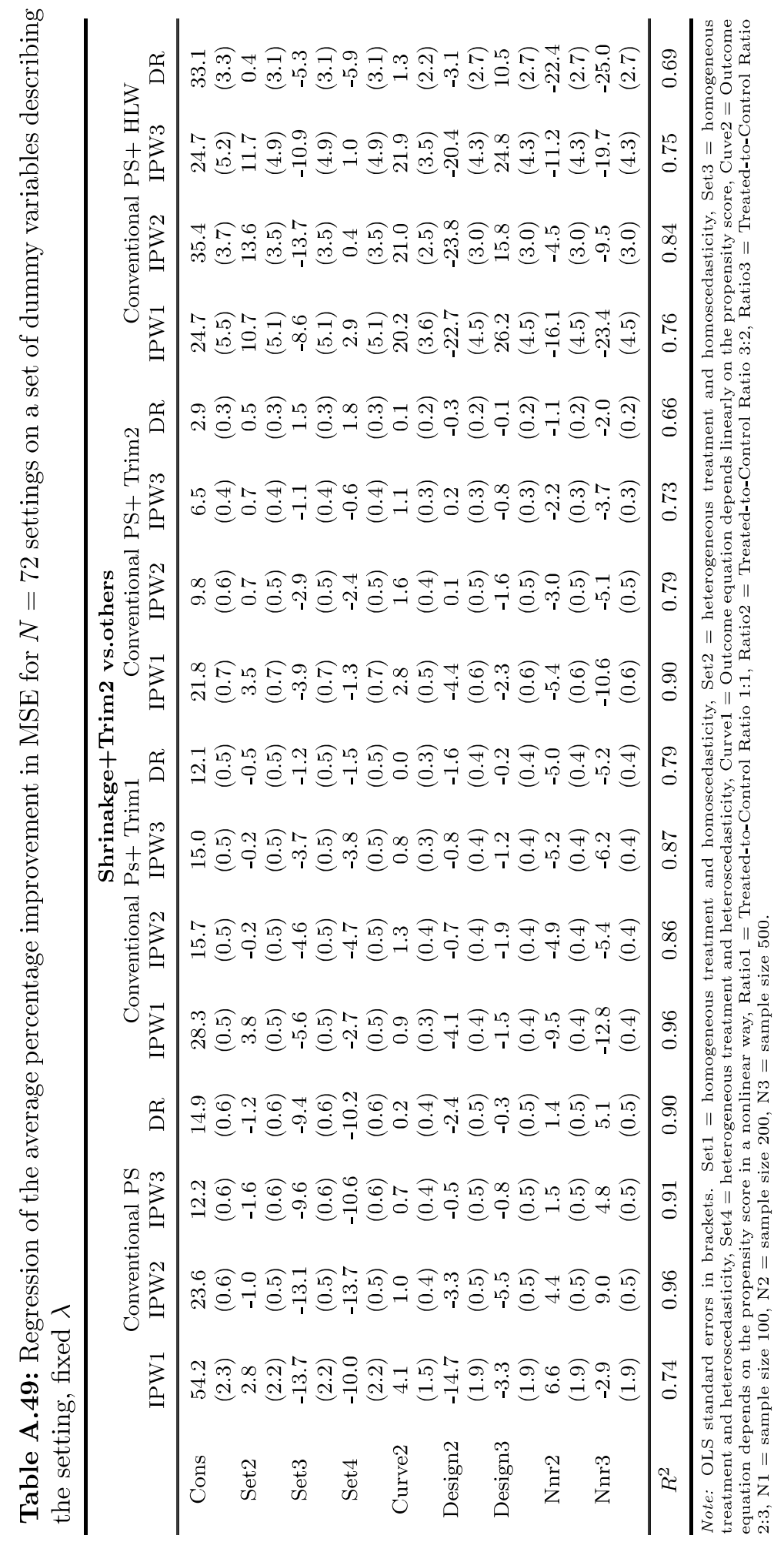




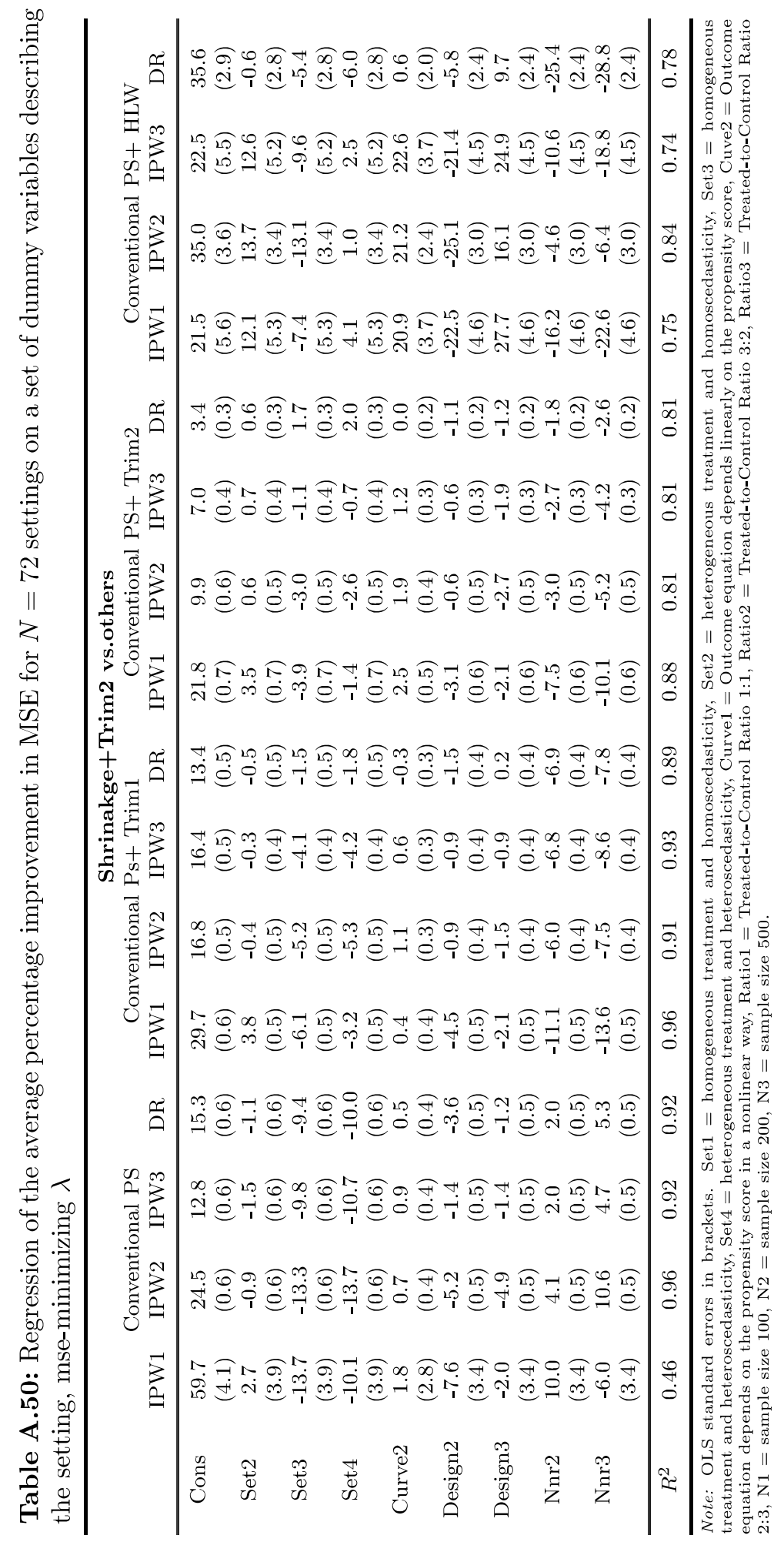




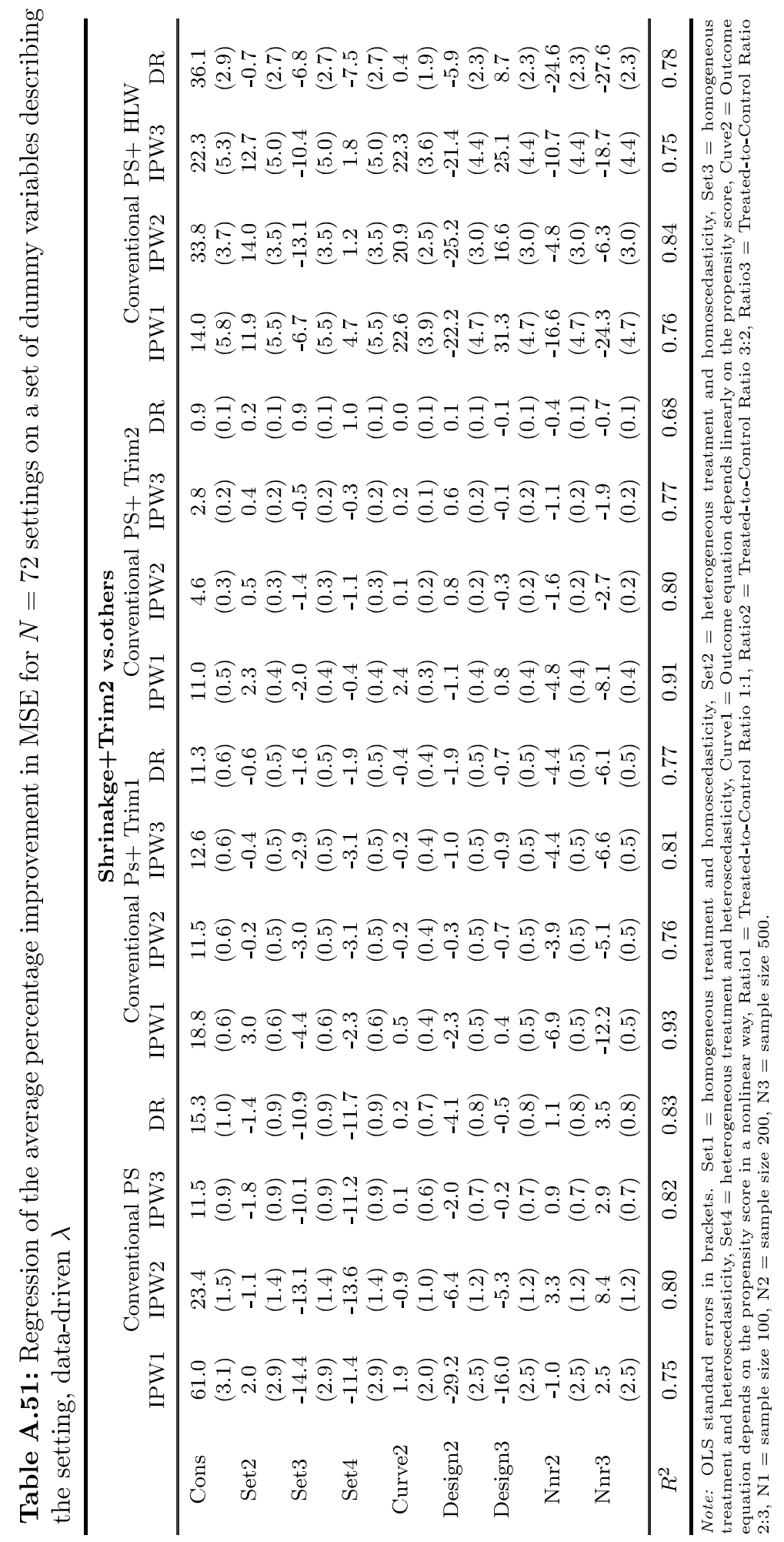




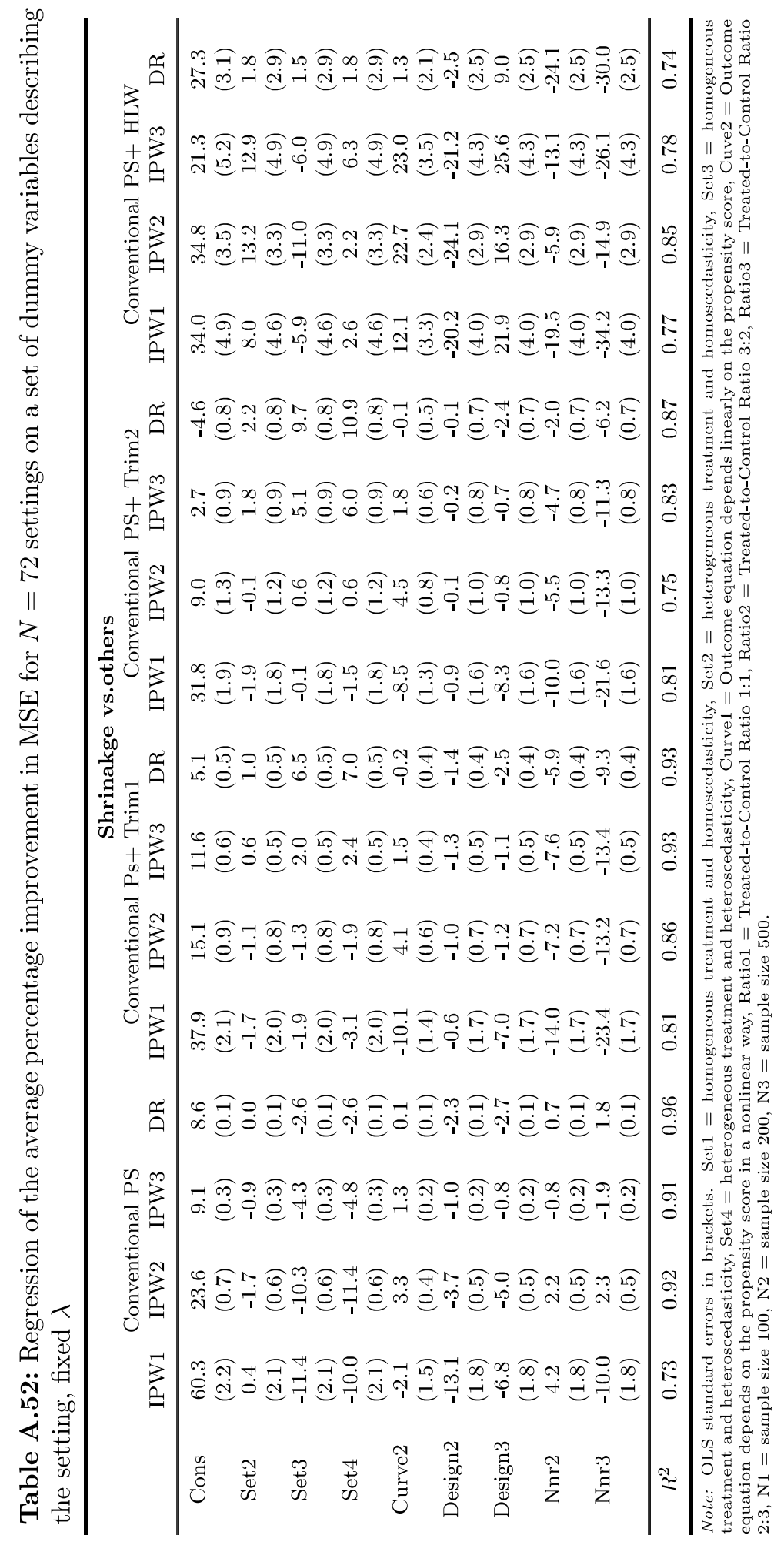




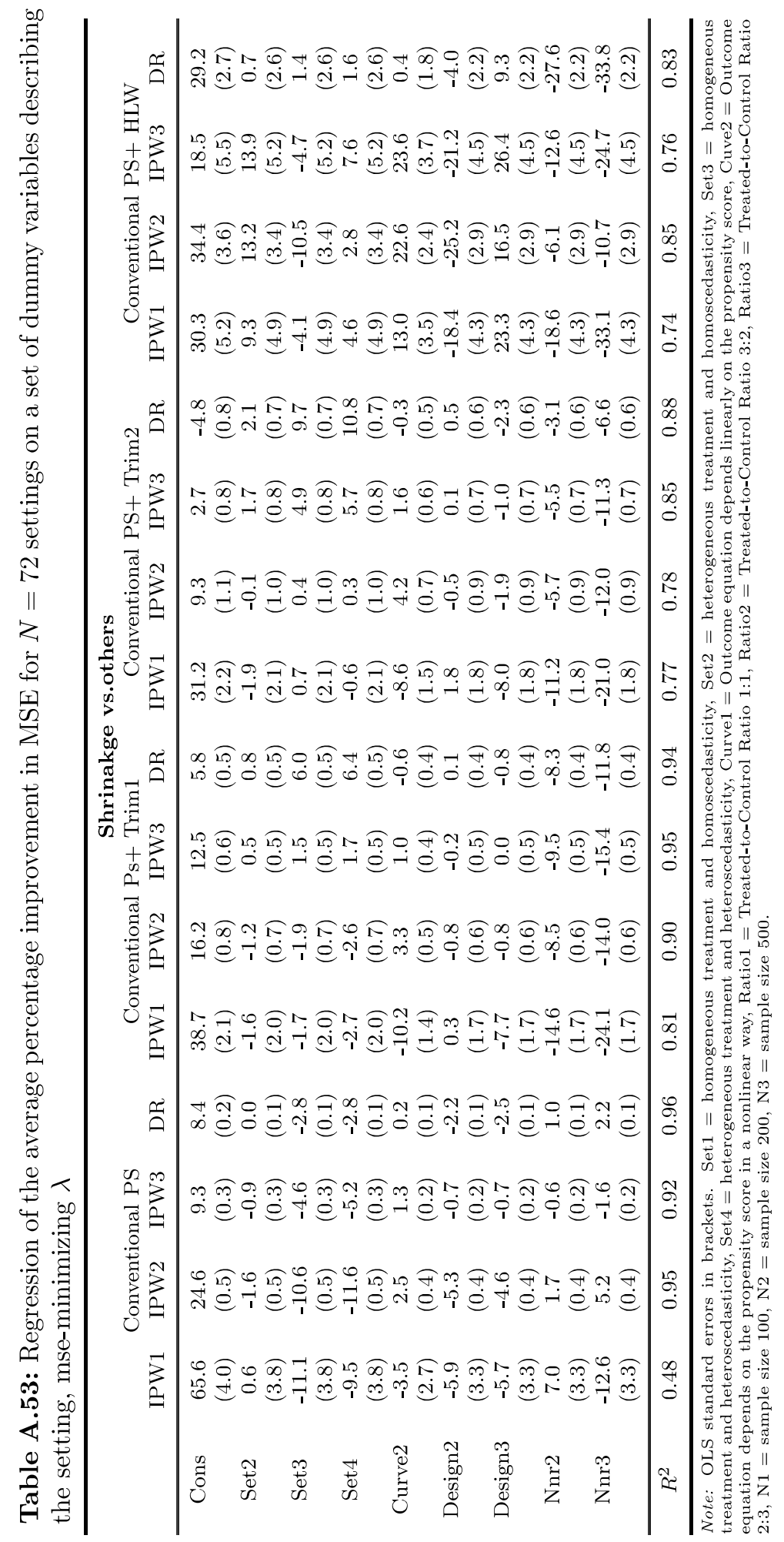




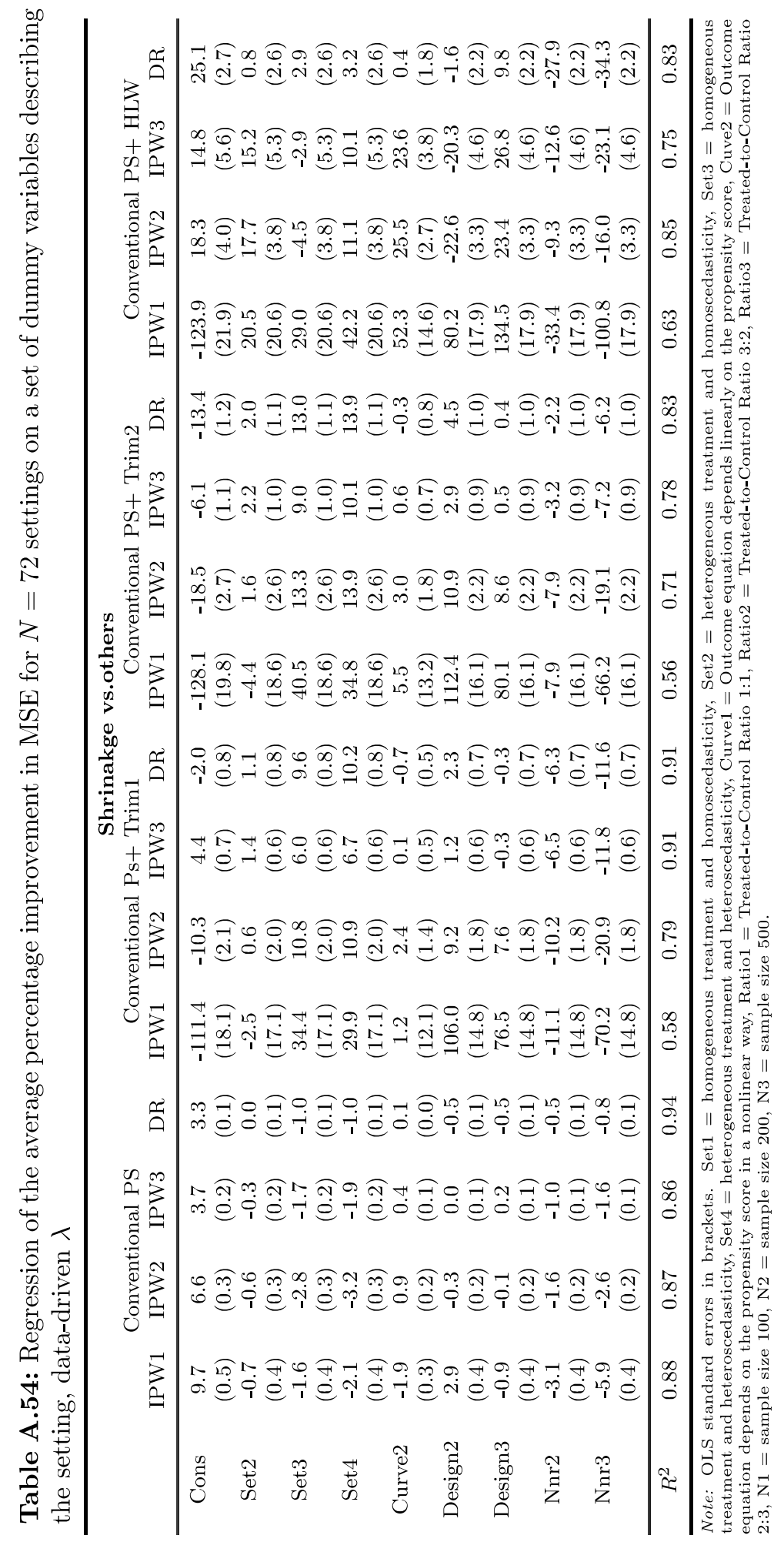




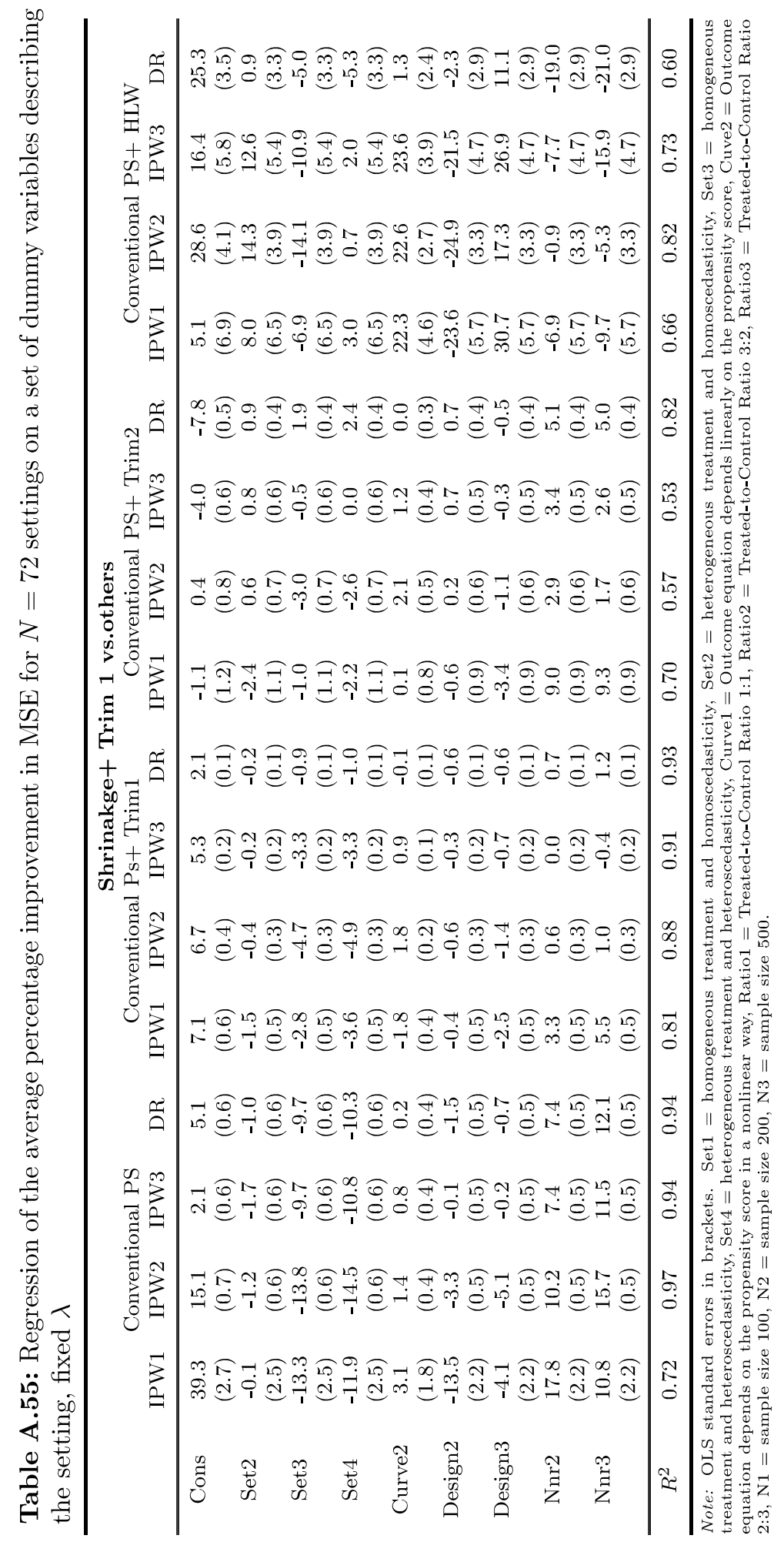




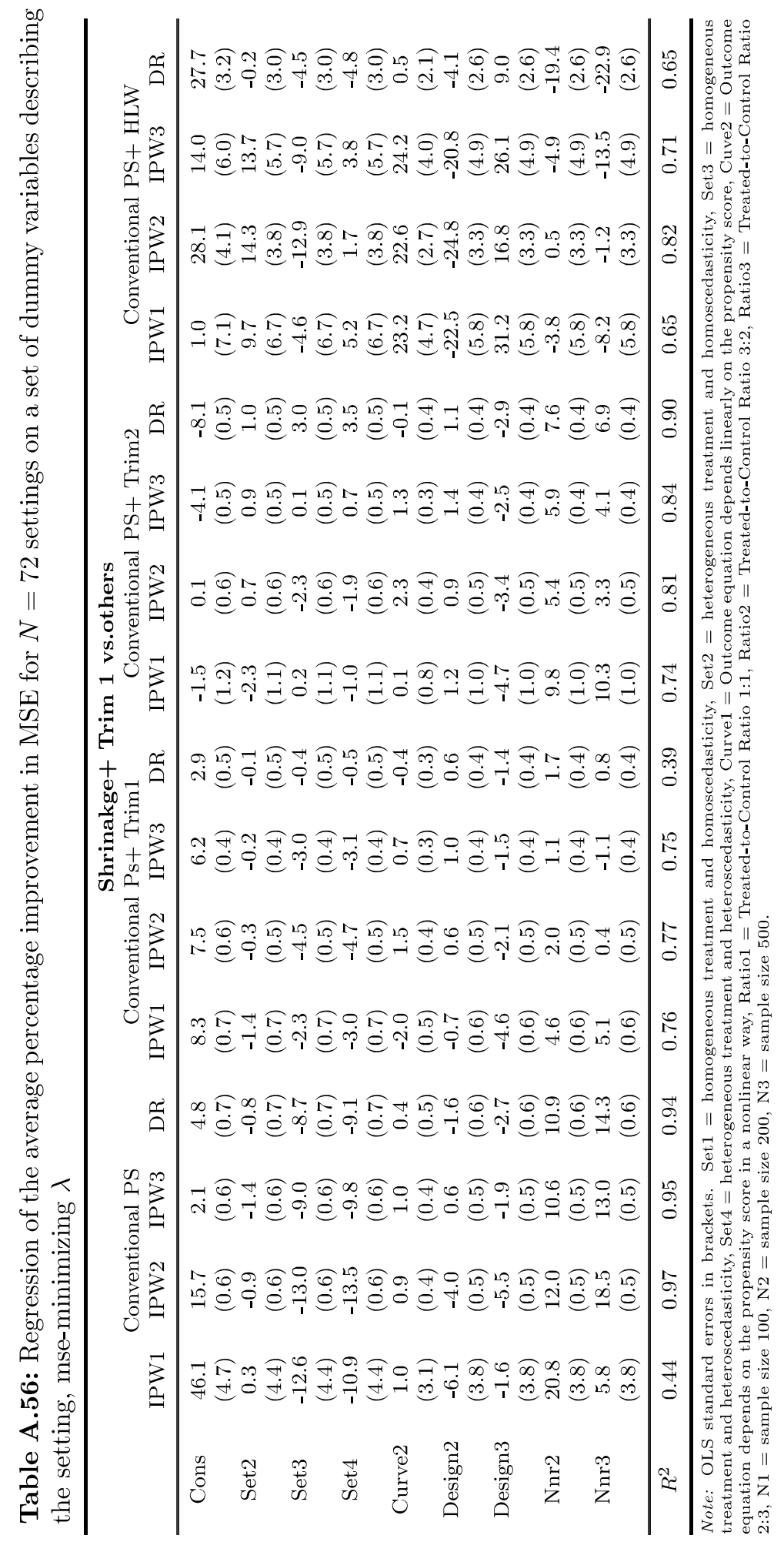




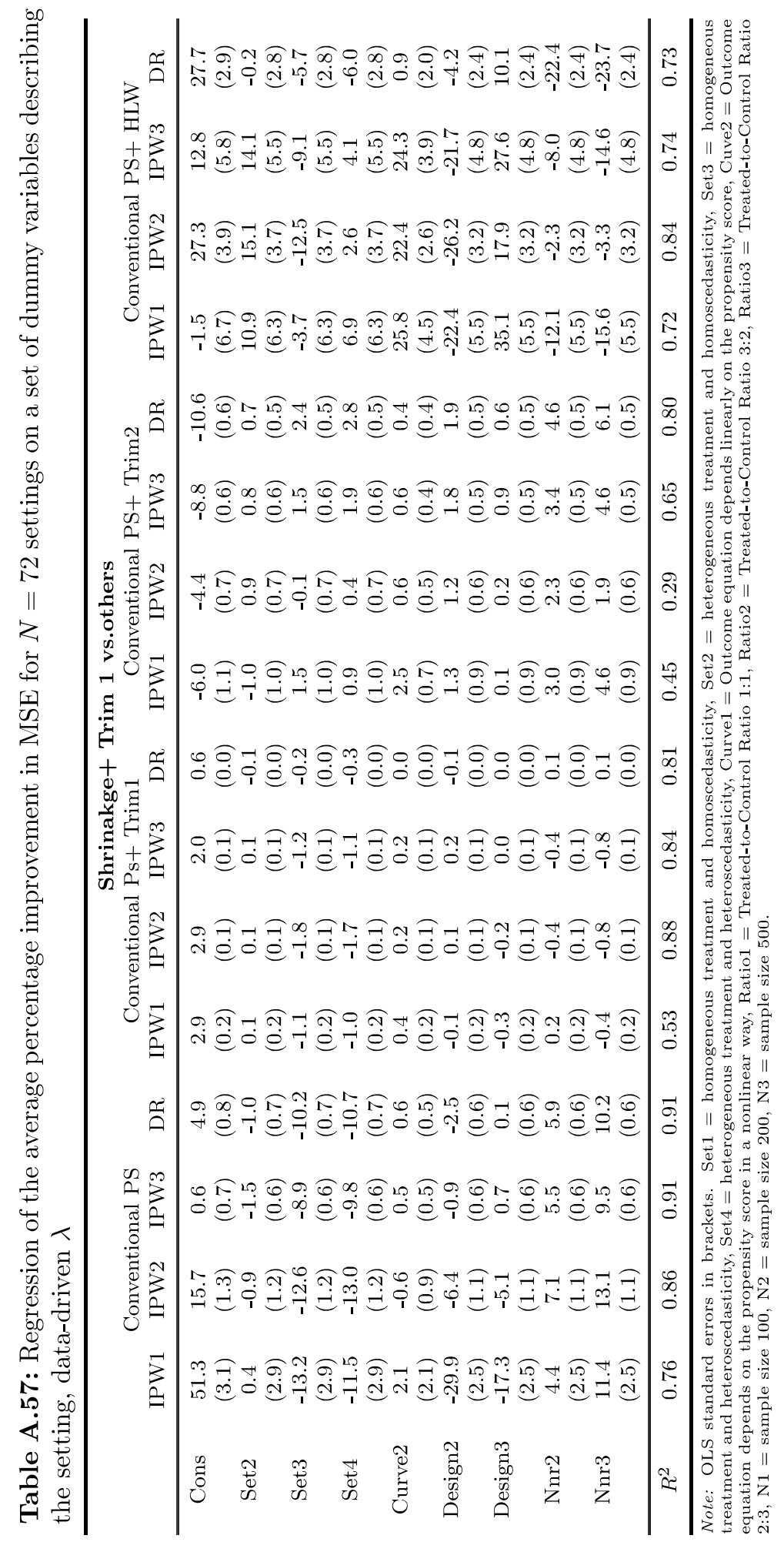

